\title{
DIE STAATENBEZIEHUNGEN INNERHALB DES GROSSRAUMES
}

\section{Monroe Doctrine und amerikanische Staatenwelt}

Obwohl die Monroe Doctrine keine Prinzipien für die Beziehungen zwischen den amerikanischen Staaten aufstellte, betraf sie diese doch mittelbar insofern, als die Doktrin Ausdruck von damals in den USA bestehenden Auffassungen von der Gestaltung der interamerikanischen Beziehungen war, die es nach außen abzuschirmen und zu schützen galt.

Der Grundgedanke der Monroe Doctrine, die Einwirkung der außeramerikanischen Großmächte auf die selbständigen Staaten des amerikanischen Kontinents auszuschließen, war von den USA aus egoistisch-nationalen Motiven proklamiert worden. Er entsprach aber, wie die positive Aufnahme der Monroe Doctrine in den revolutionär entstandenen latein-amerikanischen Staaten beweist ${ }^{1}$, einem allgemeinen und gemeinsamen amerikanischen Interesse. "Monroe did not do more than serve as an echo of the sentiment that then predominated in all the republics", schreibt Alvarez ${ }^{2}$. Die Doktrin enthält in ihrer ursprünglichen Form nichts, was den anderen amerikanischen Staaten aufgezwungen worden wäre und ihre Unabhängigkeit beeinträchtigte.

Die in der Monroe Doctrine gegebene gesamtamerikanische Übereinstimmung nach außen ließ die Gestaltung der interamerikanischen Beziehungen völlig offen. Sie konnte auf der Basis der Gleichordnung, dem bloßen Nebeneinanderexistieren der amerikanischen Staaten bis zur vertraglichen Zusammenarbeit, oder auf der Basis der Über- und Unterordnung, der Hegemonie oder imperialistischen Vorherrschaft der USA über die lateinamerikanischen Staaten erfolgen. In der Tat sind seit der Verkündung der Monroe Doctrine bis heute alle diese Spielarten in der US-Politik gegenüber lateinamerikanischen Staaten aufgetreten. Wie alle Großmächte gerieten auch die USA im ausgehenden 19. Jahrhundert in eine imperialistische Phase ihrer Außenpolitik, die sich u.a. gegenüber Mittelamerika als „Dollarimperialismus“ auswirkte. Die imperialistische Lateinamerika-Politik der USA ist aber von der Monroe Doctrine vollkommen zu trennen. Wilson hat das auf dem panamerikanischen Kongreß der Wissenschaften am 6. Januar 1916 richtig ausgesprochen: „But the Monroe Doctrine demanded merely that European

1 Alvarez, „Latin America and International Law" a. a. O., S. 311f., S. 315; Perkins, The Monroe Doctrine, 1823-26, S. $155 \mathrm{ff}$; Robertson, "South America and the Monroe Doctrine" (Political Science Quarterly, 30, 1915), S. 82, S. 100; Stuart, Latin America and the United States, New York 1943, S. 54f., S. 83; Lockey, Pan-Americanism: Its Beginnings, New York 1920, dort Kapitel VI, eine Aufzählung zeitgenössischer Meinungen über die Dokstrin in Spanisch-Amerika. Alvarez, The Monroe Doctrine. Its Importance in the International Life of the States of the New World, New York 1924, S. $120 \mathrm{ff} .$, S. $10 \mathrm{ff}$.

2 Alvarez, "Latin America and International Law", a. a. O., S. 311. 
Governments should not attempt to extend their political systems to this side of the Atlantic. It did not disclose the use which the United States intended to make of her power on this side of the Atlantic"3. Soweit die Doktrin zur Rechtfertigung einer imperialistischen Politik der Vorherrschaft und des „Big Stick“ herangezogen wurde, die die tatsächliche Suprematie der USA zur Grundlage ihrer Beziehungen zu den lateinamerikanischen Staaten machte und den völkerrechtlichen Grundsatz der Gleichberechtigung aller souveränen Staaten angriff, wurde der Sinn der ursprünglichen Doktrin verfälscht.

Das in der Monroe-Botschaft enthaltene Verbot europäischer Interventionen hat im Gegenteil das ausdrückliche Ziel, die politische Unabhängigkeit (Nichtinterventionsprinzip) und territoriale Unantastbarkeit (Nichtkolonisationsprinzip) der neuentstandenen lateinamerikanischen Staaten zu sichern, wenn auch expressis verbis gegenüber Europa. Die Monroe Doctrine berührt dagegen die Beziehungen - sogar Kriege - zwischen den amerikanischen Staaten selbst nicht ${ }^{4}$, auch nicht Kriege zwischen amerikanischen und europäischen Staaten, solange keine Gefahr der Rekolonisation oder Reannexion durch europäische Mächte bestand. Auch enthebt die Doktrin keinen amerikanischen Staat der Verantwortlichkeit für die Folgen seiner unabhängigen und souveränen Politik gegenüber einem europäischen Staat ${ }^{5}$. Die Monroe Doctrine greift also keineswegs in die Rechte, die sich aus der Souveränität der amerikanischen Staaten ergeben - insbesondere nicht in das jus ad bellum ${ }^{6}$-, oder die entsprechenden Pflichten ein. So ergibt sich mittelbar aus der Monroe Doctrine, daß sie grundsätzlich die politische Unabhängigkeit und Souveränität der selbständigen Staaten des amerikanischen Kontinents respektiert.

Insofern allerdings, als die Monroe Doctrine die gewaltsame Durchsetzung des Interventionsverbotes seitens der USA androht, berührt sie unmittelbar in einem wesentlichen Punkt das Verhältnis der USA zu den anderen amerikanischen Staaten: letztere werden zu Schutzobjekten der USA. Die USA machen ihre Gegenmaßnahmen gegen europäische Interventionen nicht ausdrücklich von der $\mathrm{Zu}$ stimmung der betroffenen amerikanischen Staaten abhängig, was gegebenenfalls eine Hilfeleistung auch gegen deren Willen und insofern einen Verstoß gegen deren Souveränität und daher eine Verletzung des Völkerrechts bedeutet, da kein Staat des Rechtes beraubt werden kann, eine Intervention zu erlauben?. Allerdings verbietet die ursprüngliche Monroe Doctrine, abgesehen von der Besitzergreifung staatsfreien Gebietes, nur solche Fälle europäischer Einmischung, die Völker-

3 Bartlett, a. a. O., S. 541.

4 s. Instruktion Clay's an Forbes vom 3. Januar 1928, anläßlich des Krieges zwischen Argentinien und Brasilien, Clark, a. a. O., S. 186; Stuart, a. a. O., S. 56; A. B. Hart, The Monroe Doctrine, New York 1916, S. 72.

5 Zur voranstehenden Beurteilung der Monroe Doctrine, vgl. Reuben Clark, Memorandum on the Mouroe Doctrine, Washington 1930, S. $187 \mathrm{ff} ., 192 \mathrm{ff} ., 199 \mathrm{ff}$.

6 Gerade das jus belli ist für C. Schmitt der Ausdruck eigener politischer Existenz eines Staates, s. darüber unten S. 130.

7 Kraus, a. a. O., S. 362, S. 392; Spencer, „The Monroe Doctrine and the League Covenant", a. a. O., S. 401 , 
rechtsdelikte darstellen. Normalerweise kann daher das Einverständnis des betroffenen amerikanischen Staates vorausgesetzt werden, sich gegen den europäischen Rechtsbrecher helfen zu lassen. Selbst in dem nicht-völkerrechtswidrigen Fall der Besitzergreifung „staatsfreien“ Gebietes würde entweder ein amerikanischer Staat die Souveränität oder Prioritätsrechte für das betroffene Gebiet beanspruchen und damit die Hilfe der USA willkommen sein oder aber überhaupt kein lateinamerikanischer Staat betroffen sein. Rein theoretisch werden allerdings die Regeln des Völkerrechts durch die Doktrin durchbrochen. Hier ist der Punkt, an dem das Element der Hegemonie in der Doktrin aufleuchtet.

Dabei ist festzuhalten, daß sich die USA mit der Erklärung der Doktrin nicht verpflichteten, sie auch anzuwenden. Die USA allein entscheiden darüber, ob eine der genannten Interventionen vorliegt und ob sie zum Schutze des betroffenen amerikanischen Staates eingreifen wollen. Hier zeigt sich die starke Flexibilität der Doktrin und vor allem, daß in ihr selbst nicht die Grundlage für die Regelung des Zusammenlebens der Staaten des amerikanischen Kontinents gesehen werden kann, wie sie etwa in einer völkerrechtlichen Allianz mit vereinbarten Rechten und Pflichten in Erscheinung tritt. Nach der Verkündung der Monroe-Botschaft im Dezember 1823 sind verschiedentlich amerikanische Staaten an die USA mit dem Ansinnen herangetreten - so Kolumbien 1824 und Brasilien 18258 -, die Durchsetzung der Monroe Doctrine gegenüber den europäischen Mächten durch ein gegenseitiges Bündnis zu sichern. Getreu dem damaligen Grundsatz der US-Diplomatie, keine bindenden Abmachungen mit anderen Staaten einzugehen, die die USA in Kriege verwickeln könnten, haben die USA diese Angebote abgelehnt. Ein besonders deutliches Beispiel ist die Stellungnahme der USA zum Kongreß von Panama 1826, auf dem Bolivar die Idee einer "Union, Alliance and Perpetual Confederation" der spanisch-amerikanischen Staaten vertrat". Kolumbien, Mexiko und die Zentralamerikanische Konföderation hatten die USA in der Hoffnung eingeladen, sie für die Durchsetzung der Monroe Doctrine fester engagieren zu können und die Doktrin zur Grundlage eines allgemeinen Abkommens zu machen, doch die USA versagten sich bewußt dieser Gelegenheit einer politischen Ordnung des mittelamerikanischen Raumes im Zeichen der Monroe Doctrine. Präsident Adams war in seinen Instruktionen für die US-Delegierten lediglich dazu bereit, dem Nichtkolonisationsprinzip der Monroe Doctrine eine stärkere moralische Kraft zu geben und es zu einer Regel des American public law zu machen durch eine gegenseitige Verpflichtung der Parteien, daß jede auf ihrem eigenen Staatsgebiet die Errichtung europäischer Kolonien verhindern werde.

Im Kongre $\beta$ folgte eine erregte Debatte, in deren Verlauf fast einmütig zum Ausdruck gebracht wurde, daß Monroes Erklärung keinerlei Verpflichtung (pledge) gegenüber einem anderen Staat darstelle ${ }^{10}$. Das Repräsentantenhaus beschloß über

8 S. den Notenwechsel bei Perkins, The Monroe Doctrine 1823-26, S. $187 \mathrm{ff} ., 197 \mathrm{f}$.

- Alvarez, „Latin America and International Law", a. a. O., S. 277 f., dort auch über den Verlauf des Kongresses.

10 Perkins, a. a. O., S. $213 \mathrm{ff}$. 
die Haltung der USA gegenüber dem Panama-Kongreß am 21. April 1826 ausdrücklich:

„.. that the Government of the United States ought not to be represented at the Congress of Panama, except in a diplomatic character, nor ought they to form any alliance, offensive or defensive, or negotiate respecting such an alliance, with all or any of the Spanish American Republics; nor ought they to become parties with them, or either of them to any joint declaration for the purpose of preventing the interference of any of the European Powers with their independence or form of Government, or to any compact for the purpose of preventing colonisation upon the continent of America; ... "11.

Damit war selbst die vorsichtige Politik Adams abgelehnt worden. Auf dem Kongreß selbst waren die USA schließlich überhaupt nicht vertreten; als nach vier Monate lang dauernder Debatte die beiden US-Delegierten endlich abreisten, starb der eine auf dem. Wege, der andere kam zu spät, so daß eine Einflußnahme auf die politische Entwicklung Lateinamerikas völlig unterblieb.

Ebensowenig wie der Wortlaut der Monroe Doctrine bezweckte die Politik ihrer Schöpfer eine Neuregelung der interamerikanischen Beziehungen unter dem bestimmenden Einfluß der USA, etwa im Sinne einer Zusammenfassung der Kräfte der einzelnen Staatswesen. Sie bedeutete erst recht keine „neue Ordnung Amerikas“, in der die USA kraft ihrer natürlichen machtmäßigen Überlegenheit oder ihrer Beschützerrolle die Anerkennung einer rechtlichen Sonderstellung von den anderen amerikanischen Staaten zu erhalten suchten, die das Prinzip der rechtlichen Gleichstellung aller unabhängigen Staaten durchbrach ${ }^{\mathbf{1 2}}$. Monroe hat in seiner Botschaft das politische System und die politischen Ideale Europas, dessen politische Ordnung auf der Grundlage des dynastisch-monarchischen Legitimitätsprinzips beruhte, von denen unterschieden, die fortan das Schicksal der Neuen Welt bestimmen sollten. Die „freie und unabhängige Stellung“ des amerikanischen Kontinents sollte auf dem Recht der Völker, ihr Geschick selbst zu bestimmen und sich selbst zu regieren, dem liberalen Freiheitsgedanken der westlichen Demokratie aufbauen. Das ist das eigentliche Ordnungsprinzip, das den amerikanischen Kontinent beherrschen sollte. Wenn Schmitt in diesem Zusammenhang schreibt, „das ist die politische Idee, die in der Monroelehre mit dem Großraum ,Amerika“ verbunden wird“, hier sei „der Kern der großen ursprünglichen Monroedoktrin, ein echtes Großraumprinzip, nämlich die Verbindung von politisch erwachtem Volk, politischer Idee und politisch von dieser Idee beherrschtem, fremde Interventionen ausschließendem Großraum "13, so ist zu betonen, daß in diesem Falle die politische Idee tatsächlich von den selbständigen Völkern des betreffenden Raumes unterstützt und getragen wurde, und keinesfalls von einer die Idee tragenden Nation vom "Reich“ im Schmittschen Sinn - dem Raum und seinen Völkern oktroyiert

11 Perkins, a. a. O., S. 219 f. Die Instruktionen Adams für die US-Delegierten zum PanamaKongre $\$$ wurden schließlich vom Plenum verworfen. Clark, a. a. O., S. $110 \mathrm{ff}$. Die endgültigen Instruktionen Staatssekretär Clay's vom 8. Mai 1826 s. Alvarez, The Monroe Doctrine, S. $155 \mathrm{ff}$. 12 Vgl. Perkins, Hands Off, a. a. O., S. 72.

13 Schmitt, Großraumordnung, a. a. O., S. $19 \mathrm{f}$. 
wurde. Denn die Frontstellung der Monroe Doctrine gegen Absolutismus und Monarchie bedeutete nicht, daß die USA den amerikanischen Staaten die republikanische Staatsform und demokratische Institutionen vorschrieben oder die $E r$ richtung von Monarchien auf dem amerikanischen Kontinent gewaltsam verhinderten, solange diese Monarchien von Europa unabhängig waren ${ }^{14}$. Diese Auffassung kommt klar in der Botschaft Monroes an den Kongreß vom Dezember 1824 zum Ausdruck:

„In this [d. i. die innere Gestaltung der lateinamerikanischen Staaten] ... we have not interfered, believing that every people have a right to institute for themselves the government which, in their judgement, may suit them best. Our example is before them, of the good effect of which, being our neighbors, they are competent judges, and to their judgement we leave it, in the expectation that other powers will pursue the same policy. The deep interest which we take in their independence, which we have acknowledged, and in their enjoyment of all the rights incident thereto, especially in the very important one of instituting their own Governments, has been declared, and is known to the world" 15 .

Wenn die USA ihre eigenen Verfassungsgrundsätze auch gern als Vorbild in Amerika nachgeahmt sahen, weil sie befürchteten, daß eine Monarchie auf amerikanischem Boden Brennpunkt für europäische Einflüsse werden könnte, so hat die andersgeartete Staatsform und Verfassung eines amerikanischen Staates nie Auswirkungen auf das tatsächliche Verhalten der USA gegenüber einem solchen Staat gehabt: Monroe selbst hat am 27. Januar 1823 das Kaiserreich Mexiko und am 26. Mai 1824 das Kaiserreich Brasilien anerkannt ${ }^{16}$. Aus Staatssekretär Henry Clay's Antwortnote an Brasilien auf das oben erwähnte Bündnisangebot von 1825 geht hervor, daß die Prinzipien der Monroe Doctrine genauso auf eine unabhängige amerikanische Monarchie Anwendung finden und eine europäische Intervention in die Geschicke einer solchen Monarchie dieselben Erwägungen seitens der USA zur Folge haben sollte, als handele es sich um eine der neuen Republiken ${ }^{17}$.

Zusammenfassend läßt sich über die Bedeutung der ursprünglichen Monroe Doctrine für die Gestaltung der Beziehungen zwischen den Staaten des von ihr erfaßten Raumes folgendes sagen:

1. Die Monroe Doctrine berührt grundsätzlich die Souveränität und die aus ihr entspringenden Rechte und Pflichten der unabhängigen amerikanischen Staaten nicht, sie oktroyiert diesen Staaten keine politische Idee oder bestimmte Regierungsform.

2. Die Monroe Doctrine garantiert die politische Unabhängigkeit und terri-

14 Clark, a. a. O., S. 210 f.; Kraus, a. a. O., S. 68 f.; Hart, a. a. O., S. 74.

15 Perkins, The Monroe Doctrine 1823-26, S. 193, Anm. 12. Deutlich auch in der Instruktion Staatssekretär Clay's für die US-Delegierten zum Panama-Kongreß vom 8. Mai 1826 (Alvarez, The Monroe Doctrine, S. $166 \mathrm{f}$.).

16 Perkins, a. a. O., S. 194, ders., „The Monroe Doctrine, 1826-1867 “, Baltimore 1933, S. 22; Kraus, a. a. O., S. 69.

17 Perkins, The Monroe Doctrine 1823-26, S. 198. 
toriale Unversehrtheit der amerikanischen Staaten gegenüber der nichtamerikanischen Außenwelt.

3. Damit steht die Monroe Doctrine mit einer völkerrechtlichen Ordnung im Einklang, die auf einer Vielheit unabhängiger Staaten und dem Grundsatz der rechtlichen Gleichheit dieser Staaten beruht. Sie garantiert den Bestand dieser Ordnung auf dem amerikanischen Kontinent gegen Eingriffe von außen.

4. Die Monroe Doctrine sieht allerdings vor, daß die USA auf Grund ihrer tatsächlichen Machtstellung zum Schutz dieser Ordnung freier und unabhängiger Staaten - deren Aufrechterhaltung sie als für ihre eigene Sicherheit unabdingbar ansehen - gegen äußere Angriffe nötigenfalls ohne Zustimmung der anderen amerikanischen Staaten vorgehen werden. Da das im konkreten Fall zur völkerrechtswidrigen Verletzung der Unabhängigkeit führen kann, durchbricht dieser Anspruch die Regeln der völkerrechtlichen Ordnung, allerdings nur, um diese Ordnung selbst in Amerika gegen völkerrechtswidrige Angriffe von außen aufrechtzuerhalten ${ }^{18}$. Die Doktrin stellt jedoch keine rechtliche Institutionalisierung dieses Anspruches dar ${ }^{\mathbf{1 9}}$.

\section{Die nationalsozialistische "Neue Ordnung Europas"}

\section{a) Allgemeine Zielsetzung}

Welche Bedeutung die beanspruchte "deutsche Monroe-Doktrin " für die Beziehungen zwischen den "raumzugehörigen" europäischen Völkern hatte, ergibt sich aus den - in Dokumenten und überlieferten Äußerungen faßbaren - Zielen der nationalsozialistischen Gestaltung des europäischen Großraumes, um derent-

18 Der nicht-völkerrechtswidrige Fall einer europäischen Besitzergreifung "staatsfreien Gebietes" in Amerika schaltet bei dieser Betrachtung aus, da hier entweder ein lateinamerikanischer Staat nicht betroffen und in seiner unabhängigen Stellung innerhalb dieser Ordnung nicht bedroht ist oder in der völkerrechtswidrigen Abwehr gegen die europäische Besitzergreifung mit den USA gemeinsame Sache macht.

19 In diesem Zusammenhang muß auch der These Triepels widersprochen werden, da $\beta$ die Monroe Doctrine zumindest einen Anspruch auf Hegemonie der USA über die lateinamerikanischen Staaten begründet habe, da sie "auch jede Duldung einer selbst auf friedliche Weise exfolgenden territorialen Veränderung zugunsten Europas" verboten habe. (Triepel, Die Hegemonie, Anm. 326), Triepel legt hier bereits die durch die Polk-Botschaft vom 2.12.1845 erweiterte Auslegung der Doktrin zugrunde, während der ursprünglichen Doktrin jede Absicht einer „bestimmenden Einflußnahme" (nach Triepel ein Merkmal echter Hegemonie) gerade fehlt. Ein Blick auf die tatsächlichen Verhältnisse auf dem amerikanischen Kontinent während der ersten Hälfte des 19. Jh's. bestätigt das: Der politische Einfluß der USA auf Lateinamerika war damals weit geringer als der Englands. Wenn sich auch einzelne lateinamerikanische Staaten unter Bezugnahme auf die Monroe Doctrine den Schutz dex USA zu sichern suchten (bezeichnenderweise vergeblich), so schauten sie doch zu dem auch wirtschaftlich einflußreichen England als zu der Macht auf, von der ihre Unabhängigkeit tatsächlich abhing, wie denn auch auf dem Panamerikanischen Kongreß von 1826 englische Vertreter teilnahmen. Man kann sich allenfalls Triepels Meinung anschließen, daß in der Monroe Doctrine insofern ein "fruchtbarer Keim" für eine hegemoniale Politik der USA lag, als ihre elastische Formulierung eine Ausdehnung (und Veränderung!) ihres ursprünglichen Inhalts zuließ. 
willen der Einfluß der „raumfremden Mächte“, Englands und der USA, ausgeschaltet werden sollte. Dabei sind auch die praktisch ergriffenen Maßnahmen zu berücksichtigen, die bereits definitive Entscheidungen für die Zukunft enthielten.

In Hitlers „Mein Kampf" ist von einer Gestaltung Europas als solcher noch nicht die Rede. Immerhin läßt eine Analyse dessen, was über die zukünftige deutsche Außenpolitik gesagt wird, ein ungefähres Bild von Hitlers Europa entstehen: Im Süden das faschistische Italien als Verbündeter, anscheinend unter deutschem Verzicht auf Südtirol ${ }^{20}$. Im Westen Frankreich, das durch seine Rassenmischung „eine lauernde Gefahr für den Bestand der weißen Rasse Europas" und außerdem den „Erbfeind“ Deutschlands darstellt ${ }^{21}$ und mit dem eine endgültige Auseinandersetzung unerläßlich ist: Frankreich soll seiner Großmachtstellung beraubt werden ${ }^{22}$. Dieser Auseinandersetzung soll die Isolierung Frankreichs durch ein deutsches Bündnis mit Italien und England vorausgehen ${ }^{23}$. Die Ausschaltung der französischen Gefahr und diese Bündnisse sollen zugleich die „Rückendeckung . . . für eine Vergrößerung des Lebensraumes unseres Volkes in Europa"24 abgeben. Als deutscher Lebensraum sind dabei im Osten Rußland - das durch die bolschewistische Revolution seine "germanische“ Oberschicht verloren hat - „und die ihm untertanen Randstaaten " vorgesehen ${ }^{25}$, deren Territorien "dem deutschen Volk den ihm gebührenden Grund und Boden auf dieser Erde . . . sichern" sollen ${ }^{26}$. In der Mitte Europas aber ein Reich aller Deutschen, das sich weit über die Grenzen von 1914. hinaus erstrecken ${ }^{27}$, durch genügend große Grundfläche eine Weltmachtstellung erringen ${ }^{28}$, „die wertvollsten Bestände an rassischen Urelementen " der allein schöpferischen nordischen Herrenrasse erhalten und sie „zur beherrschenden Stellung " emporführen soll29. Abgesehen von dem allgemeinen rassentheoretisch begründeten deutschen Führungsanspruch ist vom Verhältnis zu den anderen europäischen - insbesondere den nordischen - Staaten in "Mein Kampf " nicht die Rede. Bezeichnend aber ist der Satz, daß die nationalsozialistische Politik nicht „von völkischen Allerweltsgefühlsduseleien geleitet werden“, nicht „Anwalt anderer Völker", insbesondere nicht „der Schutzpolizist der bekannten ,armen, kleinen Völker" " sein dürfe ${ }^{30}$. England wird in dieser Konzeption teils als Verbündeter (gegen Frankreich) ${ }^{\mathbf{3 1}}$, teils zumindest als Dulder des deutschen Zuges nach dem

20 Mein Kampf, München 1934, S. $710 \mathrm{f}$.

21 a. a. O., S. 704 .

22 a. a. O., S. 757, S. $766 \mathrm{f}$.

23 a. a. O., S. 755.

24 a. a. O., S. 741.

25 a. a. O., S. 742 f., 154.

26 a. a. O., S. 739.

27 a. a. O., S. $736,738 \mathrm{f}$.

28 a. a. O., S. $728 \mathrm{ff}$., 742.

29 a. a. O., S. 439. In hundert Jahren sollten 250 Millionen Deutsche auf dem Kontinent leben (a. a. O., S. 767).

30 a. a. O., S. 741.

31 a. a. O., S. 699 f., $705,755$. 
Osten gesehen ${ }^{32}$. Wenn die Ausschließung Englands vom Festland durch die „deutsche Monroe-Doktrin “ auch erst eine Folge davon war, daß sich die Einschätzung der englischen Haltung als Irrtum erwies, so enthält doch schon „Mein Kampf“ die Idee einer Interessenabgrenzung, einer Abgrenzung von „Großräumen “, wenn man so will: England sollte für die Deutschland in Osteuropa gewährte freie Hand den deutschen Verzicht auf Kolonien, Welthandel und auf eine Kriegsflotte - also auf Eingriffe in dessen Interessengebiete in der Welt - angeboten erhalten ${ }^{\mathbf{3}}$.

Auf dem Festland selbst aber sollte nach Hitlers "politischem Testament" die Entstehung einer zweiten Kontinentalmacht - „und sei es auch nur in Form der Bildung eines zur Militärmacht fähigen Staates“ - „mit allen Mitteln, bis zur Anwendung von Waffengewalt" verhindert werden ${ }^{\mathbf{3 4}}$. Unter stärkerer Betonung des Kampfes um Lebensraum werden diese Gedankengänge in Hitlers Manuskript aus dem Jahre 1928 wiederholt und bekräftigt. Dort sind auch Spanien und Ungarn (wegen ihrer Gegensätze zu Frankreich bzw. zu dessen Verbündetem Jugoslawien) als Mitglieder der deutsch-englisch-italienischen Bundesgenossenschaft vorgesehen $^{35}$.

Deutlicher werden die Umrisse der geplanten Gestaltung Europas in den Äußerungen Hitlers von Anfang 1934, die Rauschning überliefert: In der Mitte Europas solle der „stählerne Kern“ eines „zu unverbrüchlicher Einheit geschmiedeten, großen Deutschland" stehen, das Österreich, die Tschechoslowakei und Westpolen mit umfasse und als unzerstörbarer Block von hundert Millionen das feste Fundament der Herrschaft über Europa darstelle ${ }^{\mathbf{3 6}}$. Ostpolen, das Baltikum, die Balkanstaaten, die Ukraine, das Wolgaland und Georgien sollten zu einem Ostbund zusammengefaßt werden. „Ein Bund wohl, aber nicht gleichberechtigter Partner, wohlverstanden, ein Bund von Hilfsvölkern, ohne Heer, ohne eigene Politik, ohne eigene Wirtschaft." Ähnlich sollten Holland, Flandern und Nordfrankreich zu einem "Westbund" und Dänemark, Schweden und Norwegen zu einem "Nordbund" zusammengefaßt und mit dem Reich verbunden werden, ohne daß die rechtliche Form dieser Bindung näher bezeichnet wurde. Jedenfalls gelte es, keine „Konzessionen auf einer Gefühlsbasis" und keinen "Unterschied zwischen Freunden und Gegnern“ zu machen. Die Großraumidee klingt auch hier schon an : „Die Zeit der kleinen Staaten ist vorbei . . . Es wird keine Neutralität mehr geben. Die Neutralen werden in die Kraftfelder der Großen geraten. Sie werden aufgesaugt werden. Alles dies wird nicht auf einmal geschehen. Ich werde Schritt für Schritt vorgehen, aber mit eiserner Konsequenz." 37 Schon im Sommer 1932, anläßlich einer Reihe

\footnotetext{
32 a. a. O., S. 154.

33 a. a. O., S. 154, 157 (vgl. dazu Picker, Hitlers Tischgespräche im Führerhauptquartier 1941-42, Bonn 1951, S. 123).

${ }^{34}$ Mein Kampf, S. 754.

35 Hitlers Zweites Buch, S. 217.

36 Hermann Rauschning, Gespräche mit Hitler, S. 118; vgl. auch ders., Die Revolution des Nihilismus, Zürich-New York 1938, S. 404.

37 Rauschning, Gespräche, S. 118.
} 
von Vorträgen über „Ostraumpolitik“ im Stabe Darrés ${ }^{38}$ hatte Hitler ein PanEuropa abgelehnt und ein germanisches Europa auf der Grundlage echten Herrentums gefordert: „Nie werde ich daher anderen Völkern das gleiche Recht wie dem deutschen zuerkennen. Unsere Aufgabe ist es, die anderen Völker uns zu unterwerfen." Das deutsche Volk sei berufen, die neue Herrenschicht abzugeben ${ }^{39}$. "Ohne die Macht über Europa müssen wir verkümmern. Deutschland ist Europa " ${ }^{\mathbf{0}}$.

Mochte man die Ausführungen in "Mein Kampf" und in dem Manuskript von 1928 noch als die eines Phantasten ansehen, der - einmal in Deutschland an die Macht gelangt - seine als nationalistische Propaganda geäußerten Pläne zu revidieren gezwungen sein werde, - oder mag man den nach der Erinnerung und in der Emigration niedergelegten Aufzeichnungen Rauschnings Quellenwert absprechen: die Entwicklung nach 1939 zeigte, daß eine Umgestaltung Europas etwa in dem oben aufgezeigten Sinn tatsächlich Hitlers Absichten entsprach. Allerdings stellt dabei die tatsächlich vollzogene Unterwerfung Europas allein noch keinen zwingenden Beweis dar. Sie ließe sich noch immer als ungewolltes Ergebnis der Ausweitung des von Hitler gegen Polen begonnenen Krieges hinstellen, als eine Folge politischer und militärisch-strategischer Notwendigkeiten, wie sie sich aus der jeweiligen Kriegslage ergaben, d. h. als eine letztlich nur kriegsbedingte vorübergehende Erscheinung, wenn nicht entsprechende Äußerungen Hitlers und seiner politischen und militärischen Mitarbeiter erhärten würden, daß Hitler mit den im Kriege geschaffenen Tatsachen planvoll einer bleibenden Herrschaft über den europäischen Großraum vorgearbeitet hat. Treffend gab Hitlers Chefdolmetscher Paul Schmidt nach dem Kriege zu Protokoll:

„Die allgemeinen Ziele der Nazi-Führung waren von Anfang an augenscheinlich, nämlich die Beherrschung des europäischen Festlandes ... Die Durchführung dieser grundlegenden Ziele machte jedoch den Eindruck einer Improvisation. Jeder Schritt erfolgte, wie es den Anschein hatte, jeweils beim Auftauchen einer neuen Sachlage; aber sie waren alle im Einklang mit dem oben erwähnten Endziel. “41

Bezeichnend waren schon die allgemeinen Leitsätze zur Sicherung der militärisch gewonnenen Machtbasis. Da hieß es z. B., da $\beta$ „es in einem Kriege, in dem es um die Neugestaltung einer kontinentalen Ordnung in Europa geht, zweckmäßig" sei, „die besetzten Gebiete schon während des Krieges auf die künftige Neuordnung

38 Rauschnings Berichte über diese Ostraumpolitik-Vorträge sind insofern interessant, als sie Einzelheiten offenbaren, die später tatsächlich zur Ausführung gelangten: die Angliederung Böhmens, Mährens, Österreichs, „ein größeres Ungarn, ein in seine Bestandteile zerlegtes Serbien und Kroatien, ein verkleinertes Rumänien“, die Aufteilung Rußlands, „im Nordosten der Pfeiler Finnland“. Um den „zentralen Großstaat im Mittelpunkt... ein Kranz von kleinen und mittleren unselbständigen Staatsgebilden; das sei... das Gerippe des deutschen Großreiches" (a. a. O., S. 37).

${ }^{39}$ a. a. O., S. $43 \mathrm{f}$. (Hitlers Stellungnahme gegen Pan-Europa s. auch Zweites Buch, S. $129 \mathrm{ff}$.) 40 a. a. O., S. 30.

41 Dok. PS-3308, IMT 32, S. 144. Wir zitieren nach der deutschen Wiedergabe in IMT 1 , S. 252. 
vorzubereiten ", und „da $\beta$ die besetzten ... Gebiete so geführt werden, wie sie sich späterhin am besten in die europäische Neuordnung einfügen werden und sollen". Entgegen den Bestimmungen der Haager Landkriegsordnung über die Verwaltung eines durch fremde Kriegsmacht besetzten Staates nahm die nationalsozialistische Führung das Recht in Anspruch, das "politische System und auch die diesem zugrundeliegenden und von ihm getragenen Gesetze des besetzten Gebietes abändern und die politische Ordnung im besetzten Gebiet nach ihren Wünschen und Zielen gestalten " 42 zu können. Während gegenüber den anderen besetzten Staaten (mit Ausnahme Polens) wenigstens die Fiktion aufrechterhalten wurde, daß die Ausübung der Besatzungsgewalt gemä $\beta$ dem Kriegsrecht erfolge, wurden gegenüber der Sowjetunion, die nach dem deutschen Überfall „nicht mehr als Subjekt der europäischen Politik", sondern als "Objekt der deutschen Weltpolitik" 43 galt, die Bestimmungen der Haager Landkriegsordnung spätestens ab 1942 deutscherseits überhaupt nicht mehr als geltend angesehen, „da die UdSSR aufgelöst ist und das Reich infolgedessen die Verpflichtung hat, im Interesse der Landesbewohner, alle Regierungs- und sonstigen Hoheitsbefugnisse auszuüben“. Daher seien „alle Maßnahmen zulässig, die der deutschen Verwaltung zur Durchführung dieser umfassenden Aufgabe erforderlich und geeignet erscheinen "44. Unter diese Maßnahmen fiel schließlich auch die Dezimierung bestimmter rassischer und völkischer Gruppen.

Die mehr oder weniger direkte Verwaltung der unter Reichshoheit stehenden Gebiete außerhalb der deutschen Binnengrenzen, die sogenannte „Reichsaußenverwaltung“, bildete „im Kern bereits die Grundlage ... für Durchsetzung und Erfüllung der künftigen europäischen Großraumordnung, die das Reich erstrebt“. Sie umfaßte 1943 rund $30 \%$ des nichtdeutschen europäischen Gebietes und der nicht-deutschen europäischen Gesamtbevölkerung (2865000 qkm und 154 Millionen Einwohner) ${ }^{45}$, während der größte Teil des übrigen nichtbesetzten Kontinentaleuropa durch mehr oder weniger freiwillige Bündnisse, durch Satelliten- und Schutzverhältnisse mit verschiedenen Graden von Abhängigkeit und durch erzwungene "Neutralität" unter deutschem Einfluß stand ${ }^{46}$. Umfang und Intensität der nationalsozialistischen „Neuordnungs"-Planung und -praxis unterschieden sich in den einzelnen besetzten Gebieten.

42 H. Spanner, "Fragen der Verwaltung besetzter Gebiete" (Archiv des öffentlichen Rechts, Neue Folge 34, 1944), S. $101 \mathrm{ff}$.

43 Rede Rosenbergs vor den engsten Beteiligten am Ostproblem vom 20. Juni 1941. Dok. PS-1058 (IMT 26, S. 613).

44 Dok. PS-1056 (IMT 26, S. 602); ferner: Dok. 347-EC (IMT 36, S. 344).

45 H. Ipsen, „Reichsaußenverwaltung " (Brüsseler Zeitung v. 3. 4. 43 und Monatshefte für Ausw. Pol. 10, 1943, S. 521 f.).

46 Ein entspr. Überblick über Europa in nationalsozialistischer Beleuchtung bei H. P. Ipsen, „Zwischen Krieg und Neutralität" (Brüsseler Zeitung v. 25. 5. 43. Auszüge in Monatshefte f. Ausw. Pol. 10, 1943, S. 607 ff.). 


\section{b) Die "Neuordnung" für die besetzten west- und nordeuropäischen Gebiete}

(Frankreich, Luxemburg, Belgien, die Niederlande, Dänemark, Norwegen)

Einen Anhaltspunkt für die Zielsetzung gegenüber den west- und nordeuropäischen Gebieten bietet die Studie der deutschen Seekriegsleitung vom 3. Juni 1940 über „Raumerweiterungen " für die Zeit nach dem Kriege. Sie geht davon aus, „daß die heutige Lage Deutschlands in der Enge der deutschen Bucht . . ein für die Zukunft Großdeutschlands unmöglicher Zustand" sei, und empfiehlt als „gegebene " Lösung die Einbehaltung „Belgiens, eines Teiles Nord- und Ostfrankreichs", wobei „Frankreich in seiner Wehrkraft (Volkskörper, Bodenschätze, Industrie, Wehrmacht) so zerschlagen wird, daß ein Wiedererheben als ausgeschlossen bezeichnet werden muß“. Dagegen sollten „die kleineren Staaten, wie Niederlande, Dänemark, Norwegen“ bestehen bleiben, aber „in eine Abhängigkeit von uns gezwungen werden, die uns in jedem Falle und zu jeder Zeit eine erneute leichte Besetzung dieser Länder ermöglicht ..." Oberster Leitsatz dabei war, daß die in den „durch diesen Krieg gewonnenen strategischen Räumen ... lebenden Völker sich politisch, wirtschaftlich und militärisch in völliger Abhängigkeit von Deutschland fühlen und befinden". Wenn diese militärische Studie auch an sich nicht als Beweis für die Absichten der politischen Führung gelten kann, so dürfte doch das in ihr gesetzte Ziel, das Deutsche Reich ein für allemal vor „der Möglichkeit eines in näherer oder weiterer Zukunft neu entbrennenden Krieges " ${ }^{47} \mathrm{zu}$ sichern, mit den Absichten Hitlers - dessen außenpolitisches Denken stark von militärischstrategischen Gesichtspunkten beherrscht war - in Einklang gestanden haben. Tatsächlich kam die praktisch verfolgte Politik diesen Zielen sehr nahe.

Im Westen wurde die Annexion Luxemburgs und Elsaß-Lothringens tatsächlich schon weitgehend durchgeführt. Es kann als sicher gelten, daß auch der rechtliche Vollzug der Angliederung nach dem Krieg geplant war. In einem Vermerk des Staatssekretärs im Innenministerium, Dr. Stuckarts, vom 25.9. 1940 über eine Besprechung von Westfragen in der Reichskanzlei unter Hitlers Vorsitz heißt es:

„3.) Der Führer hat ferner folgende allgemeine Richtlinien gegeben:

... Elsaß und Lothringen sollen im Laufe von $10 \mathrm{Jahren}$ völlig deutsche Gebiete werden. Elsaß und Lothringen sollen, obwohl die staatsrechtliche Einverleibung noch nicht stattgefunden hat, so behandelt werden, als ob sie bereits stattgefunden hätte. Die militärischen Stellen sollen Elsaß und Lothringen nicht als besetztes Gebiet, sondern als Heimatgebiet behandeln . . " "48

Neben Äußerungen Hitlers ${ }^{49}$, Eintragungen in Goebbels Tagebüchern ${ }^{50}$ und entsprechenden Erörterungen in Görings Hauptquartier ${ }^{51}$ deuten die in diesen

47 Nürnb. Dok. 041-C, IMT 34, S. 240 f.

48 Akten Pfundtner, Photokopie im Archiv IfZ, Rep. 320/132.

49 Picker, a. a. O., S. 196 (Gespräch vom 1. 8. 1941), S. 305 (12. 5. 1942).

50 Lochner, Goebbels Tagebücher aus den Jahren 1942-43, Zürich 1948, S. 185 f. (Eintragung vom 30.4.42).

51 S. Greheime Kommandosache: Aktenvermerk vom 20. Juni 1940 über die Besprechung in Görings Hauptquartier am 19. Juni 1940 über die politische, wirtschaftliche und militärische Planung. Dok. 1155-PS, IMT 27, S. 31. 
Gebieten getroffenen Maßnahmen auf die Absicht der endgültigen Annexion hin: Die Einsetzung von "Chefs der Zivilverwaltung“, die Angliederung an die angrenzenden deutschen Gaue unter neuer Benennung, die Politik der,Eindeutschung "52 durch Vertreibung von Franzosen und Juden sowie Ansiedlung von Deutschen ${ }^{53}$, Einführung der deutschen Sprache als Amtssprache, Verdeutschung von Namen, Einführung der deutschen Gemeindeordnung, deutschen Rechts und Geldes, sogar eines Verbotes, Baskenmützen („Franzosenmützen“) zu tragen, und schließlich 1942 auch der Wehrpflicht ${ }^{54}$. In Luxemburg wurden neben ähnlichen Eindeutschungsmaßnahmen und der Ansiedlung von Südtirolern die verfassungsmäßigen Institutionen, die beiden Kammern des Parlaments und die politischen Parteien aufgelöst ${ }^{\mathbf{5 5}}$.

Was Nord- und Ostfrankreich betraf, so waren auf Befehl Hitlers von Staatssekretär Stuckart bereits detaillierte Annexionspläne ausgearbeitet worden, nach denen die Grenze „etwa von der Mündung der Somme ostwärts am Nordrand des Pariser Beckens und der Champagne entlang bis zu den Argonnen ", von dort "nach Süden . . . weiter durch Burgund und westlich der Franche Comté bis zum Genfer See" verlaufen sollte, die also die Einverleibung der „aus historischen, politischen, ethnographischen, geographischen und sonstigen Gründen ... nicht zu West-, sondern zu Mitteleuropa "56 gehörenden Gebiete vorsahen. Auch die britischen Kanalinseln sollten zu Deutschland kommen ${ }^{57}$. Die Errichtung eines zum Reich gehörigen „burgundischen Staates" wurde erörtert" ${ }^{58}$, da Burgund von Hitler als „uralter deutscher Boden" angesehen wurde ${ }^{59}$. Himmler wollte dort ursprünglich

52 Vgl. die Aussage Dr. Globke, Dok. 513-F, IMT 37, S. 219.

53 Besprechung der mit "Siedlungsfragen" befaßten SS-Hauptämter in Berlin vom 4. August 1942 (Dok. 114-R, IMT 38, S. 330 ff.), ferner Aussage Globke, Dok. 513-F, a. a. O., S. 220; Picker, a. a. O., S. 305.

$54 \mathrm{Vgl}$. die auf Dokumente gestützten Ausführungen Faures in Nümberg (IMT 6, S. 480 ff.). Ein Teil der Dokumente über die deutschen Maßnahmen ist abgedruckt in IMT 38, S. $567 \mathrm{ff}$. 55 Vgl. dazu Dok. RF-801, IMT 38, S. 597 (Verordnung vom 22. Oktober 1940). Über das Verbot der Parteien s. Ausführungen Faures, IMT 6, S. 523 f.; Über die Eindeutschungsmaßnahmen: Amtlicher Luxemburgischer Bericht über die deutschen in Luxemburg begangenen Verbrechen, Dok. 077-UK, IMT 39, S. $137 \mathrm{ff}$.

${ }^{56}$ s. Aussage Globkes, Dok. 513-F, a. a. O., S. 222 f. Die Hitler vorgelegte erste Fassung war Hitler nicht weitgehend genug, er wünschte eine Erweiterung des Annexionsgebietes insbesondere an der Kanalküste. Ferner Picker, a. a. O., S. 78 (25. 4. 42), 81 f., 83 (13. 5. 42). Über Hitlers verschrobene Ansichten in dieser Beziehung, die sich auf die Lektüre des 1937 erschienenen Buches von Petri "Germanisches Volkserbe in Wallonien und Nordfrankreich" stützten, und gegen die Petri selbst über den Militärbefehlshaber in Belgien und Nordfrankreich, General v. Falkenhausen, eine Denkschrift an das Führerhauptquartier richtete, um "die Unhaltbarkeit solcher anderthalb Jahrtausende überspringender Schlußfolgerungen" darzulegen und gegen den Mißbrauch seiner Forschungen Einspruch zu erheben, s. Picker, a.a. O., S. $425(5.5 .42)$.

57 Picker, a. a. O., S. 187 f. (22. 7. 42).

58 Besprechung in Görings Hauptquartier v. 19. 6. 40, Dok. 1155-PS, a. a. O., S. 31 ; ferner Goebbels Tagebücher, a. a. O., S. 177 (25. 4. 42).

50 Picker, a. a. O., S. 78 (25. 4. 42). 
die Südtiroler ansiedeln, für die später die Krim vorgesehen wurde ${ }^{60}$. Auch der Gedanke eines "bretonischen Staates" tauchte auf ${ }^{\mathbf{6 1}}$.

Wenn Frankreich derart harte Friedensbestimmungen nicht schon 1940 auferlegt bekam und auch seine verhältnismäßig starke Flotte behalten durfte, dann lag das augenscheinlich vor allem an der Befürchtung Hitlers, daß sich die französische Regierung andernfalls samt der Flotte nach Nordafrika zurückziehen würde bzw. sich die nord- und westafrikanischen Besitzungen der Franzosen von der VichyRegierung trennen würden, um aktiv an die Seite Englands zu treten ${ }^{\mathbf{6 2}}$. Für Hitler war es in dieser Zeit wertvoller, den Franzosen soviel Kraft zu belassen, daß sie ihre Besitzungen gegen einen eventuellen englischen Zugriff verteidigen konnten und so wertvolle Operationsbasen "neutralisiert" blieben ${ }^{\mathbf{6 3}}$. Auf der anderen Seite hat Hitler aber die Gelegenheiten für eine wirkliche Zusammenarbeit mit Frankreich, wie sie sich z. B. anläßlich der Gespräche mit Pétain und Laval in Montoire im Oktober und mit Darlan bei Beauvais im Dezember $1940^{64}$ boten, ungenutzt vorübergehen lassen und entsprechende französische Angebote - auch nach Beginn des Rußlandfeldzuges - dilatorisch behandelt und nie durch konkrete Vorschläge für eine solche Zusammenarbeit beantwortet, um sich gegenüber Frankreich auf keinerlei Zugeständnisse festlegen zu müssen.

Eine wirkliche Aussöhnung beider Nationen, die, wie Kluke richtig schreibt, „eine Vorbedingung für die Realisierung jeder wirklichen Europakonzeption war"65, wurde jedenfalls von Hitler nicht betrieben, obwohl z. B. Darlan die Zukunft Frankreichs nur in der wirtschaftlichen und politischen Zusammenarbeit mit Deutschland in einem eurafrikanischen Großraum gesichert sah ${ }^{\mathbf{6 6}}$ und besonders bei Laval die Bereitschaft vorhanden war, diese Zusammenarbeit weitgehend nach den Bedingungen der Nationalsozialisten zu betreiben ${ }^{67}$. Hitlers Boykott der

60 Nürnberger Dok. NO-2417. s. Kluke, a. a. O., S. 255 f. Über die literarische Unterstützung der burgundischen Autonomiebewegung und den Auftrag für eine Denkschrift, die den historischen Anspruch des Reichs auf Burgund begründen sollte (a. a. O., S. 256, Anm. 75).

61 Besprechung in Görings Hauptquartier, 19.6. 40. Dok. 1155-PS, a. a. O., S. 31. Die bretonische Autonomiebewegung, die mit einem bretonischen Nationalkongreß unter der Ägide der Besatzungsmacht am 3. Juli 1940 in Pontivy in Szene gesetzt wurde, scheiterte allerdings kläglich (Kluke, a. a. O., S. 255).

62 Vgl. Kordt, a. a. O., S. 285; ferner Hitlers Brief an Mussolini vom 5. Dezember 1940 (Les Lettres Secrètes échangées par Hitler et Mussolini. Introduction de André François Poncet, Paris 1946, S. 99).

${ }^{63}$ Hitlers Direktive Nr. 18 an seine Oberbefehlshaber vom 12.11. 1940 (DIA 1939-46, Vol. II, S. 127, Auszug).

64 Schmidt, a. a. O., S. 503 ff., 513; Kordt, a. a. O., S. 269 f., 284 f. Charakteristisch für Hitlers Taktik das Gespräch zwischen Botschafter Abetz und dem Gesandten Hemmen v. 24.9.1941 (NG-1397).

65 Kluke, a. a. O., S. 253 f., S. 263 f.

66 Vgl. Darlans Denkschrift an Pétain vom 8. November 1940 (Bouthillier, Le Drame de Vichy, Bd. I, Paris 1950, Annex 7, S. $303 \mathrm{f}$.).

67 s. Telegramm des Botschafters Abetz an Ribbentrop vom 31. Oktober 1940 und die Aufzeichnung Hemmens vom gleichen Tage über eine Zusammenkunft mit Laval (Bouthillier, a. a. O., Annexes No. 2 u. 3, S. 291 ff. und 293 ff.). Nach Schmidt, a. a. O., S. 565, trat Laval 
kollaborationswilligen französischen Kräfte und die Schaffung vollendeter Tatsachen in Elsaß-Lothringen deuten darauf hin, daß es ihm hinsichtlich Frankreichs nicht um echte Kooperation im europäischen Großraum ging und daß er nach einem völligen Siege nicht bebasichtigte, Frankreich als europäischen Partner in altem Umfang und Potential wiederherzustellen. Ciano gegenüber äußerte Hitler im August 1941, er wolle Frankreich hinhalten, bis der Sieg über die Sowjetunion den Franzosen die letzten Illusionen nehme ${ }^{\mathbf{6 8}}$, und im Kreise seiner Vertrauten deutete er an, daß die Franzosen nach seiner Einschätzung stets Feinde Deutschlands sein würden, er werde daher "mit der Regierung in Vichy Fraktur reden, sobald die russische Aktion erledigt sei und er den Rücken damit frei habe"69. Goebbels war der Ansicht, daß diese „makabre genußsüchtige Nation“ der Franzosen „nichts mehr wert" sei ${ }^{70}$ und „Nennenswertes an positiven Leistungen für den Neubau Europas ... von ihr kaum noch zu erwarten " sei ${ }^{\mathbf{1 1}}$. Zwar wäre Vichy bereit, an die deutsche Seite zu treten,

"wenn wir ihnen jetzt einen annehmbaren Frieden anböten. Das aber will der Führer nicht, und zwar mit Recht nicht . . Man soll seine Trümpfe nicht vorzeitig aus der Hand geben. Vor allem aber ist es notwendig, den Krieg gegen Frankreich zu einem geschichtlichen Ergebnis zu führen ... Wir müssen deshalb die militärische und politische Macht Frankreichs endgültig vom zukünftigen Kräftespiel ausschalten. "72 Durch einen Sonderfrieden würde jedoch „eine Amputation Frankreichs gänzlich ausgeschlossen. Im Höchstfalle wären die Franzosen bereit, das Elsaß abzutreten; aber schon bei Lothringen würden sie die größten Schwierigkeiten machen. Man fragt sich, warum wir dann überhaupt einen Krieg gegen Frankreich geführt haben. Wenn die Franzosen wüßten, was der Führer einmal von ihnen verlangen wird, so würden ihnen wahrscheinlich die Augen übergehen. Es ist deshalb gut, daß man vorläufig mit diesen Dingen hinter dem Berge hält und aus dem Attentismus der Franzosen so viel herauszuholen versucht als überhaupt herausgeholt werden kann"73. „Das Gerede von Kollaboration ist nur für den Augenblick gedacht . . “"74

Dieser letzte Gedanke Goebbels' kehrt in einem. Funkspruch des Höheren SSund Polizeiführers in Frankreich, Oberg, an Himmler vom 10. 2. 1944 wieder, in dem es bezeichnenderweise heißt, „daß gemäß Führerweisung zwar nach außen hin eine Politik der Zusammenarbeit zu betreiben sei, dabei aber niemals das Ziel, Frankreich endgültig zu zerschlagen, aus den Augen verloren werden dürfte "75.

dafür ein, noch während des Krieges eine kontinentaleuropäische Konferenz über ein gemeinsames Vorgehen einzuberufen. Auch nach seiner Rückkehr ins Amt im April 1942, s. Rundfunkrede vom 22. 6. 1942 (Survey of International Affairs 1939-46, S. 396f.) und Zusammenkunft mit Hitler in Ostpreußen im Dezember 1942 (Kordt, a. a. O., S. 367).

68 Ciano, L'Europa, a. a. O., S. 673.

69 Picker, a. a. O., S. 60 (1. 4. 42), vgl. auch Table Talk, a. a. O., S. 265 (31. 1. 42).

70 Goebbels Tagebücher, S. 87 (14.2. 42).

71 a. a. O., S. 150 (2. 4. 42), ähnl. S. 46 (22. 2. 42).

72 a. a. O., S. 114, (7. 3. 42).

73 a. a. O., S. 185 f. (30. 4. 42), S. 125 (19.3. 42).

74 a. a. O., S. 177 (26. 4. 42).

75 Nbg. Dok. NO-5619. 
Mögen auch manche der geschilderten Aufteilungspläne das Merkmal des ersten Siegesrausches tragen und die zitierten $\ddot{u}$ ßerungen bis zu einem gewissen Grade die Reaktion auf den wachsenden Geist des attentisme Vichys und des Widerstandes im besetzten Teil Frankreichs widerspiegeln, so deutet doch alles darauf hin, daß Frankreich - ganz im Einklang mit der oben erwähnten militärischen Studie - als Großmacht auf dem Kontinent zumindest soweit ausgeschaltet werden sollte, daß es kein ernsthaftes Gegengewicht gegen die Achse im europäischen Großraum mehr darstellen konnte ${ }^{76}$.

Bezüglich Belgiens waren neben der erfolgten Eingliederung der Gebiete von Eupen, Malmedy und Moresnet im Mai 1940 offensichtlich noch weitere Annexionen vorgesehen. Hitler äußerte die Ansicht, „daß es sich bei Wallonien . . u um altes deutsches Land handele ... Wenn wir die Rückgabe irgendeines Gebietes daher mit vollem Recht verlangen könnten, so die Walloniens . .."77. Die Idee Mussolinis, die Wallonen Frankreich zuzuschlagen ${ }^{78}$, lehnte er ab. Er begrüßte es, „daß sich weder in Belgien noch in den Niederlanden Regierungen befänden, mit denen man zu verhandeln gezwungen sei. So könne man diktieren, was sich als politisch erforderlich erweise . . "79. Die für die Zukunft geplante gesonderte Behandlung Flanderns und Walloniens ${ }^{80}$ zeigte sich vor allem in der Förderung getrennter politischer Bewegungen in beiden Gebieten.

Flandern wurde von den Nationalsozialisten zum "germanischen Raum" gerechnet ${ }^{81}$, dessen Gebiete allen Anzeichen nach durch die Unterstützung einheimischer nationalsozialistischer und faschistischer Parteiorganisationen seitens der Besatzungsmacht in deutscher Abhängigkeit gehalten und unter einem unterschiedlichen Maß von Selbständigkeit dem "Großgermanischen Reich" angegliedert werden sollten ${ }^{82}$. Als "Germanen“ genossen diese Völker auch den Vorzug, als

${ }^{76}$ So auch Hitlers Entscheidungen, die Jodel dem Chef der Operationsabteilung der Kriegsmarine am 4. November 1940 als endgültige Absichten bezüglich Frankreichs übermittelte. United States Navy Department, Führer Conferences on Matters Dealing with the German Navy 1939-1941, Washington 1947 (1940, S. 117), vgl. auch 9. und 25. Juli 1941, (1941, S. 92 und 94.)

77 Picker, a. a. O., S. 425 (5. 5. 42).

78 Im August 1941 geäußerte Absicht Mussolinis, um Frankreich für Nizza und Korsika zu entschädigen, die zu Italien kommen sollten (Survey 1939-1946, a. a. O., S. 304).

79 Picker a. a. O., S. 100 f. (27. 6. 42).

80 Nürnb. Dok. 1155-PS, a. a. O., S. 31. s. auch Anweisung zur Förderung der Flamen (Entlassung der Kriegsgefangenen) im Gegensatz zu den Wallonen: Schreiben Keitels an Ob. d. H. vom 14. 7. 40 (NG-4188).

81 Vgl. Geheime Niederschrift vom 20. Januar 1943 über die am 12. Januar 1943 abgehaltene Besprechung des SS-Ausschusses der Arbeitsgemeinschaft für den Germanischen Raum (Dok. 705-PS, IMT 26, S. 263 f.).

82 Über die Wandlung d. Begriffes des „Großgermanischen Reiches" s. H.-D. Loock: „Zur ,Großgermanischen Politik" des Dritten Reiches" (VfZ 1960, H. 1, S. 37 ff.). Über das Verhältnis der "germanischen Gebiete" zum Reich s. u. über Holland, Dänemark u. Norwegen. Über das "Germanentum" als übernationale Parole und die spätere Umbenennung Berlins in „Germania“" s. Tischgespräche, a. a. O., S. 97 f. (8. 6. 42), die Schaffung einer ,germanischen Legion", a. a. O., S. 119 (24. 7. 42). 
Rekrutierungsreservoir für die Waffen-SS zu dienen. Ob in Belgien ernstlich daran gedacht war, diese politischen Parteien nicht nur zur Unterstützung der Besatzungspolitik heranzuziehen, sondern ihnen eine eigene Funktion als Grundstock künftiger innerer Umgestaltung einzuräumen, ist fraglich. Jedenfalls ist kennzeichnend, daß rivalisierende Gruppen abwechselnd begünstigt wurden, um verschiedene Möglichkeiten im Spiel zu halten und definitive Entscheidungen über das Schicksal Belgiens und seiner Nationalitäten, deren Eigenstaatlichkeit usw. hinauszuzögern. Charakteristisch für diese deutsche Politik ist der Ausspruch des Leiters des VNV (Vlaamsch National Verbond), Elias, „daß Deutschland zu Zugeständnissen auf volkspolitischem Gebiet immer nur dann bereit sei, wenn es ihm dreckig ginge"83.

In Flandern wurde im Mai 1941 der erwähnte VNV unter Staf de Clerq (nach dessen Tode seit Oktober 1942 unter Hendrick Elias) als alleinige Partei anerkannt und mit hohen Verwaltungsposten unter der deutschen Militärverwaltung betraut, nachdem er den Verbond van Dietsche Nationaal Solidaristen (VERDINASO) und die flämische Abteilung der Rexisten unter seine Kontrolle gebracht hatte. Der VNV trat für eine Vereinigung Flanderns mit Holland im „dietschen Staat" ein. Diese Aspirationen wurden allerdings von deutscher Seite von vornherein gedämpft. Der Chef des SS-Hauptamtes Berger erklärte dem Vlamenführer Dr. Borms: „Daß Flandern zum Reich müsse und nie ein Großdietschland entstehe, ist . . klar"84. Neben dem VNV wurden nach Beginn des Rußlandfeldzuges weitere flämische Faschistengruppen zugelassen, deren Politik dem VNV entgegenstanden. Thre Aufgabe war wohl hauptsächlich, Kontingente für die Ostfront zu stellen. Ab Ende 1942 wurde die für eine deutsche Annexion eintretende Deutsch-Vlämische Arbeitsgemeinschaft ( $D E V L A G$ ) unter Van de Wiele dem VNV gegenüber bevorzugt. Es nutzte Elias auch nichts, daß er in einem Schreiben vom Dezember 1943 in der Frage eines "dietschen Staates" vor Himmler kapitulierte:

„Bei der Betonung alldessen, was Flandern und die Niederlande . . gemeinsam haben, betrachte ich dennoch den Dietschen Staat nicht als eine unerläßliche Voraussetzung . . . Wenn der Führer es also bestimmt, betrachte ich meinen Auftrag als auf den Raum begrenzt, der von ihm uns angewiesen werden wird, und ich stehe dafür ein, daß meine Bewegung nur in diesem Raum und in dieser Begrenzung ihre aufbauende Arbeit durchführen wird. "85

In der deutschen Besatzungspolitik in Belgien stand diesen flämischen Gruppen in Wallonien die faschistische Rex-Bewegung Degrelles gegenüber, gegen die wiederum die prodeutschen Amis du Grand Reich Allemand ( $A G R A$ ) ausgespielt wurden, während die Wallonische Nationalsozialistische Partei wegen ihrer geringen Anhängerschaft von vornherein nicht gefördert wurde. Neben der $S S$ Legioen Vlaanderen Staf de Clerq's gründete auch Degrelle eine Légion Wallonie, die 1943 als SS-Brigade Wallonien der Waffen-SS eingegliedert wurde ${ }^{\mathbf{8 6}}$. Degrelle

\footnotetext{
${ }_{83}$ Bericht des SS-Obersturmbannführers Riedweg über die Lage in den germanischen Ländern, Dok. 705-PS, a. a. O., S. 264.

84 Schreiben Bergers an Himmler v. 14. 12. 42 (Nürnberger Dok. NG-5495).

85 Schreiben an Himmler v. 15. 12. 43 (NO-623), dazu Begleitschreiben Bergers (NO-624).

86 Zur deutschen Besatzungspolitik in Belgien vgl. Survey 1939-46, a. a. O., S. $121 \mathrm{f} ., 483 \mathrm{f}$;
} 
äußerte in seiner Rede im Januar 1943, daß auch die Wallonen Germanen seien und für eine zukünftige "Germanische Gemeinschaft" kämpfen müßten ${ }^{87}$. Nach dem Bericht des Militärbefehlshabers in Belgien und Nordfrankreich, General von Falkenhausen, hat Berger in einer öffentlichen Rede in Brüssel geäußert, daß die Teilung Belgiens in zwei Reichsgaue beschlossene Sache sei ${ }^{88}$. Diese Absicht wird in einem Schreiben Bergers an Himmler vom 21. Oktober 1942 bestätigt, in dem er vorschlug, „daß wir jetzt in vorsichtiger, aber klarer Form beginnen, den Reichsgau Flandern auf die Beine zu stellen und mit der Ordnung des Reichsgaues Wallonien beginnen "89.

Bei seiner Zusammenkunft mit dem belgischen König am 19. November 1940 verweigerte Hitler dem König die Zusage außenpolitischer und - im Hinblick auf die deutsche Flamenpolitik - innerpolitischer Unabhängigkeit Belgiens und forderte eine so starke politische und militärische Anlehnung Belgiens an Deutschland, daß das Land unter deutschen militärischen Schutz kommen und „die Belgier selbst kaum noch eine Armee nötig haben würden "90. Stellt man ferner Hitlers Äußerung in Rechnung, daß der belgische König „, in der politischen Versenkung verschwinden “ müsse ${ }^{91}$, weil er den „Zusammenschluß der germanischen Welt wie der dänische und der schwedische König " störe ${ }^{92}$, so kann man mit Sicherheit annehmen, daß Belgien nach dem deutschen Endsieg nicht in seiner alten Form wiederhergestellt, sondern - wie in der genannten militärischen Studie gefordert - entweder teilweise annektiert oder geteilt und in enge Abhängigkeit vom Deutschen Reich gebracht worden wäre.

Die Niederlande, Dänemark und Norwegen sind diejenigen deutschbesetzten Staaten des "germanischen Raumes", in denen die Politik der Einsetzung von "Quisling-Regierungen " systematisch vorangetrieben wurde, wenn auch mit unterschiedlichem Erfolg ${ }^{93}$. Die dabei benutzten einheimischen Parteiinstrumente waren die Nationaal Socialistische Beweging (NSB) unter Anton Mussert in den Niederlanden, die Dansk National Socialistiske Arbejder Parti (DNSAP) unter Fritz Clausen in Dänemark und die Nasjonal Samling (NS) unter Vidkun Quisling in Norwegen. Diese Parteien wurden als soweit gleichgeschaltet angesehen, daß ihre Tätigkeit schließlich auch in Deutschland selbst zugelassen wurde ${ }^{\mathbf{9 4}}$. Hitler war der Meinung, daß auf diese drei Männer, wenn sie einmal an die Regierung gebracht ferner die Ausführungen Faures, gestützt auf den amtl. Bericht der belg. Regierung (RF-394), IMT 6, S. $580 \mathrm{ff}$.

87 Frankfurter Zeitung vom 20.1.1943.

88 Nbg. Dok. NO-617.

89 Nbg. Dok. NO-1469, vgl. auch Aufzeichnung des Gesandten v. Bargen v. 8. 7. 43 (NG-1636).

90 Schmidt, a. a. O., S. $508 \mathrm{ff}$, S. 510.

91 Picker, a. a. O., S. 120 (24. 7. 42).

92 a. a. O., S. 57 f. (28. 3. 42).

$93 \mathrm{Vgl}$. den Überblick über die deutsche Besatzungspolitik in den "germanischen " Ländern in dem Aufsatz von Loock (s. Anm. 82).

94 Verfügungen, Anordnungen, Bekanntgaben, herausgegeben von der Partei-Kanzlei, München o. J. Bd. II, S. 213 ff. (V. I. 18/224). Auch der VNV und die Rex-Bewegung wurden zugelassen. 
worden seien, unbedingter Verlaß sein werde, weil sie sich dermaßen in Mitschuld verstrickt hätten, daß sie auf Gedeih und Verderb mit ihm verbunden seien $^{95}$.

Was die Niederlande angeht, so war - gemäß den Erörterungen in Görings Hauptquartier vom 19. Juni 1940 - beabsichtigt, sie selbständig zu lassen, „jedoch eng an das Reich anzuschließen "96. Hitler sprach von Holland als von einem "Glied des Reiches" "97. Er genehmigte Himmlers Idee, in Holland zwei „Reichsschulen " einzurichten, auf denen die gemeinsame Erziehung deutscher und holländischer Kinder „eindeutig auf den Gedanken des germanischen Reiches ausgerichtet sei ${ }^{98}$ “.

Im Gegensatz zu Frankreich und Belgien, die beide unter einer Militärverwaltung standen, wurde in Holland ein ziviler Reichskommissar (Seyß-Inquart) eingesetzt, der alle nach der holländischen Verfassung dem König und der Regierung zustehenden Befugnisse übernahm, das holländische Parlament und den Staatsrat suspendierte und mit Ausnahme der holländischen Nationalsozialist en alle politischen Parteien auflöste ${ }^{99}$. Sein geheimer Auftrag lautete, „die aus Gründen der Erhaltung der Niederländisch-Indischen Gebiete unabhängig zu haltenden Niederlande, abgesehen von den militärischen Sicherungen, wirtschaftlich möglichst an das Reich zu binden ". Diese Aufgabe ist zu lösen, heißt es weiter in SeyßInquarts erstem Bericht über die Lage in den Niederlanden, "wenn es gelingt, eine politische Willensbildung zustandezubringen, die die wirtschaftliche Bindung der Niederlande an das Reich als Ausfluß des Willens des niederländischen Volkes erscheinen läßt"100. Das Hauptinstrument zur Bildung dieses "Volkswillens" war die erwähnte, schon vor dem Kriege in Holland bestehende Nationaal Socialistische Beweging (NSB) unter Anton Mussert, der für ein relativ unabhängiges Holland im Rahmen eines Bundes germanischer Staaten eintrat ${ }^{101}$. Der holländische Zweig des hauptsächlich in Flandern sitzenden Verbond van Dietsche Nationaal Solidaristen wurde noch im Jahre 1940 mit der NSB vereint. Het Nationale Front wurde im Frühjahr 1941 aufgelöst, und die Nationaal Socialistische Nederlandsche Arbeiderspartij ( $N S N A P$ ), eine Kopie der NSDAP, die für die Eingliederung Hollands ins Reich eintrat, spaltete sich, wobei sich im Laufe des Sommers 1941 ein Teil der NSB anschloß, und der Rest sich auflöste. Danach wurde die NSB zum zehnten Jahrestag ihres Bestehens am 14. Dezember 1941 zur einzigen von deut-

\footnotetext{
95 Table Talk, S. 345 (27. 2. 42).

96 Nbg. Dok. 1155-PS, a. a. O., S. 30.

97 Picker, Tischgespräche, a. a. O., S. 45 (8. bis 10. 11. 41), vgl. auch S. 67 (5. 4. 42).

98 a. a. O., S. 68 (5.4.42). Zur Einrichtung von Nationalpolitischen Erziehungsanstalten in den germanischen Ländern s. NG-4619.

99 Verordnungen vom 29. 5. 1940, IMT 39, S. 594f., vom 22. 6. 1940, a. a. O., S. $601 \mathrm{f}$., vom 4. 7. 1941, a. a. O., S. $605 \mathrm{f}$.

100 Bericht SeyB-Inquarts für die Zeit vom 29. Mai bis 19. Juli 1940 enthalten in Dok. 997-PS, IMT 26, S. 413).

101 Sein von der SS protegierter Rivale, Rost van Tonningen, sprach dagegen in einem Brief vom 9. 3. 43 an den persönlichen Referenten Himmlers, SS-Ostubaf. Brandt, schlechthin von einer „Vereinigung der Niederlande mit dem Reich“ (Nbg. Dok. NO-4893).
} 
scher Seite zugelassenen Partei in Holland erklärtt ${ }^{102}$. Da im Frühjahr 1942 Niederländisch-Indien mittlerweile von den Japanern erobert worden und damit dem „Ostasiatischen Großraum “ zugefallen war, glaubte man auch in dieser Beziehung auf die Gefühle der Niederländer, die am Königshaus als dem einigenden Band ihres europäischen und überseeischen Reiches festhielten ${ }^{103}$, keine Rücksicht mehr nehmen zu müssen und die Einordnung Hollands in den nationalsozialistischen Großraum forcieren zu können: Am nächsten Jahrestag der NSB im Dezember 1942 wurde Mussert von Hitler als „Führer des niederländischen Volkes" anerkannt und die Einschaltung der NSB in die Verwaltung der Niederlande beschlossen ${ }^{104}$. Am 30. Januar 1943 durfte Mussert eine Art beratendes Kabinett (Staatspolitisk Sekretariaat) bilden ${ }^{105}$, während jedoch die wirkliche Macht weiterhin in deutscher Hand blieb. Zwar war so die NSB, die nach einer hochgegriffenen Schätzung nur 110000 Mitglieder bei 9 Millionen Einwohnern zählte ${ }^{106}$, zum einzigen politischen Willensträger gemacht worden, doch erfüllte sich ihre Hoffnung nicht, von Deutschland mit der Leitung der niederländischen Verwaltung betraut zu werden, um Holland unter eigener Verwaltung an das Reich anzuschließen. In einer Besprechung des SS-Ausschusses der Arbeitsgemeinschaft für den germanischen Raum vom 12. Januar 1943 war die Rede davon, Seyß-Inquarts Prinzip sei die „Abnutzung Musserts, um ihn hinterher fallen zu lassen "107.

Mit Beginn des Rußlandfeldzuges wurde die Nederlandsche Legioen aus Freiwilligen gebildet. Die im September 1940 gegründete Nederlandsche SS kam im Mai 1942 als Germaansche SS en Nederland unter deutsches Kommando; zur gleichen Zeit wurde die Standarte Westland als ein Regiment der Waffen-SS gegründet. Bei der Vereidigungszeremonie der holländischen SS im Haag am 17. Mai 1942 und in einer Rede in Lunteren am 31. Juli des gleichen Jahres hatte Mussert die Hoffnung ausgedrückt, daß einst eine germanische Armee mit einer neuen holländischen Armee als deren Glied zur Verteidigung eines Bundes der germanischen Völker erstehen werde ${ }^{108}$. Demgegenüber erklärte Himmler, daß Holland nach dem Kriege „nur so viele Soldaten zugestanden erhalten könne, als jetzt als Legionisten an der Ostfront kämpften. Denn für die Landesverteidigung brauche er [Mussert] kein holländisches Bundesheer, da sie nach dem Kriege ausschließlich unsere Sache bleibe" 109.

Hatte Mussert in seiner Utrechter Rede zum zehnjährigen Bestehen der NSB

102 s. Dokumente der Deutschen Politik, Bd. 9, 1941, Teil II, S. 553. Über die deutsche Besatzungspolitik, Loock a. a. O.; Survey 1939-46, a. a. O., S. $498 \mathrm{f}$.

103 Seyß-Inquart weist in dem erwähnten Bericht (Dok. 997.PS, a. a. O., S. 427) darauf hin, daß sich der Anschluß der Niederlande an das Reich deshalb auf die Königsfrage zuspitze. 104 A d G 1942, S. 5757, Seyß-Inquart hatte sich bei Hitler dafür eingesetzt (NG-5078).

105 Verordnung vom 30.1. 1943, JN-Dok., IMT 39, S. 623.

106 Vgl. Survey 1939-46, S. 500.

107 s. das bereits erwähnte Dokument 705-PS, a. a. O., S. 264.

108 Survey 1939-46, S. 76. Über die Eidesleistung Musserts an Hitler „als Führer aller Germanen" s. Tischgespräche, S. 243 (20.5. 42).

109 Tischgespräche, a. a. O., S. 67 (5. 4. 42). 
am 14. 12. 1941 von einer gleichberechtigten „Teilnahme des niederländischen Volkes an der Kolonisation und Erschließung der osteuropäischen Gebiete" gesprochen ${ }^{110}$, so sollte er auch darin enttäuscht werden. In einer Unterredung mit Rosenberg am 8. Mai 1942 äußerte sich Hitler kritisch über die Ansiedlung von Holländern in der Libauer Gegend: er wünsche „keine großen Kolonien“ der Holländer im Osten, „wenn es nicht mehr als 1000 Menschen seien, dann könnten sie verdaut werden"111. Nichts aber kennzeichnet die Verlogenheit der nationalsozialistischen „Germanenideologie“ "besser als die Äußerung Görings am 6. August 1942 anläßlich einer Besprechung über die ernährungswirtschaftliche Ausbeutung der besetzten Gebiete, bei der er über die Versorgung der holländischen Bevölkerung sagte: „Wenn dieses Volk so schwach ist, daß es keine Hand mehr heben kann, wo wir es nicht zur Arbeit gebrauchen, - um so besser ... Ob die Herren Holländer Germanen sind oder nicht, ist mir dabei völlig gleichgültig; . . “112.

Alle Versuche Musserts, von Hitler eine Fixierung des zukünftigen Verhältnisses der Niederlande zum Reich zu erlangen, schlugen fehl. Bereits am 27. August 194.0 hatte er Hitler die Gründung eines „Bundes germanischer Völker“ mit gemeinsamer Wehrmacht und Wirtschaft vorgeschlagen, dem ein durch belgisches Gebiet vergrößerter niederländischer Staat angehören sollte. Mussert wünschte eine solche Form des Bundes, „daß darin deutlich zum Ausdruck kommt, daß es nur möglich ist, einer Überherrschung oder Einverleibung zu entgehen dank der Tatsache, daß es eine N.S.B. gibt und dank der Tatsache, daß der Führer das Vertrauen hat, daß die N.S.B. unter meiner Führung das niederländische Volk zum Nationalsozialismus bringen wird"113. Solche Vorschläge trafen allerdings bei Hitler, der seine Absichten nicht enthüllen und sich für die Zukunft nicht festlegen wollte, auf taube Ohren.

Aus alledem ergibt sich, was die vorgesehene Stellung der Niederlande im europäischen Großraum betrifft, im günstigsten Falle das Bild eines ideologisch "gleichgerichteten " und von Deutschland abhängigen Vasallenstaates.

Dänemark, das im April 1940 in „nicht feindlicher Gesinnung “ zum Schutz vor angeblich bevorstehenden Übergriffen der Westmächte besetzt wurde und dem zugesichert wurde, daß durch die getroffenen Maßnahmen keine Verletzung der territorialen Integrität und der politischen Unabhängigkeit beabsichtigt werde ${ }^{114}$, stand zunächst nicht unter einer von Deutschland eingesetzten Militär- oder Zivilverwaltung. Die durch die Besetzung notwendige Einwirkung auf die dänische

110 DDP, Bd. 9, II, S. 553.

111 Nbg. Dok. 1520-PS, IMT 27, S. 288.

112 Stenographischer Bericht bei Poliakov und Wulf, Das Dritte Reich und seine Diener, Dokumente, Berlin 1956, S. 472. Bezeichnend auch der Satz in einem Brief Bergers v. 8.2.44 an Oberg über den Einsatz nichtdeutscher Soldaten: „Für jeden Fremdländischen, der fällt, weint keine deutsche Mutter" (NO-5618).

113 zit. bei Loock, a. a. O., S. 53. Dort auch Hinweise auf weitere Denkschriften Musserts in den folgenden Jahren.

114 Vgl. das deutsche, beim Einmarsch überreichte Memorandum, Dok. 628-D, IMT 35, S. $201 \mathrm{ff}$. 
Verwaltung vollzog sich in der Form der „diplomatischen auswärtigen Verwaltung "115 über das Auswärtige Amt und mit den Mitteln des diplomatischen Verkehrs zwischen theoretisch souveränen Staaten und wurde vom deutschen Gesandten in Kopenhagen, v. Renthe-Fink, wahrgenommen. Jedoch konnte schon in diesem Stadium von einer politischen Unabhängigkeit Dänemarks nicht mehr die Rede $\operatorname{sein}^{116}$. Nach dem Ausbruch des Rußlandfeldzuges konnte die dänische Regierung nicht umhin, am 25. November 1941 wenigstens dem Antikominternpakt beizutreten. Zu Beginn des Jahres 1942 äußerte Hitler im vertrauten Kreise: „bezüglich Dänemarks müsse über kurz oder lang eine Lösung in der Person Clausens gesucht werden "117. Durch die Propagierung des "germanischen Gedankens" werde er (Hitler) dem "König von Dänemark sein Volk langsam unter der Sitzfläche“ wegziehen ${ }^{118}$. Clausen werde der "Nachfolger" des Königs sein ${ }^{119}$. In einer von Ribbentrop angeforderten „Notiz über die dänische Frage“, wurde für die „Suspendierung der Thronfolge und wesentlicher Teile der Verfassung “ in Dänemark, d. h. praktisch der Abschaffung der dänischen Monarchie, von den zuständigen Sachbearbeitern des Auswärtigen Amtes als geeigneter Zeitpunkt „ein durch den Tod des jetzigen Königs eintretender Thronwechsel" ins Auge gefaßt und dadurch einer sofortigen Aktion vorgebeugt. Es müsse in dieser Frage äußerst geschickt vorgegangen werden, denn - so heißt es in dieser Notiz weiter - „wir würden damit unsere machtpolitischen Ziele vorzeitig decouvrieren und in anderen Teilen Europas, namentlich in den zum germanischen Bereich gehörenden Ländern, das Gefühl lebendig werden lassen, daß ihnen das gleiche Schicksal bevorsteht" 120 .

Eine von Hitler als zu kurz und damit als „beleidigend“ empfundene Antwort des dänischen Königs auf ein Telegramm Hitlers wurde dann auch im Oktober 1942 zum Anlaß genommen, das wahre Gesicht der deutschen Okkupation und die endgültigen Absichten der Nationalsozialisten bezüglich der Zukunft Dänemarks zu offenbaren. Der deutsche Gesandte wurde zurückberufen - als Reaktion darauf auch der dänische Gesandte aus Berlin - und durch SS-Gruppenführer Best mit dem Titel eines „Bevollmächtigten des deutschen Reiches" ersetzt. Gegenüber dem neu ernannten deutschen Oberbefehlshaber in Dänemark, SS-General v. Hanneken, bekannte Hitler nunmehr offen, daß eine Wiederherstellung Dänemarks unter Räumung durch die deutschen Truppen nach dem Kriege nicht in Frage käme, weil der Besitz Dänemarks und Norwegens unabdingbar sei, um England in Schach zu halten. Dänemark müsse eine „deutsche Provinz" werden. Die den

115 H. Ipsen, „Reichsaußenverwaltung“, a. a. O., S. 521, über die Stellung v. Renthe-Finks, vgl. DIA 1939-46, Vol. II, S. $213 \mathrm{f}$.

${ }^{116}$ Ein deutliches Beispiel für die deutschen Eingriffe bereits in diesem Stadium bieten die deutschen Forderungen v. 12. 4. 41 an die dänische Regierung anläßlich der Grönland-Affäre (IMT 6, S. 554f.).

117 Tischgespräche, a. a. O., S. 58 (28. 3. 42).

118 a. a. O., S. 98 (8.6.42).

119 Table Talk, a. a. O., S. 345 (27. 2. 42).

120 Notiz für den Herrn RAM v. 25. 10. 42, verfaßt von Gaus, v. Renthe-Fink und v. Grundherr (NG-2307). 
Dänen beim Einmarsch gemachten Versprechungen seien nunmehr obsolet geworden durch das Verhalten der dänischen Regierung, die u. a. versäumt habe, Deutschland Nordschleswig anzubieten. Es sei in Zukunft unmöglich, daß in einem neuen Europa unter deutscher Führung eine Staatsform bestehen bleiben könne mit einer demokratischen Regierung und einem Königshaus. Beide müßten daher beseitigt werden und sobald wie möglich durch ein Regime unter der Führung der dänischen Nationalsozialisten abgelöst werden. Es sei dabei unwichtig, daß Clausen in Dänemark nur geringen Anhang habe. Er brauche in Dänemark eine willfährige Marionettenregierung, deren Leiter sich stets bewußt sein müsse, daß er im Falle eines Rückzuges der deutschen Truppen am nächsten Laternenpfahl hängen würde. Er habe dem neuen Bevollmächtigten entsprechende Instruktionen zugehen lassen ${ }^{121}$. In der Tat hoffte man auch seitens der SS, daß Best in Dänemark „ein Schulbeispiel völkischer Reichspolitik bieten" werde, wobei allerdings offenbar war, da $B$ man sich dabei auf die Clausen-Partei allein nicht würde stützen können, wenn auch Clausen im Vordergrund stehen müsse ${ }^{\mathbf{1 2 2}}$. Als im November 1942 die von Best geforderte Umbildung der dänischen Regierung durch Hereinnahme dänischer Nationalsozialisten abgelehnt worden war, wurde ein letzter Versuch der "Machtergreifung" der dänischen Nazis durch die Zulassung von Parlamentswahlen im März 1943 unternommen. Die durch die deutsche Gesandtschaft finanziell und moralisch unterstützte Partei Clausens erlitt jedoch mit nur $2,5 \%$ der abgegebenen Stimmen und 3 von 149 Sitzen in der Deputiertenkammer eine glatte Niederlage ${ }^{\mathbf{1 2 3}}$. Nach diesem Fehlschlag des "weichen" Kurses Bests"124 übernahm nunmehr SS-General von Hanneken durch die Erklärung des Ausnahmezustandes die Gewalt in Dänemark. Man ging zur direkten Polizei- und Terrorherrschaft über: Clausen wurde fallengelassen $\mathbf{1 2 5}^{\mathbf{2 5}}$ und nur noch die rein militärischen Organisationen wie die Waffen-SS Danmark und das berüchtigte Schalburg-Korps (das zur Terrorisierung der eigenen Bevölkerung eingesetzt wurde) unterstützt ${ }^{\mathbf{1 2 6}}$.

Noch im Sommer 1943 wurden die dänische Flotte und Armee (später auch die Polizei) entwaffnet und interniert, der König als Kriegsgefangener behandelt, Parlament und Regierung aufgelöst und die Deportation der Juden nach Theresienstadt durchgeführt ${ }^{\mathbf{1 2 7}}$. Selbst wenn man in Rechnung stellt, daß viele der letztgenannten Maßnahmen unter dem Druck der verschlechterten Kriegslage (be-

121 Hitlers mündliche Instruktionen vom 1. Oktober 1942 für den neuen Oberbefehlshaber SS-General v. Hanneken. Memorandum v. Grundherrs im Auswärtigen Amt vom 3. Oktober 1942, (NG-3918).

122 Nbg. Dok. 705-PS, IMT 26, S. 263.

123 Dok. 901-RF, IMT 38, S. 630, 669; ferner die Ausführungen Edgar Faures in Nürnberg (IMTT 6, S. 555 ff.).

124 Über Bests "schwächlichen" und "weichen" Kurs s. Kritik in Goebbels Tagebüchern, a. a. O., S. $388 \mathrm{f}$. (8. 9. 43).

125 Clausen soll von der Partei ausgestoßen, von Deutschland wegen „Veruntreuung von Geldern" verhaftet und an die Ostfront gebracht worden sein (Survey 1939-46, a. a. O., S. 528).

126 Survey, a. a. O., S. 527 f., $530 \mathrm{f}$.

127 Dok. 901-RF, a. a. O., S. 671 . Über die Judenverschleppung s. 633 f. und 675. 
ginnender Rückzug im Osten, Landung der Alliierten in Sizilien und Süditalien, Umsturz in Italien, drohende Invasionsgefahr im Westen) durchgeführt wurden, so deuten doch - auch bei vorsichtiger Auslegung - alle Anzeichen darauf hin, daß Dänemark im projektierten europäischen Großraum bestenfalls die Rolle eines Vasallenstaates, wenn nicht sogar einer „deutschen Provinz“ zugedacht war.

Augenscheinlich bestanden ernste Absichten auch Norwegen in irgendeiner Form an das Deutsche Reich zu binden. Die Erörterungen in Görings Hauptquartier ${ }^{128}$ sowie Hitlers Ausführungen gegenüber v. Hannecken ${ }^{129}$ und gegenüber seinen Vertrauten ${ }^{130}$ belegen das. Hitler äußerte $u . a$. ., das Land eigne sich im Gegensatz zu dem auf der gleichen geographischen Breite liegenden Karelien auf Grund des Golfstromes sogar zur Besiedlung durch Deutsche ${ }^{131}$; infolge seiner zahlreichen Wasserfälle werde es seine „europäische Mission“ als „Elektrizitätszentrale “ für den Nordteil des europäischen Großraumes erfüllen ${ }^{\mathbf{1 3 2}}$.

Hier in Norwegen sollte die nationalsozialistische Methode, durch die Einsetzung einer Nazi-Partei in die Regierung eine Art Vasallität zu schaffen - mit welchem. Erfolg auch immer - am weitesten vorangetrieben werden: der Name "Quisling" ist über Norwegen hinaus zu einem Begriff geworden.

Eine Darlegung Rosenbergs über „Die politische Vorbereitung der NorwegenAktion " aus dem Jahre 1940 enthält detaillierte Angaben über die enge Verbindung, die schon vor der Besetzung Norwegens zwischen Quislings Nasjonal Samling und den nationalsozialistischen Machthabern in Deutschland bestand ${ }^{\mathbf{1 3 3}}$. In diesem Bericht Rosenbergs heißt es ferner, daß es Quisling als seine Aufgabe ansehe, "gestützt auf eine kleine aber fest entschlossene Minderheit, Norwegens Schicksal an das Großdeutschlands, als eines Kraftzentrums einer nordisch-germanischen Lebensgemeinschaft zu binden "134.

Bereits am ersten Tage des deutschen Einmarsches war der Versuch einer Regierungsbildung durch Quisling an der Ablehnung durch das norwegische Volk gescheitert ${ }^{135}$. Darauf wurde am 24. April 1940 - ganz analog dem späterenVorgehen

128 Dok. 1155-PS, a. a. O., S. 30.

129 Memorandum v. Grundherrs, a. a. O., S. 220.

130 Tischgespräche, a. a. O., S. 67 (5. 4. 42).

131 a. a. O., S. 64 (5. 4. 42).

132 a. a. O., S. 197 f. (2. 8. 4.1).

133 Dok. PS-004 (IMT 25, S. 26 ff.); Dazu auch kurzer Tätigkeitsbericht des Außenpolitischen Amtes der NSDAP von 1938-43, Dok. PS-007, a. a. O., S. 34ff. Anlage I, Norwegen (S. 40 ff.). Über Quislings Unterredung mit Raeder am 11. 12. 39 und Hitler am 12., 16. und 18. Dezember 1939 s. IMT 14, S. 106, 108; über finanzielle Unterstützung von 2-300000 RM s. Dok. 957-PS, IMT 26, S. 411.

134 Dok. PS-004, a. a. O., S. 28.

135 Der König weigerte sich gegenüber dem deutschen Gesandten Bräuer, Quisling, dessen Partei nie mehr als $2 \%$ der Wähler repräsentierte, entgegen den Verfassungsbestimmungen in die Regierung einzusetzen. Bräuer forderte daraufhin Quisling, der sich zum Regierungschef ausgerufen hatte, wieder zum „Rücktritt" auf, um den Weg für einen norwegischen „Administrationsrat" freizumachen. Vgl. dazu Loock a. a. O., S. 4.1 (auch zum folgenden); Kordt a. a. O., S. 243. 
in den Niederlanden - ein ziviler Reichskommissar (Terboven) in Norwegen eingesetzt $^{136}$. Nachdem die sich über den Sommer hinziehenden Verhandlungen über eine Änderung der Verfassung auf dem Wege „legaler Revolution“ und über die Bildung einer den Deutschen genehmen Regierung vergeblich geblieben waren, wurde der König, der nach dem Zusammenbruch des von den Alliierten unterstützten Widerstandes das Land am 7. Juni 1940 verlassen hatte, von Terboven am 25. September entthront, ferner wurden der provisorische norwegische Administrationsrat, das Parlament und die politischen Parteien außer der Quisling-Partei aufgelöst und dreizehn "provisorische Staatsräte" eingesetzt ${ }^{\mathbf{1 3 7}}$, von denen zehn der NS entstammten, während man den unpopulären Quisling selbst im Hintergrund hielt. Erst nach fast anderthalb Jahren wurde am 2. Februar 1942 der Zeitpunkt für gekommen erachtet, eine "Norwegische National-Regierung“ unter Quisling einzusetzen. Dieser übertrug sich durch ein Dekret vom 7. Februar 1942 die nach der Verfassung dem König und dem Parlament zustehenden Befugnisse, blieb aber tatsächlich Terboven völlig unterworfen ${ }^{\mathbf{1 3 8}}$.

Terboven hatte bei der Bildung der norwegischen Regierung erklärt, „daß ein im Nationalsozialismus geeintes, starkes norwegisches Volk . . . ein entscheidender und nicht zu entbehrender Bestandteil der germanischen Gemeinschaft sein " werde ${ }^{139}$. Es sollte sich aber bald erweisen, daß Deutsche und Norweger offensichtlich abweichende Ansichten von der Gestaltung dieser Gemeinschaft hatten: Hitlers Reaktion auf den ersten „außenpolitischen Schritt" Quislings wirft ein bezeichnendes Licht auf seine Absichten sowohl gegenüber Norwegen als auch gegenüber den anderen „germanischen "Völkern. Wie der Vorschlag Musserts kann auch der Schritt Quislings als Prüfstein dieser Absichten und Hitlers Reaktion als symptomatisch für die Behandlung und zukünftige Stellung der nord- und westeuropäischen Staaten angesehen werden. Nachdem Quisling in mehreren Denkschriften an Hitler eine "selbständige NS-Regierung“ und, ähnlich wie Mussert, einen "großnordischen Bund“ mit einem "freien, unteilbaren und unabhängigen “ Norwegen vorgeschlagen hatte ${ }^{140}$, bot er nunmehr als Regierungschef in einem Memorandum vom 10. Februar 1942 Hitler einen Präliminarfrieden und ein Bündnis zwischen Deutschland und Norwegen an, das den Grundstock für einen „Großgermanischen Bund“ abgeben sollte. Im Präliminarfrieden sollte Deutsch-

\footnotetext{
136 DDP 8, I, S. $36 f$.

137 Rundfunkrede Terbovens über Norwegens Neuordnung (DDP 8, I, S. 76 ff.).

138 Goebbels nennt Quislings Behauptung, daß er nunmehr die gesamte Macht des Königs, des Parlaments und der Regierung auf sich vereine, angesichts der Anwesenheit des Reichskommissars "skurril“, jedoch bestehe das Interesse, „die norwegische Regierung möglichst groß und selbständig erscheinen zu lassen". (Tagebücher, a. a. O., S. 72, 4. 2. 42). Über die deutsche Besatzungspolitik vgl. den Aufsatz von Loock a. a. O.,; Bericht der Norwegischen Regierung Dok. 079-UK, IMT 39, S. $205 \mathrm{ff}$. (Auszug); Ausführungen Faures in Nürnberg, IMT 6, S. $563 \mathrm{ff}$; Survey 1939-46, S. 534ff.

139 am 1. Februar 1942 (AdG 1942, S. 5381).

140 Denkschriften vom 2. 8. 41 und 17.9. 41 (Archiv IfZ, Mikrofilm MA 110). Der Vorschlag eines Bundes bereits in der Denkschrift v. 25. 10. 40 (Archiv IfZ, Mikrofilm Ma 2).
} 
land Aufenthalt, Operationsfreiheit und volle Unterstützung der deutschen Streitkräfte in Norwegen für die Dauer des Krieges, ferner den Einsatz der vollen Kapazität der norwegischen Wirtschaft für den europäischen Krieg (wenn auch expressis verbis nur gegen England) zugesichert bekommen als Gegenleistung für die Gewährung der norwegischen Unabhängigkeit und Zulassung eigener norwegischer Vertretungen im Ausland. Der deutsche Einfluß bleibe dabei durch die gegenwärtige norwegische Regierung und die hinter ihr stehende Bewegung gesichert. Von dieser "politischen Offensive“ in Norwegen versprach sich Quisling eine Beruhigung des Landes, eine Ausschaltung des Einflusses der norwegischen Exilregierung in London und eine Entkräftung der Behauptung der Westmächte, daß Deutschland überall als Unterdrücker auftrete. Das deutsch-norwegische Bündnis, das durch den Beitritt anderer "germanischer" Staaten zu einem germanischen Bund erweitert werden sollte, sah folgendes vor:

1. Aktive gegenseitige Teilnahme an der Verteidigung beider Staaten unter deutschem Oberbefehl,

2. gemeinsame Flotte und Luftwaffe als Offensivwaffe, deren Kosten nach dem Verhältnis der Bevölkerung beider Staaten aufgeteilt werden sollten und für die Norwegen Flottenbasen und Luftstützpunkte dem Reich als Führer des germanischen Bundes zur Verfügung stellen wollte,

3. eine eigene norwegische Nationalarmee und Küstenverteidigung unter norwegischem Kommando. Mit dem Aufbau einer Armee von drei Divisionen auf der Grundlage der Wehrpflicht sollte sofort begonnen werden, während die freiwillige Norwegische Legion auf die Stärke eines vergrößerten Regiments gebracht werden sollte.

4. Die notwendige gemeinsame Außenpolitik sollte durch gegenseitigen geheimen und vertraulichen Austausch von Informationen durch die beiden Auswärtigen Ämter geführt und garantiert werden. In weiterer Zukunft sollte ein „Großgermanischer Bund" unter deutscher Führung errichtet werden mit einem periodisch unter deutschem Vorsitz in Berlin tagenden Rat der Ministerpräsidenten oder Außenminister der germanischen Länder, der die Grundsätze der gemeinsamen Außenpolitik aufstellen sollte, mit gemeinsamer Bundesflotte und -luftwaffe und gemeinsamer Verteidigung der germanischen Gebiete.

Quisling versprach die Mobilisierung aller nationalen norwegischen Kräfte für die Zusammenarbeit mit Deutschland und für eine solche „Neue Ordnung“ in Europa. Die Absicht der Gründung eines solchen Bundes nach dem Kriege sollte sofort bekanntgegeben werden, um auch die anderen nordisch-germanischen Völker zu einer aktiven Mitarbeit nach dem Beispiel Norwegens zu bewegen. Wenn Deutschland tatsächlich einen solchen germanischen Bund wolle, dann dürfe dem nicht durch Maßnahmen Abbruch getan werden, die in Skandinavien Opposition hervorriefen. Ferner wurde der Wunsch ausgesprochen, daß Deutschland und Norwegen baldigst zu einem endgültigen Frieden gelangen mögen, der am Jahrestag des deutschen Einmarsches, am 9. April, verkündet werden sollte. Danach könne Norwegen sogleich dem Antikomintern-Pakt beitreten und später auch dem 
Dreimächtepakt, sobald es sich zur Erfüllung der damit verbundenen Verpflichtungen stark genug fühle ${ }^{141}$.

Es ist äußerst aufschlußreich, daß Hitler auch nur eine Erörterung dieses Planes einer Zusammenarbeit, der ihm volle Sicherheit bezüglich der militärischen Besetzung und der wirtschaftlichen Ausnutzung Norwegens während des Krieges bot und auch eine hegemoniale Führungsstellung des Reiches über die nord- und westeuropäischen Völker nach dem Kriege zusicherte, rundweg ablehnte. Das geschah, obwohl der Gedanke eines Friedensschlusses mit Norwegen von Raeder, der sich seit Mai 1940 bei Hitler wiederholt für einen Abbau der Zivilverwaltung, einen Friedensschluß zur Gewinnung des norwegischen Volkes und damit der Erleichterung der Verteidigung Norwegens eingesetzt hatte, und vom Marinebefehlshaber in Norwegen, Generaladmiral Böhm, unterstützt wurde ${ }^{\mathbf{1 4 2}}$. Hitlers Antwort an Quisling lautete, es könnten „während des Krieges keinerlei Verhandlungen und Erörterungen über den endgültigen oder einen vorläufigen Friedensschluß zwischen dem Großdeutschen Reich und Norwegen oder über sonstige Maßnahmen stattfinden, die die Stellung Norwegens zum Reich nach Beendigung des Krieges irgendwie festlegen oder vorwegnehmen "143. Goebbels bezeichnete in seinem Tagebuch Quislings Glauben an derartige deutsche Zugeständnisse und dessen Absicht, „im Hintergrunde ein gänzlich freies Norwegen anzustreben “, als „naive Vorstellungen “ und begrüßte Hitlers ausweichende Antwort ${ }^{\mathbf{1 4 4}}$.

Nach Ansicht Raeders scheiterte der Friedensschluß nicht zuletzt an der Wirksamkeit Terbovens, der Hitler falsch unterrichtet, Quisling Schwierigkeiten in den Weg gelegt und bei der eigenen Bevölkerung diskreditiert habe, weil er „Gauleiter von Norwegen bleiben wollte". Terboven habe damit Hitlers Absicht sabotiert, das norwegische Volk „wohlgeneigt" zu machen und „Norwegen als einen souveränen Staat mit einem nordgermanischen Reich in Verbindung zu bringen "145. Auch Goebbels schreibt, daß es Terboven für die diffizile norwegische Frage an politischem Geschick mangele, daß er seine Aufgabe „als SA-Mann aufgefaßt " habe und im wesentlichen „Holzhauerarbeit" leiste ${ }^{\mathbf{1 4 6}}$. Das alles darf aber nicht darüber hinwegtäuschen, daß es Hitlers grundsätzliche Absicht war, sich vor einem Endsieg nicht festzulegen und die Trümpfe nicht aus der Hand zu geben, bevor er nicht die

141 Text des Memorandums DIA II, S. $221 \mathrm{ff}$. Es wurde während des Staatsbesuchs Quislings, Mitte Februar 1942, in Berlin überreicht. In einem weiteren Memorandum vom 6. 9. 42 drängte er abermals auf Verwirklichung seiner Pläne und faßte als Zeitpunkt für den Beitritt zum Antikomintern- und Dreimächtepakt den 2. Jahrestag der „Machtergreifung“ in Norwegen, den 25. 9. 42, ins Auge. (Mikrofilm Archiv IfZ, MA 110 und Ma 2.)

142 Aussage Raeders in Nürnberg IMT 14, S. 114f.; ferner: Eidesstattliche Erklärung Kapitän Richard Schreibers IMT 41, S. $61 \mathrm{ff}$.

143 Schreiben Reichsminister Lammers an Quisling vom 17. September 1942, Nbg. Dok. NG-3418 und NG-2177, IMT 14, S. 116. Bereits am 22. 6. 42 war eine Absage ergangen. (Archiv IfZ, Mikrofilm MA 110.)

144 Goebbels, a. a. O., S. 85 (13. 2. 42).

145 Raeders Aussage, IMT 14, S. 114.

146 Goebbels S. 331 (9. 5. 43), 355 (22. 5. 43). Auch Hitler sei gegen eine Erschwerung der Lage durch allzu radikale Maßnahmen Terbovens (506; 7. 12. 43). 
"Neuordnung" nach seinem Willen diktieren konnte. Auch im Februar 1943, nach der Katastrophe von Stalingrad, blieb er bei der Ansicht, daß - wenn möglicherweise im kommenden Frühjahr ein Vertrag mit Norwegen abgeschlossen werden würde - die Bedingungen diesem Land auferlegt würden. Dann würde auch die Frage der Stellung Norwegens zum Reich entschieden werden, nämlich ob es weiterhin einen Reichskommissar haben solle oder einen Reichsbevollmächtigten empfangen dürfe ${ }^{147}$.

Quisling hat auch nach Hitlers Absage an der Idee einer "germanischen Gemeinschaft" festgehalten. Das zeigt sein Befehl vom 21. Juli 1942 zur Schaffung der Germanske SS-Norge, die eine Abteilung der Stor-Germanske-SS (großgermanischen SS) darstellen und dem Ziel dienen sollte, „die germanischen Völker einer neuen Zukunft entgegenzuführen und die Grundlage für eine germanische Gemeinschaft zu schaffen "148.

Admiral Aßmann gibt die von Hitler 1939 geäußerte Ansicht über die zukünftige Stellung der nordischen Staaten mit den Worten „Nordgermanische Gemeinschaft mit eingeschränkter Souveränität in enger Anlehnung an Deutschland “149 wieder. In einer Rede über die „Nordische Schicksalsgemeinschaft" vom 9. Juli 1940 betonte Rosenberg, daß Deutschland die militärische Sicherung des "großgermanischen Raumes" für alle Zukunft übernehmen werde. Er stand dabei in völliger Übereinstimmung mit den Zielen der erwähnten militärischen Studie:

„Das Schicksal hat es jetzt so gewollt, daß das Deutsche Reich den gesamten Raum, aus dem einst die germanischen Völker auswanderten [wozu offensichtlich auch Schweden gehört! Der Verf.] unter seine Hut genommen hat. Es versteht sich von selbst, gleich unter welcher Form der Schutz dieses einstigen großgermanischen Raumes erfolgen wird, daß das Deutsche Reich auch niemals mehr darauf verzichten kann, sich vor der Wiederholung eines ähnlichen Überfalles zu schirmen, wie ihn England im April 1940 über Norwegen gegenüber Deutschland versuchte. Es zeichnet sich hier also eine für alle germanischen Völker klare Lebensnotwendigkeit ab, nach außen hin eine gemeinsame politische und wirtschaftspolitische Front zu bilden . . ."150.

Die SS sah es als ihre Aufgabe an, „die großen Pläne einer wahren Germanisierung des mitteleuropäischen und nordischen Raumes durchzuführen und vor allen Dingen die Grundlagen zu schaffen, damit später ohne Zwischenlösung, unter vollster Wahrung der völkischen Eigenart, Kultur und Sitten, diese Völker an das großgermanische Reich geknüpft werden können“151. Der Reichsarbeitsdienst zählte Norwegen, Dänemark, die Niederlande und Flandern zu „denjenigen Staaten

147 Vgl. Woermanns Bericht über ein Gespräch mit Lammers vom 20. Februar 1943, zit. Survey 1939-46, S. 128, Anm. 2. Noch im Januar 1945 hoffte Quisling seine Vorschläge verwirklichen zu können (NG-4643).

148 Dok. RF-926, IMT 38, S. 694f.; bereits im Januar 1941 war das Freiwilligen- „Regiment Nordland" der Waffen-SS einverleibt worden, für die russische Front wurde die "Norwegische Legion" gegründet (Survey, a. a. O., S. 543, Anm. 2).

149 Tagebucheintragung am 6. September 1939 (IMT 29, S. 508).

150 AdG 1940, S. 4612.

151 Schreiben Bergers an Himmler v. 8. 10. 42 (NO-900). 
des mittel- und nordeuropäischen germanischen Lebensraumes, die in einer bestimmten Form mit dem deutschen Reich fest verbunden werden ", und die daher durch das "wirksamste Erziehungsmittel zur germanischen Volksgemeinschaft", den Arbeitsdienst, innerlich für diese Gemeinschaft gewonnen werden müßten ${ }^{\mathbf{1 5 2}}$. Die Pläne für einen künftigen Großwirtschaftsraum unter deutscher Führung sahen die wirtschaftliche Eingliederung dieser Länder in Form einer vollen Währungs- und Wirtschaftsunion mit Deutschland vor, während die Einbeziehung der Länder des Donauraumes in den Großwirtschaftsraum in der bisherigen Form des Außenhandels erfolgen sollte ${ }^{\mathbf{1 5 3}}$. Hitler selbst äußerte: gegenüber den gewaltigen Bevölkerungsmassen des Ostens könnten die germanischen Völker nur vereint bestehen und den Kern bilden, um den sich das zukünftige Europa gruppieren werde ${ }^{\mathbf{1 5 4}}$. $\mathrm{Ob}$ bei der Schaffung dieses "Kerns" an feste Verträge mit den einzelnen von "nationalsozialistischen " Parteien beherrschten Staaten gedacht war (wie von Vertretern der NSDAP und zeitweilig auch von Hitler), oder ob er durch eine germanisch-europäische Elite „zusammengeschweißt" werden sollte (wie es Himmler und die SS beabsichtigten) ${ }^{\mathbf{1 5 5}}$; - eine mit der Vorkriegszeit vergleichbare Unabhängigkeit hätten die drei Staaten Holland, Dänemark und Norwegen auf keinen Fall behalten: Sie wären entweder ideologisch gleichgeschaltete Vasallenstaaten oder „deutsche Provinzen“, bzw. "Reichsgaue" geworden.

\section{c) Unterwerfung und bevölkerungspolitische Ziele in den besetzten Ostgebieten}

(Polen, "Protektorat Böhmen und Mähren", baltische Staaten, Sowjetunion)

Viel schroffer und eindeutiger auf Unterwerfung abgestellt waren die endgültigen Absichten der nationalsozialistischen Politik im Osten. Mit der Bildung des rechtlich zum Reichsgebiet gehörenden "Protektorats" und des zwar „nicht kraft ausdrücklicher Entscheidung, so doch der Sache nach" ebenfalls Reichsgebiet darstellenden "Generalgouvernements"156 war die klare Absicht der definitiven Liquidierung des tschechischen Reststaates und Polens und ihrer dauerhaften Besitzergreifung verbunden. Was Polen anbelangt, so wurden aus den westpolnischen Gebieten die zwei neuen Reichsgaue „Danzig-Westpreußen “ und „Wartheland“ gebildet, ferner die Regierungsbezirke Kattowitz an Schlesien und Zichenau an Ostpreußen angegliedert ${ }^{157}$. Aus den polnischen Gebieten zwischen dem Reich und $\overline{152}$ Schreiben des Reichsarbeitsführers v. 20.10.42 an Hitler (Photokopie im Politischen Archiv des Auswärtigen Amtes, Film 27, Sts. 9, Nr. 1-2).

153 Aufzeichnungen über Großwirtschaftsraum für Ribbentrop v. 1. 6. 40, ausgearbeitet von Ritter und Clodius (NG-3884).

154 Table Talk, a. a. O., S. 328 (22. 2. 42).

155 Über die unterschiedlichen „Europa-Konzeptionen" von Partei und SS vgl. Loock a. a. O., S. 62 f. Dort S. 40, Anm. 18 Himmlers Meinung über die Stellung dieser Staaten in einer Rede vor Kreisleitern am 28.11.40: „Ich glaube unter deutscher Führung an die germanische Völkergemeinschaft mit eigener Sprache und Kultur dieser Völker, nicht aber daran, daß etwa Norwegen, Schweden(!), Dänemark, Holland und evtl. weitere Gebiete wirtschaftlich, militärisch oder außenpolitisch tun und machen können, was sie wollen."

156 H. P. Ipsen, "Reichsaußenverwaltung", a. a. O., S. 521.

157 Erlaß Hitlers vom 8. Oktober 1939 (DDP 7/II, 1939, S. 599 ff.). 
der deutsch-sowjetischen Demarkationslinie wurde das "Generalgouvernement" für die besetzten polnischen Gebiete“ geschaffen ${ }^{158}$. Der Wegfall des Zusatzes „für die besetzten polnischen Gebiete" durch eine Verfügung vom 15. August 1940 „brachte eindeutig zum Ausdruck, $\mathrm{da} B$ es sich hier nicht um eine nur durch Krieg bedingte und daher mit Friedensschlu $\beta$ endende deutsche Besetzung handelte, sondern daß dieses Land, das zwar währungs- und zollpolitisch selbständig ist, aber keine eigene staatliche Souveränität besitzt, nach nunmehr erfolgter Stabilisierung dauernd mit dem Deutschen Reiche als dessen ,Nebenland' . . verbunden bleiben wird"159. Damit war die Eigenstaatlichkeit Polens für immer ausgeschlossen worden ${ }^{160}$. Rechtlich gesehen erhielten die Polen nicht einmal eine autonome Verwaltung wie die Tschechen ${ }^{161}$, sondern nach den Worten des Generalgouverneurs Frank „... eine Art Selbstverwaltung in den untersten Schichten, vollkommen asynthetisch, vollkommen unverbunden untereinander, vollkommen losgelöst aus dem Zusammenhang und unmittelbar kontrolliert von den deutschen Stellen ..."162. Nach dem Einfall in Rußland wurden auch die sowjetisch besetzten Teile Polens aufgeteilt: der Bezirk Bialystok wurde Ostpreußen, Galizien dem Generalgouvernement, der Nordostteil Polens mit Wilna dem Reichskommissariat Ostland, Wolhynien dem Reichskommissariat Ukraine zugeschlagen ${ }^{\mathbf{1 6 3}}$.

War Polen als Staat untergegangen, so erwies sich die Phrase von einer „Heimstätte" des polnischen Volkes im nationalsozialistischen Großraum unter deutscher Führung und deutschem Schutz ${ }^{164}$ angesichts der Eindeutschungspolitik und der Ausmerzung des polnischen nationalen Charakters in diesen Gebieten als blutiger Hohn. Eine Denkschrift des rassenpolitischen Amtes der NSDAP vom November 1939 nennt als „Ziel der Ostpolitik“ die Schaffung einer rassisch einheitlichen deutschen Bevölkerung in den eingegliederten Gebieten, die durch drei Maßnahmen erreicht werden sollte:

„Erstens die vollständige und endgültige Eindeutschung der hierzu geeigneten Schichten,

zweitens die Abschiebung aller nicht eindeutschbaren fremdvölkischen Kreise und

158 Erlaß Hitlers vom 12. Oktober 1939 (a. a. O., S. 671 f.).

150 DDP 8/II, S. 598; ähnlich Freytagh-Loringhoven, Deutschlands Außenpolitik 1933-1941, S. 245.

160 Proklamation Generalgouverneur Franks vom 26. Oktober 1939 (DDP 7/II, S. 673); Rede Franks in Krakau am 15. August 1940 (DDP 8/II, S. 598, Auszug).

161 F. Klein, ,Zur Stellung des Generalgouvernements in der Verfassung des Großdeutschen Reiches" (Archiv d. öfentl. Rechts, Neue Folge, 32, S. 248); Karl Lasch, „Die deutsche Aufgabe im Osten" (ZAkDR 7, 1940, S. 350).

162 So Frank im Reichsverteidigungsausschuß am 2.3. 40 (Nbg. Dok. 2233-PS, IMT 29, S. 436). Über die deutsche Politik in Polen vgl. neuerdings: M. Broszat, Nationalsozialistische Polenpolitik 1939-1945, Stuttgart 1961.

163 Survey 1939-46, a. a. O., S. 553. Über die Pläne der endgültigen Abgrenzung des Reiches von den Reichskommissariaten s. Denkschrift Stuckarts über die deutsche Ostgrenze vom 11. 9. 1941. Photokopie im Pol. Archiv d. AA, Film 20, Ref. 12, Nr. 3.

164 So Frank in Kattowitz am 15. März 1940 (zitiert bei Klein, a. a. O., S. 234). 
drittens die Neubesiedlung durch Deutsche. "165

Auch ein im Januar 1940 abgeschlossenes geheimes Gutachten über die „Rechtsgestaltung deutscher Polenpolitik nach volkspolitischen Gesichtspunkten " besagt, daß zwar eine physische Vernichtung des polnischen Volkes nicht möglich sein werde, daß aber durch entsprechende Maßnahmen die eingegliederten polnischen Gebiete eingedeutscht und im Generalgouvernement selbst eine „Entmachtung des polnischen Volkes" herbeigeführt werden müsse. Zunächst sollten die polnische Intelligenz und die Juden aus den eingegliederten Gebieten ins Generalgouvernement gebracht werden, bis zu einer „umwälzenden Neuordnung des Ostens, die den überschüssigen Juden - sei es in Sibirien, sei es im angrenzenden Raum, z. B. nach Umsiedlung der Weißrussen ostwärts - Platz schafft". Gleichzeitig sollte „eine planvolle Einkapselung oder Umzingelung der Bezirke mit polnischer Mehrheit durch breite deutsche Siedlungsstreifen " durchgeführt werden 166. Die phantastisch anmutende Zukunftsplanung des berüchtigten, vom Reichssicherheitshauptamt ausgearbeiteten "Generalplan Ost" vom April 1942 sah die Aussiedlung der gesamten „rassisch unerwünschten“ polnischen Bevölkerung auch des Generalgouvernements in einem Zeitraum von 30 Jahren nach Sibirien vor ${ }^{167}$. Himmler genehmigte diesen Plan in seiner Eigenschaft als „Reichskommissar für die Festigung des deutschen Volkstums“, fügte aber hinzu, die „totale Eindeutschung . . . des gesamten Generalgouvernements" müsse bereits in 20 Jahren zu schaffen sein. „Der jetzige Vorschlag, das Generalgouvernement ... nur mit Stützpunkten zu versehen, entspricht meinen Gedanken und Wünschen nicht. "168 Die Germanisierungsmaßnahmen wurden unter Himmler tatsächlich in Angriff genommen: durch die Verschleppung von Polen und Juden aus dem Warthegau, von polnischen Arbeitern nach Deutschland, um die folgende polnische Generation zahlenmäßig gering zu halten, und die „Abschöpfung“ „eindeutschungsfähiger “ Polen (auch im Generalgouvernement) ${ }^{\mathbf{1 6 9}}$. In einer Ansprache vor dem Offizierkorps der Leibstandarte SS "Adolf Hitler" vom 7. September 1940 gab Himmler selbst die Durchführung von Massenmorden an Polen im Zuge der Germanisierungsmaßnahmen zu ${ }^{\mathbf{1 7 0}}$. Auch das Generalgouvernement selbst sollte „in die eiserne Zange deutschen Volkstums " genommen ${ }^{\mathbf{1 7 1}}$ und in der Zukunft deutsches Siedlungsland werden. Zunächst sollte der Distrikt Lublin deutsch besiedelt werden, um

\footnotetext{
165 Denkschrift v. 25.11. 39 (NO-3732), S. 16.

166 Geheimes Gutachten der Akademie für Deutsches Recht, abgeschlossen im Januar 1940: "Rechtsgestaltung deutscher Polenpolitik nach volkspolitischen Gesichtspunkten “, Dok. 661-PS, IMT 26, S. $206 \mathrm{ff}$., S. 208, 207, $210 f$.

${ }_{167}$ Zum Generalplan Ost s. Dokumentation von H. Heiber in VfZ 1958, H. 3, S. $281 \mathrm{ff.}$. bes. S. $307 \mathrm{f}$.

168 Schreiben Himmlers an Greifelt v. 12. 6. 42 (a. a. O., S. 325).

$169 \mathrm{Vgl}$. dazu vor allem Broszat a. a. O., Kapitel IV (Bevölkerungstransfer) und V. A. (System völkisch-rechtlicher Eindeutschung und Aussonderung), über die Deutsche Volksliste S. $118 \mathrm{ff}$, Zahlen für die Polenaussiedlung aus den eingegliederten Gebieten S. $101 \mathrm{f}$.

170 Dok. PS-1918, IMT 29, S. 104.

171 Tischgespräche, a. a. O., S. 69 (5. 4. 42).
} 
„an die nordisch bzw. deutsch besiedelten baltischen Länder über Distrikt Lublin einen Anschluß an das deutschbesiedelte Siebenbürgen herzustellen. Er [d.i. der Höhere SS- und Polizeiführer Lublin, Globocnik] will so im westlichen Zwischengebiet das verbleibende Polentum siedlungsgemä $ß$,einkesseln und allmählich wirtschaftlich und biologisch erdrücken. Der west-östlich gerichteten Expansion aus dem Warthegau soll der ost-westlich gerichtete Druck aus dem Raum von Lublin und nördlich und südlich davon folgen . . “"172.

Frank äußerte am 19.4. 1941 in einer Rede in Krakau: „... das Weichseltal wird vom Quell bis zur Mündung ins Meer einmal so deutsch sein, wie das Rheintal es ist"173.

So also sah in der Praxis die „Achtung vor dem fremden Volkstum" aus, auf der, wie die deutschen Großraumtheoretiker behaupteten, die Beziehungen des Reiches zu den anderen Völkern innerhalb des europäischen Großraumes beruhen würden. Daß auch der einzelne Angehörige eines solchen seines Staates beraubten Volkes im nationalsozialistischen Großraum - selbst wenn er außerhalb von Besatzungsrecht und Gestapoherrschaft unter das im Reich geltende Recht gestellt wurde keinen Schutz mehr fand, offenbart sich gerade am polnischen Beispiel in der Tatsache, daß die Justiz in den angegliederten polnischen Gebieten rücksichtslos in den "Volkstumskampf" eingespannt wurde: die Schaffung eines diskriminierenden Sonderstrafrechts für Polen diente ebenso wie die bevölkerungspolitischen Eingriffe der Unterdrückung, nicht dem "Schutz des polnischen Volkstums" 174.

Das bedeutete im gegebenen Fall nicht weniger als zweierlei Recht sogar innerhalb des eigentlichen Reichsgebietes, je nachdem, ob es sich um einen "Germanen " oder um einen "Slawen" handelte. Kein anderer als Roland Freisler forderte in diesem Zusammenhang, daß Deutschland in seinem "Großlebensraum, . . . in dem es nicht allein lebt, der aber als ganzes sein Reich umfaßt" für jedes der anderen Völker - insbesondere auf dem Gebiet des Strafrechts - ein „den Ordnungsbedürfnissen des Großraumes des Reiches entsprechendes" Recht schaffen müsse nach dem Grundsatz, „daß jedermann im Machtbereich des Deutschen Reiches nach einem bestimmten Recht zu leben gehalten sein müsse, ... daß das aber durchaus nicht bedeute, daß dies Recht für alle Völker in diesem Reich dasselbe sein müsse" 175 .

Nach der Zerschlagung der Tschechoslowakei durch die Angliederung des Sudetenlandes und die Bildung eines slowakischen Staates war das tschechische Volksgebiet besetzt und durch Hitlers Erlaß vom 16. März 1939 als „Protektorat Böhmen

172 Schreiben des SS-Hauptsturmführers Mueller aus Lublin an den Chef des Rasse- und Siedlungshauptamtes SS, SS-Gruppenführer Hofmann v. 15. 10. 41 (NO-5875); ferner vertraulicher Bericht v. 27. 3. 42 über Besiedlungspläne Lublin und Zamosc, PS-910, IMT 26, S. 408, vertraulicher Bericht über die von Himmler in Krakau am 13. und 14. März 1942 entwickelten Germanisierungspläne a. a. O., S. 409f. Zur Zwangsaussiedlung von Polen im Distrikt Lublin auch Broszat a. a. O., S. 178.

173 Dok. 2233-PS, IMIT 29, S. 471.

174 Vgl. das Kapitel „Strafjustiz und Polensonderstrafrecht" bei Broszat a. a. O., S. 137 ff.

175 Roland Freisler, "Grundsätzliches zur Ministerratsverordnung über das Strafrecht gegen Polen und Juden" (DR 41, 1941, S. 2630). 
und Mähren" seiner Eigenstaatlichkeit beraubt"176 und dem Reich einverleibt worden. Trotz einer gewissen Autonomie und Selbstverwaltung (vorbehaltlich der deutschen Kompetenz-Kompetenz) mit eigenem Oberhaupt und Organen wurde das Gebiet praktisch von Deutschland regiert, da die Protektoratsregierung ohne die Zustimmung des eingesetzten Reichsprotektors nicht handlungsfähig war und die wichtigsten Verwaltungsfunktionen für die auswärtigen, militärischen und staatspolizeilichen Aufgaben vom Reich ausgeübt wurden ${ }^{177}$. Entgegen der oft ausgesprochenen Behauptung, daß es „der nationalsozialistischen Auffassung von Volk, Volkstum und Rasse entspricht ..., fremdvölkisches Volkstum grundsätzlich zu achten und auf jedweden Versuch einer Germanisierung zu verzichten "178, war auch hier gerade die Germanisierung das Endziel der nationalsozialistischen Politik. In einer Dienstbesprechung vom 9. Oktober 1940 wurden auf der Grundlage einer Ende August an Hitler eingereichten Denkschrift des Staatssekretärs beim Reichsprotektor, Karl Hermann Frank ${ }^{179}$, drei Vorschläge zur Lösung der "tschechischen Frage" besprochen, von denen einer Hitlers Billigung fand. Die "deutsche Durchdringung Mährens und Rückbau des tschechischen Volksteiles auf ein Restböhmen " wurde "als nicht befriedigend" abgetan. Die ,,totalste Lösung, nämlich die Aussiedlung der gesamten Tschechen “ wurde als „in absehbarer Zeit undurchführbar" bezeichnet ${ }^{180}$. Die dritte Lösung lautete:

„Assimilierung des Tschechentums, d. h. Aufsaugen etwa der Hälfte des tschechischen Volksteiles im Deutschtum, insoweit diese blut- und sonst wertmäßig Bedeutung hat. Diese wird u. a. auch durch vermehrten Arbeitseinsatz von Tschechen im Reichsgebiet ... also durch Zerstreuung des geschlossenen tschechischen Volksteiles erfolgen. Die andere Hälfte des tschechischen Volksteiles muß auf die verschiedensten Arten entmachtet, ausgeschaltet und außer Landes gebracht werden. Dies gilt besonders für die rassisch mongoloiden Teile und den Großteil der intellektuellen Schicht."181

Diese Art der Germanisierung sollte unter Brechung jeden auftauchenden Widerstandes und unter Förderung der deutschen Besiedelung des Protelstorats durchgeführt werden. In dem Bericht über die Besprechung heißt es weiter:

„Der Führer hat nach Vortrag als Richtlinie für die Lösung des tschechischen Problems die Lösung nach c) (Assimilierung) gegeben und entschieden, daß bei äußerer Beibehaltung der Autonomie des Protektorats die Germanisierung

176 Vgl. F. Klein, „Die staats- und völkerrechtliche Stellung des Protektorats Böhmen und Mähren" (Archiv d. öffentl. Rechts, Neue Folge 31, S. 262).

177 Fuchs, "Die deutsche Verwaltung im Protektorat Böhmen und Mähren" (ZAkDR 7, 1940, S. $91 \mathrm{ff}$.).

178 Klein, a. a. O., S. 272.

179 Denkschrift v. 26. 8. 1940, durch Neurath an Hitler weitergeleitet. Text Nbg. Dok. PS-3859, s. auch NG-5173.

180 Bericht des Wehrmachtbevollmächtigten beim Reichsprotektor, Generalleutnant Friderici, vom 15. Oktober 1940, Dok. 862-PS, IMT 26, S. 376.

181 a. a. O., „Diese Kategorie sei auszumerzen" heißt es in Dok. 739-D (Bericht vom 5. Oktober 1940 über einen Empfang Neuraths und Franks bei Hitler IMT 35, S. 440). Vgl. zu diesem Problem auch Hitler in Table Talk, a. a. O., S. 234, 263, 557. 
noch Jahre einheitlich vom Amt des Reichsprotektors wahrgenommen werden müsse"182.

Offener konnte die "Heuchelei" im Dienste der Beherrschung anderer Völker, die Hitler den Tschechen gegenüber zum Prinzip gemacht wissen wollte ${ }^{183}$, nicht zum Ausdruck kommen. Daß den Tschechen nach einem deutschen Endsieg nicht einmal mehr die 1939 oktroyierte Form des Protektorats zugestanden werden sollte, geht auch aus den Worten Hans Franks in der Sitzung des Reichsverteidigungsausschusses vom 2. März 1940 hervor, der für Böhmen und Mähren ein Regime von der Struktur des Generalgouvernements forderte:

„Das Protektorat ist keine ideale Lösung, weil es einen Übergang darstellt und weil es auf die Dauer nicht möglich ist, daß ein von uns beherrschtes Volk so viele Selbständigkeiten besitzt, wie das tschechische . . .“184.

Die bereits erwähnte Denkschrift Karl Hermann Franks vom 26. August 1940 offenbart auch die Gründe für die Abschaffung der bestehenden Protektoratsform:

Wir „müssen eines Tages aus der passiven Haltung heraustreten und gegen diesen Raum und das tschechische Volkstum zum Angriff im Zuge einer Gesamtreichsplanung übergehen. Dies bedingt dann eine Änderung der staatsrechtlichen Konstruktion des Protektorats, da das ungestörte Weiterfunktionieren des gegenwärtigen Verwaltungsapparates des Reichsprotektors allein noch nicht die Assimilierung oder Germanisierung der Tschechen bewirkt.. "185

Die Absichten bezüglich der Baltenstaaten und der Sowjetunion hat Rosenberg, der am 20. April 1941 zum „Beauftragten für die zentrale Bearbeitung der Fragen des osteuropäischen Raumes" ernannt worden war ${ }^{\mathbf{1 8 6}}$, bereits vor dem Überfall auf die Sowjetunion niedergelegt. Danach sollte der russische „Riesenraum seinen geschichtlichen und völkischen Gegebenheiten entsprechend in Reichskommissariate aufgegliedert werden, deren jedes für sich eine andere politische Zielsetzung in sich trägt"187.

Die drei Baltenstaaten Estland, Lettland und Litauen sollten mit Weißruthenien und den Gebieten ostwärts Estlands und Lettlands bis kurz vor Leningrad zu einem "Reichskommissariat Ostland" zusammengefaßt werden ${ }^{188}$ mit dem Ziel, "die Form eines deutschen Protektorats zu erstreben und dann durch Eindeutschung rassisch möglicher Elemente, durch Kolonisierung germanischer Völker und durch Aussiedlung nicht erwünschter Elemente dieses Gebiet zu einem Teil des Groß-

182 Dok. 862-PS, a. a. O., S. 377.

183 Tischgespräche, a. a. O., S. 75 (18. 4. 42).

184 Dok. 2233-PS (IMT 29, S. 435).

185 Dok. 3859-PS.

186 Durch Hitlers Erlaß gleichen Datums, Dok. 865-PS, IMT 26, S. 383 f. Zur deutschen Besatzungspolitik allg. : A. Dallin, Deutsche Herrschaft in Rußland 1941-1945, Düsseldorf 1958. 187 Dok. 1030-PS, IMT 26, S. 577, vgl. auch: Dok. PS-1058 (IMT 26, S. 610 ff.); ferner: Dok. PS-1056 (IMT 26, S. 592 ff.). Genauer realisierter Aufbau der Kommissariate vgl. NO-2546, PS-1033, PS-1036.

188 Dok. 1030-PS, a. a. O., S. 577; ferner: Dok. 1029-PS (IMT 26, S. 574); Dok. 347-EC (IMT 36, S. 346). 
deutschen Reiches umzuwandeln "189. Als dieser Plan ins Stadium der Realisierung trat, wurde er in einer Besprechung vom 16. Juli 194.1 von Hitler gebilligt, der ausdrücklich betonte, "das gesamte Balten-Land müsse Reichsgebiet werden ".190 Am darauffolgenden Tage wurde Rosenberg zum „Reichsminister für die besetzten Ostgebiete" ernannt ${ }^{\mathbf{1 9 1}}$ und das Reichskommissariat Ostland unter Hinrich Lohse mit den vier Generalkommissariaten Estland, Lettland, Litauen (mit einer gewissen Selbstverwaltung) und Weißruthenien errichtet ${ }^{\mathbf{1 9 2}}$. Was die Eindeutschung durch Umsiedelungen angeht, war vorgesehen, „daß im ersten Fünfjahresplan der Umsiedlung nach dem Kriege . . . das Baltikum zum mindesten mit einer deutschen Oberschicht versehen " werden sollte ${ }^{193}$. Laut Himmler gehörten vor allem die Esten "wirklich zu den wenigen Volksstämmen, die wir ohne eigenen Schaden nach Ausscheidung ganz geringer Teile mit uns verschmelzen können "194.

Die Ukraine sollte nach Rosenberg ebenfalls ein Reichskommissariat werden mit der Absicht, „zunächst die Sicherung von Nahrungsmitteln und Rohstoffen für das Deutsche Reich, damit die Festigung der deutschen Kriegführung, sodann die Errichtung eines freien ukrainischen Staates im engsten Bündnis mit dem Großdeutschen Reich " in die Wege zu leiten. Für das letztere Ziel sollte das ukrainische Geschichts- und Nationalbewußtsein geweckt, eine Universität in Kiew gegründet und sogar eine ukrainische politische Partei als Verbindungselement zwischen dem Reichskommissar, seinen ukrainischen Beratern und den breiten Massen der Bevölkerung zugelassen werden ${ }^{\mathbf{1 9 5}}$. Obwohl dabei auch bei Rosenberg die Sicherung der Ernährung und Rohstoffversorgung Deutschlands im Vordergrund stand ${ }^{\mathbf{1 9 6}}$, geriet er mit dem Gedanken einer ukrainischen Autonomie zusehends in Gegensatz zu Hitlers Auffassungen ${ }^{197}$, und es zeigte sich in der Folge, daß Rosenberg zu schwach war, um seine Ideen durchsetzen zu können. Bereits mit der Ermennung Kochs zum Reichskommissar für die Ukraine am 20. August 194.1 gegen den Willen Rosenbergs war die Entscheidung gefallen. Koch sah in der Ukraine lediglich ein „Ausbeutungsobjekt "198, demgegenüber er nach seinem eigenen Bekenntnis eine Politik 18 Dok. 1029-PS, a. a. O., S. 574; als germanische Kolonisationsvölker sah Rosenberg vor: Deutsche, Dänen, Norweger, Holländer und nach dem Endsieg sogar Engländer. Vgl. Rosenbergs Denkschrift Dok. 1017-PS (IMT 26, S. 550).

190 Aktenvermerk vom 16. Juli 1941 über eine Besprechung Hitlers mit Rosenberg, Lammers, Keitel und Göring, aufgezeichnet von einem unbekannten Teilnehmer. Dok. 221-L (IMT 38, S. 86 ff.)., S. 90 .

191 Dok. PS-1997 (IMT 29, S. 235 ff.).

192 Einzelheiten über Ostland, s. Dallin a. a. O. bes. S. $193 \mathrm{ff}$.

193 Dok. 910-PS (IMT 26, S. 410), vgl. auch Bericht über Sitzung des Ostministeriums vom 4. 2.42 (NO-2585), ferner Generalplan Ost (a. a. O.).

194 Schreiben Himmlers an SSHA v. 1. 1. 1943 (NO-3301).

195 Dok. 1028-PS (IMT 26, S. 567 f.); fermer Dok. 1017-PS, a. a. O., S. 550 f.

196 Dok. 058-USSR (Auszug IMT 7, S. 377); Rosenberg wollte zwar die wirtschaftliche Ausnutzung und Besiedelung der Ukraine, wandte sich aber gegen eine offene Abstempelung der beherrschten Völker als "Slawen- und Kolonialvolk"; vgl. Aktennotiz für Hitler v. 16. 3. 42, Dok. 045-PS (IMT 25, S. 97).

197 Bereits in der Besprechung vom 17. Juli 1941 s. Dok. 221-L, a. a. O., S. $89 \mathrm{f}$.

198 Aufzeichnung von Bräutigam vom 25. Oktober 1942, Dok. 294-PS (IMT 25, S. 341). 
"nach den Richtlinien des Führers" und der in „Mein Kampf" definitiv niedergelegten Auffassung vom Slawentum als einer „minderwertigen Rasse“ führte ${ }^{199}$. „Das Ziel unserer Arbeit muß sein“, äußerte er 1942 auf einer Tagung in Rowno, „daß die Ukrainer für Deutschland arbeiten und nicht, daß wir das Volk hier beglücken "200. Daß diese Einstellung auch der Auffassung Hitlers entsprach, geht schon daraus hervor, daß Hitler bei den Differenzen zwischen Rosenberg und Koch (der Rosenberg offiziell unterstand, jedoch mit dem Führerhauptquartier über Bormann direkte Verbindung hatte) überwiegend Koch unterstützte, ihn zumindest nicht an der Fortführung seines Kurses hinderte ${ }^{201}$. Auch Hitlers eigene Äußerungen über die Behandlung der Völker der besetzten Ostgebiete, die er im vertrauten Kreise tat, zeigen seine Übereinstimmung mit der Auffassung Kochs. Hitler betonte $u$. a.: jede staatliche Organisation dieser Völker sei zu verhindern, die Gemeindeverwaltung sei die höchste Stufe der Verwaltungsorganisation, die er ihnen zugestehen werde, wobei „keine Gemeinsamkeiten zwischen benachbarten Dorfgemeinschaften “ entstehen sollten ${ }^{202}$ : „Der Weg zur Selbstverwaltung führt zur Selbständigkeit!“203 Stets müsse man davon ausgehen, „daß diese Völker uns gegenüber in erster Linie die Aufgabe haben, uns wirtschaftlich zu dienen "204. Vor allem dürften sie geistig und kulturell nicht gefördert werden, auch dürfe in Kiew keine Universität errichtet werden, da man sich sonst nur „die grimmigsten Feinde" heranzüchte ${ }^{205}$. Bildung sei nur soweit erforderlich, da $\beta$ die deutschen Befehle verstanden und ausgeführt werden könnten. Auch auf dem Gebiet der Hygiene und Gesundheitsfürsorge solle diesen Völkern nichts gebracht werden ${ }^{206}$. Hitler stimmte der Ansicht Bormanns zu, daß einer Zunahme der ukrainischen Bevölkerung vorgebeugt werden müsse, „denn eines Tages wollten wir ja doch dieses gesamte Land deutsch besiedelt haben “207. Er trat für eine strenge Trennung der zukünftigen deutschen Herrenvolk-Siedlungen von den Einheimischen

199 Denkschrift Kochs an Rosenberg vom 16. März 1943 Dok. 192-PS (IMT 25, S. 285); ferner Schreiben des Hauptabteilungsleiters Landwirtschaft im Ostministerium, Riseke, an Rosenberg vom 30. März 1943 über zahlreiche Zuwiderhandlungen Kochs gegen Anweisungen Rosenbergs. Dok. Ro-19 (IMT 41, S. 195).

200 Vermerk von Engelbrechten über die Tagung in Rowno vom 26. bis 28. August 1942 mit Rede Kochs (NG-2720).

201 Über Differenzen Koch-Rosenberg s. Dallin a. a. O., S. 140 ff.; vgl. ferner Goebbels, Tagebücher, a. a. O., S. 301 (15. 4. 43). Goebbels setzte sich als gewiefter Taktiker bei Hitler für die Rosenbergsche Richtung ein, sogar für eine Einrichtung von "Scheinregierungen " in den Ostgebieten. Er konnte mit seiner Idee einer "Ostproklamation" jedoch bei Hitler nicht durchdringen (a. a. O., S. $100-25.2 .42$; S. 199 - 13. 5. 42; S. $209-22.5 .42$; S. 237, 242 2. 3. 43 ; S. 259 - 9. 3. 43 ; S. $271-14.3 .43$; S. $300-15.4 .43)$.

202 Tischgespräche, a. a. O., S. 72 (11. 4. 42).

203 a. a. O., S. $50(3.2 .42)$.

204 a. a. O., S. 72.

205 a. a. O., S. 50 und $116(22.7 .42)$.

206 a. a. O., S. 116.

207 a. a. O., S. 115 (22. 7. 42). 
ein ${ }^{208}$. Die Ukraine solle eine neue „deutsche Ostmark“ werden ${ }^{209}$. Zur Ausführung dieser Ideen im einzelnen heißt es über eine Besprechung im Führerhauptquartier vom Sommer 1942:

„Entsprechend dem Befehl des Führers werden Teile der Ukraine im Laufe der nächsten 20 Jahre vollkommen deutsch besiedelt. Der Beginn der Siedlung richtet sich nach den Hauptverkehrswegen West-Ost und Nord-Süd, nach den geplanten Autostraßen und den neu zu schaffenden großen durchgehenden Eisenbahnlinien, also Krakau-Lemberg-Schitomir-Kiew, Leningrad-Mogilew-Kiew, Schitomir-Winitza-Odessa.

Die stützpunktartige Siedlung ist so gedacht, daß an den Kreuzungspunkten Städte mit 15-20000 Einwohnern entstehen und um diese Städte eine vollkommen deutsche Landbevölkerung angesiedelt wird. "210

Die Ausführung dieser Pläne kam allerdings über geringfügige Experimente in der Form von Ansiedlungen von Volksdeutschen aus Wolhynien in einigen Rayons (z. B. Schitomir und Kolinowka) und dem Aufbau des aus sieben Dörfern bestehenden "Volksdeutschen Gebietes Hegewald “ in der Nähe von Himmlers Hauptquartier nicht hinaus. Nach der Niederlage von Stalingrad befahl Hitler im Zeichen des totalen Krieges dann die Einstellung aller langfristigen Nachkriegspläne ${ }^{211}$.

Die Krim sollte laut Rosenberg als „strategischer Schlüsselpunkt für die Beherrschung des ganzen Schwarzen Meeres und Sicherung der Ukraine" nebst einem entsprechenden Vorgelände auf dem Festland nördlich der Krim zu Deutschland kommen 212. Hitler stimmte dieser Absicht in der Besprechung vom 16. Juli 1941 zu und betonte: „Die Krim muß von allen Fremden geräumt und deutsch besiedelt werden", sie solle „mit einem erheblichen Hinterland ... Reichsgebiet werden; ..." 213. Es war geplant, die Krim in "Gotenland", die Städte Simferopol und Sewastopol in "Gotenburg" und "Theoderichhafen " umzubenennen 214. Für die Besiedelung der Krim befürwortete Hitler den Plan des Gauleiters Frauenfeld, "die Südtiroler geschlossen nach der Krim zu verbringen", da das Klima dort für sie geeignet, der Transport über die Donau verhältnismäßig einfach und damit die Südtiroler Frage zwischen Deutschland und Italien ein für allemal gelöst sei ${ }^{\mathbf{2 1 5}}$.

208 a. a. O., S. 117 u. S. 44f. (8. bis 10.11. 41). Rosenberg wurde angewiesen, für die Durchsetzung all dieser aufgezählten Grundsätze Sorge zu tragen, Schreiben Bormanns v. 23. 7. 42 (NO-1878); s. auch Himmlers "Gedanken über die Behandlung der Fremdvölkischen im Osten" (NO-1880/81) VfZ, 1957, H. 2, S. 194ff.

209 Tischgespräche, S. 80 (8. 5. 42).

210 Aktenvermerk Bergers über eine Besprechung im Führerhauptquartier (NO-2703), vgl. auch Vermerk NG-1118.

211 Dallin, a. a. O., S. $297 \mathrm{ff}$.

212 Dok. 1028-PS, a. a. O., S. 572.

213 Dok. 221-L., a. a. O., S. 87, 90; vgl. auch Table Talk, S. 4f. (5./6. 7.41) und S. 16 (27. 7. 41).

214 Dok. 1517 (IMT 27, S. 272) u. Table Talk. a. a. O., S. 110 (2./3. November 1941).

215 Tischgespräche, a. a. O., S. 314 (2. 7. 42) Frauenfelds Vorschlag an Himmler vgl. NO24.17. 
Ein dem SS- und Polizeiführer für die Krim zugeteiltes „Krimkommando “ bereitete an Ort und Stelle die spätere Besiedlung vor ${ }^{216}$. Die bisherigen russischen Bewohner sollten nach Rußland ausgesiedelt werden, "wohin ist mir ganz wurscht, Rußland ist groß genug“ (Hitler) ${ }^{217}$. Die Rumänen sollten „Bessarabien und Odessa nebst einem Streifen, der von Odessa in West-Nordwest führt" 218 erhalten. Transnistrien wurde Rumänien im August 1941 auch tatsächlich zugeteilt.

Für Kaukasien war von Rosenberg ein drittes Reichskommissariat geplant, das eine Anzahl von Völkerschaften und Volkssplittern zusammenfassen sollte ${ }^{219}$ mit dem Ziel, einen „Föderativstaat mit einem deutschen Bevollmächtigten “ zu bilden ${ }^{220}$, „um die Landverbindung mit dem nahen Osten, d. h. die Sicherung Kontinentaleuropas, zu verwirklichen. Nur diese Verbindung zu den Ölquellen kann Deutschland und ganz Europa unabhängig von jeder Seekoalition für alle Zukunft machen. Ziel für die deutsche Politik muß sein, Kaukasien und seine nördlichen Ausläufer politisch und militärisch zu beherrschen "221. Dieser Plan trat nie in das Stadium seiner Verwirklichung. In der Besprechung vom 16. Juli 1941 allerdings äußerte Hitler, das Gebiet um Baku müsse - wie auch die WolgaKolonie - „deutsches Reichsgebiet" werden, „deutsche Konzession" und MilitärKolonie ${ }^{222}$. Hinsichtlich dieses Raumes, meinte er ein Jahr später, dürften keinerlei Versprechungen gemacht werden, Deutschland müsse den Kaukasus „in straffste Aufsicht nehmen ", wenn es sein Öl erhalten wolle ${ }^{223}$. Überhaupt sah Hitler in den russischen Ostgebieten ein rohstofflieferndes Kolonialland, das es zu entindustrialisieren galt ${ }^{224}$.

Als viertes Reichskommissariat war „Moskau" vorgesehen, das das durch die Reichskommissariate Ostland und Ukraine reduzierte "russische Kernland" bis zum Ural und die jenseits dieses Gebirges liegenden Industriebezirke Magnitogorsk und Tscheljabinsk umfassen sollte. Das deutsche Regime in diesem Gebiet sollte allein „auf die Niederhaltung jeglichen russischen und bolschewistischen Widerstandes ausgerichtet sein “225. In einer wie auch immer gearteten staatlichen Restexistenz Rußlands jenseits des Urals zwischen dem europäischen und ostasiatischen Großraum schien Hitler keine Bedrohung seiner Pläne mehr zu sehen.

216 Bericht über die Arbeitsergebnisse in der Zeit vom Winter 1942/43 bis zum Frühjahr 1944 (NO-4009).

217 Mitteilungen des Generalkonsuls Bräutigam (Ministerialdirigent im Ostministerium) v. 12. 8.41 (NG-2775).

218 Besprechung vom 16. Juli 1941, Dok. 221-L, a. a. O., S. 89.

219 Dok. PS-1058 (IMT 26, S. 620).

220 Dok. 1030-PS, a. a. O., S. 578. Über ähnliche Vorstellungen des Auswärtigen Amtes vgl. NG-1657.

221 So Rosenberg im Juli 1941. Dok. 058-USSR (Auszug IMT 7, S. 361). Daselbst S. 377 ist auf dasselbe Dokument allerdings unter dem Datum: 27. Juli 1942 Bezug genommen.

222 Dok. 221-L., a. a. O., S. 90.

223 Tischgespräche, a. a. O., S. 80 (9. 5. 42).

224 PS-1539 u. NG-3513. Erst die kriegswirtschaftlichen Notwendigkeiten ließen ihn diese Einstellung revidieren.

225 PS-1019, IMT 26, S. 557. 
d) Finnland und die abhängigen Staaten im Südosten (Slowakei,

Ungarn, Rumänien, Bulgarien, Jugoslawien, Griechenland)

Finnland im Nordosten, die Slowakei und die verbündeten Balkanstaaten im Südosten standen als Satellitenstaaten - wie sie übrigens Goebbels in seinen Tagebüchern selbst betitelt ${ }^{226}$ - in unterschiedlichen Abhängigkeitsverhältnissen zum Reich und hätten auch im endgültigen Großraum kaum eine bessere Stellung eingenommen.

Finnland konnte sich während des Krieges Deutschland gegenüber eine verhältnismäßig unabhängige Stellung bewahren. Es war außer seinem Beitritt zum Antikominternpakt im November 1941 über die praktisch notwendige Zusammenarbeit gegen den gemeinsamen Feind Sowjetunion hinaus mit Deutschland durch kein formales Abkommen verbunden und unterhielt während des ganzen Krieges diplomatische Beziehungen zu den USA. Wenn Hitler während des raschen Vormarsches im Osten im Sommer 1941 gelegentlich der Besprechung am 16. Juli 1941 mit Rosenberg, Lammers, Keitel und Göring auch äußerte, „mit aller Vorsicht müsse die Angliederung Finnlands als Bundesstaat vorbereitet werden "227, so hat Hitler doch solche Pläne angesichts der tapferen Haltung der Finnen im Rußlandfeldzug, die er in seiner Reichstagsrede vom 11. Dezember 1941 besonders lobend hervorhob, entweder geändert, oder der Ausdruck „Bundesstaat" war von vornherein im Sinne von „verbündetem Staat" zu verstehen gewesen. Im April 1942 versicherte er jedenfalls, er bereue es nicht, das nach dem ersten finnisch-russischen Kriege erfolgte finnische Angebot, ein „deutsches Protektorat" zu werden, abgelehnt zu haben. Es sei ,richtiger, sich solch ein Heldenvolk als Bundesgenossen zu erhalten, als es dem germanischen Reich einzugliedern zu versuchen, da es dann doch nur zu Schwierigkeiten komme". Die Finnen im Norden und die Türken im Süden seien „ideale Lösungen unseres politischen Flankensystems überhaupt“. Abgesehen davon eigne sich das Klima in Karelien nicht für die Deutschen ${ }^{228}$. Nur die Halbinsel Kola solle wegen ihrer Nickelvorkommen zu Deutschland kommen, während man Ostkarelien den Finnen überlassen werde ${ }^{229}$. Die Grenze zwischen Deutschland und Finnland solle die Newa sein und mitten durch das zerstörte Leningrad gehen, dessen Häfen und Werftanlagen verfallen sollten, „denn nur einer könne Herr in der Ostsee als dem deutschen Binnenmeer sein "230.

Der slowakische Staat, dessen Gründung das ureigenste Werk der nationalsozialistischen Außenpolitik zur Zerschlagung der Tschechoslowakei war, stellte

226 Goebbels Tagebücher, a. a. O., S. 447 (23. 9. 43). Auch Mussolinis „Faschistische Republik" wird von ihm dazugerechnet.

227 Dok. 221-L., IMT 38, S. 90.

228 Picker, a. a. O., Eintragung vom 5. April 1942, S. 64. Die Idee vom „Eckpfeiler Finnland“" war bereits im Sommer 1932 bei der Erörterung der "Ostraumpolitik" im Stabe Darrés aufgetaucht (Rauschning, Gespräche mit Hitler, S. 33).

229 Dok. 221-L, a. a. O., S. 90.

230 Picker, a. a. O., $65 \mathrm{f}$; ; ähnlich am 8. August $1942 \mathrm{im}$ Beisein des Reichsarbeitsführers Hierl (Trevor-Roper, a. a. O., S. 621 f.); L-221; Halder Tagebuch PS-1796, vgl. den Entwurf Leibbrandts über die Grenzen "Großfinnlands" (PS-1054). 
das Musterbeispiel eines „selbständigen“ Staates im nationalsozialistischen Großraum dar. Der „Vertrag über das Schutzverhältnis zwischen dem Deutschen Reich und dem Slowakischen Staat" vom 18./23. März 1939 verpflichtete die Slowakei, ihre Außenpolitik nur im Einvernehmen mit Deutschland zu führen was "den Wirkungsraum der deutschen politischen Führung in außenpolitischer Hinsicht über den slowakischen Staat" ausdehnte ${ }^{\mathbf{2 3 1}}$-, ihre militärischen Kräfte in engem Einvernehmen mit Deutschland zu organisieren und in einer bestimmten Zone ihres Staatsgebietes die Errichtung und Besetzung deutscher militärischer Anlagen zu gestatten. Auch innenpolitisch sicherten sich die Nationalsozialisten durch den Aufbau eines „echten Volksgruppenrechtes“, das der deutschen Minderheit eine Ausnahmestellung gewährte, ein Mitspracherecht zu: Die Führung der deutschen Minderheit wurde zu einem Staatsorgan umgeformt, indem ein deutscher „Staatssekretär für die Angelegenheiten der deutschen Volksgruppe in der Slowakei “, Franz Karmasin, das Recht erhielt, bei der Gesetzgebung mitzuwirken oder zu intervenieren ${ }^{232}$. Den Deutschen wurde ferner eine Partei und eine Wehrorganisation („Freiwillige Schutzstaffeln“), die Freiheit des Bekenntnisses zum Nationalsozialismus, der Gebrauch des Hakenkreuzes, Hitlergrußes etc. zugebilligt; sehr weitgehende Zugeständnisse innerhalb eines „selbständigen Staates“, wenn man bedenkt, daß zur gleichen Zeit von deutscher Seite den Elsässern das Tragen von Baskenmützen und der Besitz einer Trikolore verboten wurde.

Die Abhängigkeit von Deutschland zeigte sich vor allem in der deutschen Einflußnahme auf die Bildung und Umbildung der slowakischen Regierung nach deutschen Wünschen, um diejenigen slowakischen Politiker auszuschalten, die für eine größere Handlungsfreiheit der Slowakei eintraten (z. B. Sidor, Durčanský). Ein Memorandum des deutschen Gesandten in Preßburg an das Auswärtige Amt vom 25. Juni 1940 bringt die Verschärfung der deutschen Einflußnahme nach dem Norwegen- und Frankreichfeldzug zum Ausdruck:

„Mit dem 9. April und 10. Mai begann auch ein neues Kapitel im deutschslowakischen Verhältnis. Die neue politische Lage erlaubt es, unsere Visitenkarte zurückzuziehen, die wir so lange herausgehalten haben, um sie bekanntwerden zu lassen. Jetzt ist die Zeit gekommen, um wieder einmal absolut klarzustellen, besonders im Hinblick auf die Länder Südosteuropas, daß die Slowakei zu unserem Lebensraum gehört, d.h., daß allein unsere Wünsche maßgeblich sind. “ ${ }^{233}$

Im Herbst 1940 wurde dann auch ein System von "deutschen Beratern" in den verschiedenen Zweigen der slowakischen Verwaltung aufgebaut, um die slowakische Innenpolitik - besonders in der Judenfrage - gleichzuschalten ${ }^{234}$.

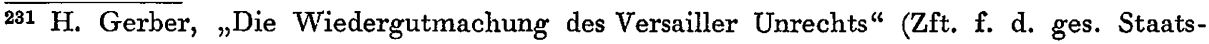
wissenschaft, Bd. 100, 1940, S. 378).

232 DDP 7/I, S. 20 ff.; zur Stellung der Volksgruppe fermer: Kurt O. Rabl, „Zur jüngsten Entwicklung der slowakischen Frage" (ZRVR 9, 1939/40, S. 284ff.), ders., „Verfassungsrecht und Verfassungsleben in der neuen Slowakei“ (a. a. O., Bd. 10, 1940/41, S. $127 \mathrm{ff}$.).

233 Aus Documents on German Foreign, Policy, ser. D. vol. X, S. 88 rückübersetzt bei: Broszat, „Das deutsch-slowakische Verhältnis 1939/40 und seine Rïckwirkung auf die slowakische Judenpolitik" (Gutachten des Instituts für Zeitgeschichte, München 1958, S. 223). 234 rgl. dazu a. a. O., S. 223 , S. 225.
} 
So sah im nationalsozialistischen Großraum ein „Staat" aus als „der in die Form des Rechtes gekleidete Ausdruck des völkischen Willens zur eigenständigen Existenz", als "das äußerlich-machtmäßige Mittel“ eines Volkes, „seine ihm von Gott selbst aufgegebene Sendung zu erfüllen "235. Nach außen aber wurde seitens der Nationalsozialisten größter Wert darauf gelegt, die Slowakei als souveränen Staat zu behandeln, so z. B. gelegentlich des Beitritts der Slowakei zum Dreimächtepakt am 24. November 1940, durch den sie nochmals die Führung Deutschlands und Italiens im europäischen Großraum anerkannte ${ }^{236}$.

Von den Balkanstaaten Ungarn, Rumänien und Bulgarien, die ebenfalls durch ihren Beitritt zum Dreimächtepakt die Führung Deutschlands und Italiens im europäischen Großraum ausdrücklich anerkannt hatten ${ }^{237}$, standen vor allem die beiden ersteren in einem ausgesprochenen Abhängigkeitsverhältnis zu Deutschland. Ihre politische Abhängigkeit zeigte sich einmal darin, daß sie die Regelung ihrer Gebietsstreitigkeiten im Wiener Schiedsspruch vom 30. August 1940 der Entscheidung der Achsenmächte unterwerfen mußten ${ }^{238}$, zum anderen darin, daß sie alle Wendungen der nationalsozialistischen Außenpolitik mitzumachen gezwungen waren: Kaum hatte Ungarn auf Drängen Hitlers einen Nichtangriffspakt mit Jugoslawien, dem gegenüber es Gebietsansprüche erhob, abgeschlossen, als es nach dem Umsturz in Belgrad Ende März 1941 aufgefordert wurde, sich dem deutschen Vorgehen gegen Jugoslawien aktiv anzuschließen ${ }^{239}$, während Rumänien und Bulgarien ihr Staatsgebiet als Ausgangsbasis für die deutschen militärischen Operationen zur Verfügung stellen mußten. Wurde Rumänien im Juni 194.0 angewiesen, sich den sowjetischen Forderungen auf Abtretung Bessarabiens und der Nordbukowina zu beugen, so wurde es ein Jahr später mit der Aussicht auf Rückgewinnung dieser Gebiete für den Feldzug gegen die Sowjetunion gewonnen ${ }^{240}$. Auch Ungarn wurde dazu bewogen, aktiv am Krieg gegen die Sowjetunion teilzunehmen, während es Bulgarien - mit dessen pro-russischer Einstellung sich Hitler abgefunden zu haben schien - gelang, sich aus diesem Krieg herauszuhalten und weiterhin diplomatische Beziehungen zur Sowjetunion aufrechtzuerhalten, bis die Sowjets 1944 ihrerseits das Land besetzten.

Wie die Slowakei mußten auch Ungarn und Rumänien den deutschen Minderheiten weitgehende Rechte einräumen. Durch das deutsch-rumänische Protokoll

${ }_{235}$ Rabl, Verfassungsrecht, a. a. O., S. 134.

236 DDP 8/I, S. $417 \mathrm{ff}$.

237 Beitritt Ungarns 20. 11. 40, Rumäniens 23. 11. 40 (DDP 8/I, S. 412ff.), Bulgariens 1.3. 41 (DDP 9/I, S. $406 \mathrm{ff}$.).

${ }^{238}$ DDP 8/I, S. 383 ff.; Hitler befürchtete, daß durch diese Gegensätze die Zufuhr rumänischen Öls nach Deutschland gefährdet wurde (So Hitler zu Ciano am 28. August 1940, Ciano Diaries, a. a. O., S. 288).

${ }^{239}$ Kordt, a. a. O., S. 291, über die deutsche Einwirkung auf Abbruch der diplomatischen Beziehungen mit Jugoslawien und Griechenland s. NG-2732.

${ }^{240}$ Kordt, a. a. O., S. 257 u. 308. Nach dem sowjetischen Einmarsch in Bessarabien und die Nordbukowina kündigte Rumänien die wertlos gewordene britische Garantie vom April 1939 und schloß sich der Achse an. 
vom 30. August 1940 und eine darauf folgende Abmachung zwischen dem Führer der deutschen Volksgruppe, Andreas Schmidt, und Antonescu wurde die deutsche Minderheit in Rumänien als Subjekt des öffentlichen Rechts anerkannt und erhielt eigenes Verordnungsrecht, freies Bekenntnis zum Nationalsozialismus, entsprechende Organisationen usw. zugestanden. In einem Aufruf Schmidts an die deutsche Volksgruppe vom 3. Oktober 1940 hieß es bezeichnenderweise: „Die Einstellung der deutschen Volksgruppe zum rumänischen Staat wird durch die Tatsache bestimmt, daß sich Rumänien unter dem legionären Regime restlos in das von Deutschland geführte politische System eingegliedert hat"241. Das deutsch-ungarische Protokoll vom 30. August 1940242 erkannte den 1938 gegründeten „Volksbund der Deutschen in Ungarn" als Vertretung der deutschen Minderheit an, gestattete ihr, ungehindert ihr Volkstum zu bewahren und sich zum Nationalsozialismus zu bekennen, und sprach ihr eine proportionale Beteiligung an der öffentlichen Verwaltung zu. Rechtsstatus der Minderheit und Befugnisse ihrer Führung waren allerdings mit denen der deutschen Minderheiten in der Slowakei, Rumänien und Kroatien nicht zu vergleichen, auch das Hissen der Hakenkreuzfahne wurde ihr nicht erlaubt. Außerdem weigerte sich ein großer Teil der Volksdeutschen, dem Volksbund beizutreten ${ }^{243}$.

Einmal durch die Kriegsereignisse von den Westmächten abgeschnitten, wurden die Balkanstaaten, deren Volkswirtschaften sich ihrer Struktur nach mit der Deutschlands gut ergänzten und die schon vor dem Kriege rege Außenhandelsbeziehungen mit Deutschland unterhielten, auch wirtschaftlich von den Achsenmächten stärker abhängigin ${ }^{24}$. Ihre Abhängigkeit wurde noch dadurch vergrößert, daß Rumänien seit Oktober 1940 (zum Schutze der für die deutsche Kriegführung wichtigen Ölfelder von Ploesti245), Bulgarien seit dem Aufmarsch gegen Jugoslawien und Griechenland Anfang März 1941 deutsche Truppen im Lande hatten und Ungarn deutsche Truppentransporte durch sein Staatsgebiet zulassen mußte ${ }^{246}$. Die nationalsozialistische Auffassung von „Zusammenarbeit“ mit einem solchen

241 DDP 8/I, S. 392f. Ü̉ber die Rechte der deutschen Gruppen in der Slowakei, Ungarn, Rumänien und Kroatien vgl. R. Freisler, „Entwicklung des Volkstumsrechtes der deutschen Volksgruppen" (Deutsche Juristenzeitung 1941, S. 881 f. und 897 f.).

242 DDP $8 /$ I, S. $395 \mathrm{ff}$.

243 Vgl. Survey 1939-46, S. 71 f. vgl. auch Dokumentation dex Vertreibung der Deutschen aus Ost-Mitteleuropa, Bd. II, Düsseldorf 1956, S. 28E, 8, 24.

244 Im Interesse der eigenen Kriegführung förderten die Nationalsozialisten teilweise die wirtschaftliche Entwicklung dieser Staaten, s. z. B. Protokoll über die deutsch-rumänische Zusammenarbeit bei der Durchführung eines Zehnjahresplanes für den Aufbau der rumänischen Wirtschaft vom 4. 12.1940 (DDP 8/I, S. 419 ff.). Vgl. Carl Clodius, „Neue Wege der europäischen Handelspolitik" (Nationale Wirtschaftsordnung und Großraumwirtschaft, Jahrbuch 1941, S. 87 ff.).

245 Kordt, a. a. O., S. 258 u. 274. Im Januar 1941 nahmen die deutschen Truppen hier bei der Niederwerfung des Putsches der „Eisernen Garde“ Horia Simas teil, obwohl Kreise der NSDAP mit der „Eisernen Garde" sympathisierten.

246 Freytagh-Loringhoven, Deutschlands Außenpolitik 1939-1941, S. 292 f.; Kordt, a. a. O., S. 287. 
„verbündeten“ und „souveränen“ Staat offenbarte sich eindrücklich gegenüber Ungarn im Jahre 1944, nachdem die deutsch-italienische Achse bereits zusammengebrochen war. Im Entwurf einer Denkschrift des Reichssicherheitshauptamtes vom März 1944 wurde „auf weite Sicht eine Eingliederung des ungarischen Raumes als eines wesentlichen Teiles des alten Habsburger Machtbereiches" in das Reich als „unerläßlich" bezeichnet ${ }^{247}$. Da eine rein militärische Intervention ungüngstige Auswirkungen auf die anderen Satellitenstaaten befürchten ließ, wurde eine Drohbotschaft Hitlers an Reichsverweser Horthy vorgeschlagen, um diesen zu veranlassen, eine aus verläßlichen Kollaborateuren bestehende Regierung, „allenfalls mit deutschen Beratern“, zu bilden und eine „staatsstreichartige Durchführung dieses Regierungswechsels" vorzunehmen. Auf diese Weise bleibe "die trojanische Methode ... gewahrt, ebenso aber auch der gute Schein für uns"248. Doch Hitler entschied sich für die Besetzung des Landes: Er lud Horthy auf das Schloß Kleßheim ein und stellte seine Forderungen, ,die auf eine Art deutsches Protektorat über Ungarn hinausliefen "249. Horthy wurde unter dem Vorwand von Luftangriffen und Telefonunterbrechungen von der Außenwelt abgeschnitten, bis er einer neuen Regierung unter dem bisherigen ungarischen Gesandten in Berlin, Sztójay, und der Besetzung Ungarns durch deutsche Truppen zugestimmt hatte ${ }^{\mathbf{2 5 0}}$.

Ein dennoch drohender Abfall Ungarns konnte im Oktober 194.4 nur notdürftig durch die Verhaftung Horthys und die Bildung einer Regierung unter dem Führer der Pfeilkreuzler, Szálasi, verhindert werden ${ }^{251}$, nachdem das Satellitensystem bereits durch den Abfall Rumäniens und Bulgariens im August und Finnlands im September 1944 endgültig zusammengebrochen war.

Das Schicksal Jugoslawiens war typisch für das eines Kleinstaates, der sich von Anfang an nicht freiwillig in den nationalsozialistischen Großraum ein- und unterordnen wollte. Zunächst ließ Hitler, der Jugoslawien gern als Gegengewicht gegen allzu weitgehende italienische Ambitionen auf dem Balkan in seinem Lager gesehen hätte, diesem Staat das griechische Saloniki als Gegenleistung für den Beitritt zum Dreimächtepakt anbieten. Nur widerstrebend und nach erheblichen deutschen

247 Dok. D-679 (IMT 35, S. 359). Nach Aussage v. Papens bestanden Bestrebungen der Nazis, „Ungarn auf irgendeine Weise später durch Besetzung zu einem Teil des Deutschen Reiches zu machen". (IMT 16, S. 418); Hitler selbst verachtete die Magyaren (Schmidt, a. a. O., S. 512, Kordt, a. a. O., S. 308). Über die Versprechungen, die Hitler den Rumänen auf ungarisches Gebiet machte, vgl. Hillgruber, Hitler, König Carol und Marschall Antonescu, Wiesbaden 1954. Stellt man dazu Hitlers Äußerungen (Tischgespräche, S. 52; 26. 2. 42) und besonders Goebbels Drohungen gegen Ungarn in Rechnung (Tagebücher, a. a. O., S. 92 - 20. 2. 42; S. 111 - 6. 3. 42; S. 117 - 11. 3. 42), so kann man mit einem Vorgehen gegen Ungarn im Falle eines deutschen Sieges rechnen. Vgl. auch Table Talk, a. a. O., S. 622 (9. 8. 42).

248 Dok. D-679, a. a. O., S. 663 f. Die Denkschrift nennt verläßliche ungarische Kollaborateure für die Regierungsbildung, a. a. O., S. $364 \mathrm{f}$.

249 Schmidt, a. a. O., S. 577.

250 Schmidt, a. a. O., S. 577 f.; Kordt, a. a. O., S. 386 f.; Survey 1939-46, S. 628 f. Es ist unklar, ob Horthy der Besetzung zustimmte oder nicht vielmehr vor vollendete Tatsachen gestellt wurde.

251 Einzelheiten über das entwürdigende deutsche Vorgehen s. Survey 1939-46, S. 631. 
Einwirkungen trat die jugoslawische Regierung Zwetkowitsch, durch das italienische Vorgehen gegen Griechenland mißtrauisch geworden, am 25. März 1941 dem Dreimächtepakt bei, nicht ohne sich vorher die Zusicherung erwirkt zu haben, daß damit keinerlei Verpflichtungen militärischer Art oder bezüglich Gewährung eines Durchmarschrechtes verbunden seien. Als sich jedoch zeigte, daß die jugoslawische Regierung angesichts der Stimmung im Lande, die den Schritt als einen Verrat am griechischen Partner des Balkanbundes ansah, diese Belastung nicht überstand und am 27. März durch einen Militärputsch gestürzt wurde ${ }^{252}$, marschierte Hitler in Jugoslawien ein und verfügte im Einvernehmen mit Italien die Aufteilung des Staates unter die Mitglieder des Dreimächtepaktes. Die Gebiete der Untersteiermark, Kärntens und Krains kamen zum Reich, ein Teil Sloweniens mit Laibach, ferner die dalmatinische Adriaküste mit den vorgelagerten Inseln und Montenegro zu Italien. Albanien wurde im Nordosten vergrößert. Das Gebiet zwischen Mur und Drau und die Batschka wurden Ungarn, Nordmazedonien mit der Stadt Skoplje bis zum Ochridosee Bulgarien zugeschlagen. Das Gebiet am Eisernen Tor mit seinen Kupfervorkommen behielt sich Hitler zur Ausnutzung vor. Es sollte als besondere Verwaltungseinheit unter deutschen Schutz gestellt werden ${ }^{\mathbf{2 5 3}}$. Restserbien verblieb unter deutscher Militärverwaltung mit einer Marionettenregierung unter dem serbischen General Neditsch ${ }^{254}$, während aus Kroatien mit einem Zugang zur Adria bei Sušák und den Gebieten Bosnien und Herzegowina ein „selbständiger Staat" gebildet wurde ${ }^{\mathbf{2 5 5}}$, dem Namen nach ein Königreich unter einem Mitglied des italienischen Königshauses, in Wirklichkeit ein autoritärer Führerstaat unter dem Poglavnik Pavelitsch, dem Führer der Ustascha-Bewegung ${ }^{\mathbf{2 5 6}}$. Dieser Staat trat ebenfalls dem Dreimächtepakt bei und wurde gelegentlich von Staatsbesuchen etc. als "souveräner Staat" behandelt" ${ }^{257}$, obwohl er schon durch die Aufrechterhaltung der deutsch-italienischen Besatzung zur Sicherung der Verbindungslinien von der Achse - insbesondere nach dem Aufleben der Partisanenkämpfe - total abhängig war. Auch in ihm wurde die deutsche Minderheit als juristische Person des öffentlichen Rechts anerkannt, ihr wurde das unbehinderte Bekenntnis zum Nationalsozialismus, die deutsche Fahne, eigene Staffeln in der

252 Zur Vorgeschichte des deutschen Überfalls auf Jugoslawien vgl. Kordt, a. a. O., S. $288 \mathrm{ff}$. 253 Tischgespräche, a. a. O., S. 53 (26. 2. 42) und 102 (29. 6. 42), Nbg. Dok. NG-4812.

254 Vorläufige Richtlinien für die Aufteilung Jugoslawiens vom 12. April 1941, Dok. PS-1195, IMT 27, s. $60 \mathrm{ff}$; f ferner: Kordt, a. a. O., S. $294 \mathrm{ff}$.

255 Dokumente zur Gründung und Anerkennung des Kroatischen Staates, den Deutsch-Kroatischen Staatsvertrag v. 13. Mai 1941 und den Staatsaufbau s. ZRVR 11, 1942/43, S. $122 \mathrm{ff.}$ u. DDP 9/I, S. 421 f., 423 ff. Hitler über die Loyalität der Kroaten s. Table Talk, a. a. O., S. 95 (29. 10. 41).

256 Vgl. Eugen Sladovic von Sladoevicki, „Verfassungs- und Verwaltungsrecht des unabhängigen Staates Kroatien" (Archiv des öffentl. Rechts, Neue Folge 33, 1943, S. 222 ff.). Die Grundsätze der Ustascha-Bewegung werden hier als mit vielen Punkten des NSDAP-Programms inhaltlich übereinstimmend bezeichnet (a. a. O., S. 228).

257 So z. B. anläßlich des Empfangs des Poglavnik bei Hitler auf dem Obersalzberg am 6. Juni 1941 (DDP 9/I, S. 426f.) und in Schloß Klessheim am 27. April 1943 (Schmidt, a. a. O., S. 553). 
Ustascha-Miliz etc. zugesagt, und die deutschstämmigen Beamten wurden sowohl auf Hitler als auch auf den Poglavnik vereidigt. Der Führer der Volksgruppe erhielt als "Staatsdirektor" ein eigenes Verordnungsrecht für deren Angelegenheiten, Mitspracherecht bei der Anstellung von Beamten deutscher Abstammung usw ${ }^{\mathbf{2 5 8}}$. Noch weitergehende Rechte und Befugnisse erhielt innerhalb Rest-Serbiens die NS-Organisation der deutschen Volksgruppe im jugoslawischen Banat ${ }^{259}$.

An Griechenland, das im Oktober 1940 von Italien überfallen und im April 1941 durch deutsches Eingreifen besiegt worden war, war Hitler selbst nicht territorial interessiert; es wurde aber Objekt von Annexionen seitens anderer Mitglieder des Dreimächtepaktes: Bulgarien erhielt einen Teil Westthraziens zwischen Struma und Maritza und damit Zutritt zum Ägäischen Meer, Albanien sollte im Süden bis Jannina erweitert werden und die ionischen Inseln zu Italien kommen ${ }^{260}$. In der zweiten Hälfte des Krieges machte sich aber auf deutscher Seite eher die Tendenz geltend, den italienisch-albanischen Ansprüchen entgegenzutreten und auf die Karte einer mit Deutschland verbündeten griechischen Marionettenregierung zu setzen.

Die Einbehaltung Kretas als deutschen Stützpunkt auch nach dem Kriege lehnte Hitler, der sich an der zukünftigen Gestaltung des Mittelmeerraumes im großen und ganzen desinteressiert zeigte, ab, um der Türkei gegenüber keinen Verdacht auf eine beabsichtigte Kontrolle der Dardanellen zu erregen ${ }^{\mathbf{2 9 1}}$.

\section{e) Der bevormundete italienische Bundesgenosse}

Dem verbündeten Italien war im Stahlpakt und im Dreimächtepakt eine gleichberechtigte und selbständige Stellung bei der Führung im europäisch-afrikanischen Großraum zugesprochen worden. Als Standardthese für die deutsche Auslandspropaganda wurde festgelegt, Italien habe "seinen unantastbaren Lebensraum zu beanspruchen, den es im Interesse Gesamteuropas auf politischem, wirtschaftlichem und kulturellem Gebiet frei gestalten wird “262. Sein Lebensraum sollten Nord- und Ostafrika und das Mittelmeergebiet sein, dessen östlichen Teil es sich durch die Schaffung des Protektorats Albanien im Jahre 1939 und durch den Angriff auf Griechenland im Oktober $1940 \mathrm{zu}$ beherrschen anschickte. Doch gerade der Griechenland-Feldzug und die Niederlagen in Ost- und Nordafrika bewiesen, daß Italien ohne deutsche Unterstützung zur Kriegführung nicht in der Lage war und in Wirklichkeit „zum unterstützungsbedürftigen Partner und fast zum Satelliten herabgesunken "263 war. Auch die Behandlung des italienischen Partners

258 Dokumentation der Vertreibung a. a. O., Bd. V.

259 ZRVR 11, 1942/43, S. $253 \mathrm{ff} .$, S. $621 \mathrm{f}$.

260 Kordt, a. a. O., S. 296.

261 Table Talk, S. 466 (8. 5. 42). Auch ein Deutschland angetragenes Protektorat über die Klosterrepublik vom Berge Athos lehnte Hitler ab (Kordt, a. a. O., S. 296 u. Tischgespräche, S. 102, 29. 6. 42).

${ }^{262}$ Standardthesen und Richtlinien für die deutsche Auslandspropaganda. Geheime Reichssache. These Nr. 25, 4; angeordnet am 5. 11.1942 (zitiert bei Kluke, a. a. O., S. 262).

263 Kluke, a. a. O., S. 261. 
durch Hitler ließ dessen untergeordnete Stellung deutlich hervortreten : Mussolini wurde über die deutschen Aktionen, z. B. die Alktion gegen Dänemark und Norwegen, die Offensive im Westen oder den Angriff auf die Sowjetunion nie vorher unterrichtet und durfte auch an den Waffenstillstandsverhandlungen mit Frankreich nicht teilnehmen. Mussolini selbst beklagte sich darüber oft gegenüber $\mathrm{Ciano}^{\mathbf{2 6 4}}$ und machte sich über die Stellung Italiens nach einem deutschen Endsieg keinerlei Illusionen:

„Die besiegten Staaten werden eigentliche Kolonien sein, die Verbündeten mit Deutschland alliierte Provinzen, die bedeutendste unter ihnen Italien. Wir müssen uns mit diesem Zustand abfinden, weil uns jeder Versuch einer Reaktion aus der Lage einer verbündeten Provinz in die wesentlich schlechtere Lage einer Kolonie bringen würde. Selbst wenn sie morgen Triest für den deutschen Lebensraum beanspruchen wollten, müßten wir nachgeben. “265

Diese Befürchtungen Mussolinis waren nicht unbegründet. Goebbels berichtet ,über Hitlers Ausführungen anläßlich der Reichs- und Gauleiterbesprechung im Mai 1943:

„Der Führer betont in diesem Zusammenhang wiederum, daß wir froh darüber sein müssen, keine Japaner auf dem europäischen Kontinent zu besitzen. Wenn die Italiener uns heute auch sehr viele Sorgen und Schwierigkeiten bereiten, so müssen wir uns doch glücklich preisen, daß sie uns bei der späteren Organisierung Europas keine ernsthafte Konkurrenz stellen können . . . Heute ... sind wir praktisch die einzige in Betracht kommende Führungsmacht auf dem europäischen Festland. “266

So sehr Hitler persönliche Freundschaft mit Mussolini und Sympathie mit dem faschistischen Regime verbanden ${ }^{\mathbf{2 6 7}}$, hatte er für die Italiener im allgemeinen, besonders für die italienische Wehrmacht, nur Verachtung übrig ${ }^{268}$. Im vertrauten Kreise äußerte er, daß Italien nach Ungarn in sozialer Hinsicht die am stärksten krankende Gemeinschaft im europäischen Großraum sei ${ }^{269}$. Die nationalsozialistische Einschätzung der Italiener als unter dem "Herrenvolk“ stehend ergibt sich auch daraus, daß z. B. bei der Abschiebung von „aus rassischen oder politischen Gründen nicht genehmen Personen " aus dem Elsaß gegenüber Italienern keine Ausnahme gemacht wurde ${ }^{270}$, daß die Heiratsbeschränkungen für Deutsche mit

264 s. Ciano, Diaries a. a. O., S. 263 (9. 6. 40), S. 359 (31. 5. 41), S. 364 f. (10. 6. 41), S. 372 (30.6.41).

265 Aufzeichnung Cianos v. 13. 10. 41 zit. bei H. A. Jacobsen: 1939-1945. Der Zweite Weltkrieg in Chronik und Dokumenten. Darmstadt 1961, S. 270.

266 Goebbels, Tagebücher, a. a. O., S. 325 (8. 5. 4.3).

267 Tischgespräche S. 41 (21.7. 41); S. 76 f. (23. 4. 42); S. 120 f. (24. 7. 42); Table Talk S. $135(20.11 .41)$; S. 266 (31. 1. 4.2).

268 Table Talk S. 174 f. (4. 1. 4.2); S. 584f. (22. 7. 42); S. 614 (5. 8. 42); S. 660 (26. 8. 42) über die Armee; S. 312 f. (17. 2. 42); S. 592 (24. 7. 42); S. 614 (5. 8. 42) über den Hof und den Adel; S. 178 (4. 1. 42); S. 430 (12. 4. 42) über mangelnde Geheimhaltung in Italien.

269 Table Talk, S. 117 (5.11. 41).

270 Aktenvermerk vom 29. 8. 1942 über eine Besprechung der mit „Siedlungsfragen" befaßten SS-Hauptämter. Dok. R-114 (IMT 38, S. 335 f.). Dem italienischen Konsul wurde entsprechende Mitteilung gemacht. 
Italienern aufrechterhalten blieben ${ }^{271}$ und beispielsweise im Protektorat die Italiener als auf einer Stufe mit den Tschechen stehend behandelt wurden ${ }^{\mathbf{2 7 2}}$.

Nach dem Umschwung in Italien und nachdem Mussolini als Chef der „Faschistischen Republik“ auf die Stellung eines Quisling herabgesunken war, wurde aus der wahren Einstellung der Nationalsozialisten gegenüber diesem Land kein Hehl mehr gemacht. Der deutsche Lebensraum wurde nunmehr über die „Alpengrenze, an der sich das Germanische Reich des Nordens und das Römische Reich des Südens " ursprünglich für immer begegnen sollten ${ }^{\mathbf{2 7 3}}$, auf Norditalien ausgeweitet. Das Alpenvorland und das adriatische Küstenvorland wurden als „Operationszonen " unter die Verwaltung der Gauleiter von Tirol-Vorarlberg bzw. Kärnten gestellt, mit der Absicht, sie auch politisch den benachbarten deutschen Gauen anzuschließen: in Südtirol wurden die Anschlußbewegung gefördert, der Gebrauch der italienischen Sprache schrittweise verboten und die italienischen Institutionen unterdrückt ${ }^{274}$. Goebbels forderte neben der Einverleibung Südtirols noch das ehemals dem Habsburger Reich angehörende Venetien ${ }^{275}$, und auch Hitler erwog, ob "Venetien in einem losen Verband in das Reich mit aufgenommen " werden solle ${ }^{\mathbf{2 7 6}}$. Goebbels bedauerte, daß man mit Rücksicht auf den befreiten Duce und die neue faschistische Regierung in Oberitalien nicht gleich die erforderlichen Annexionen vornehmen könne ${ }^{277}$. Er hoffte aber, daß Hitler in dieser Hinsicht fest bleiben und sich „nicht durch eine wiedererwachende Freundschaft zum Duce von diesem Entschluß abbringen " lassen werde ${ }^{278}$.

\section{f) Die Neutralen (Schweden, Schweiz, Spanien, Portugal)}

Es dürfte kein Zweifel darüber bestehen, daß nach einem deutschen Sieg auch die neutralen Staaten des europäischen Festlandes, Schweden, die Schweiz, Spanien und Portugal ihre unter Schwierigkeiten verteidigte Unabhängigkeit verloren hätten. Daß Schweden und die Schweiz von Hitler nicht besetzt wurden, hatte rein opportunistische Gründe: sie lagen nicht in der unmittelbaren deutsch-englischen bzw. deutsch-französischen Kampfzone, ihre Besetzung hätte unnötige Opfer erfordert und im Falle Schwedens eine unliebsame Unterbrechung der laufenden Eisenerzzufuhr, im Falle der Schweiz die Sperrung des Simplon und des St. Gotthards bedeutet, über die das von deutschen Lieferungen abhängige Italien versorgt wurde. Schweden, das durch die kriegsbedingte Abschnürung von der Welt

271 Selbst nach Unterzeichnung des Dreimächtepaktes wurde in einer vertraulichen Information an alle Parteistellen nochmals darauf hingewiesen; s. V. I. 15/2 vom 12.12.1940 „Verfügungen, Anordnungen, Bekanntgaben ", München, Zentralverlag der NSDAP, o. J., II, S. 64. 272 Bericht des italienischen Generalkonsuls aus Prag; Ciano, Diaries, a. a. O., S. 451 (22. 2. 42).

273 Max Clauß, "Tatsache Europa" (Das Reich Nr. 22 vom 20. 10. 1940, S. 5, Sp. 1).

274 Survey 1939-46, S. 97.

275 Tagebücher, S. 408 (11. 9. 43), S. 413 f. (13. 9. 43).

276 a. a. O., S. 4411 (23. 9. 43).

277 a. a. O., S. 414 (13. 9. 43), S. 408 (11. 9. 43).

278 a. a. O., S. 4411 (23. 9. 43). 
auf den Import von Rohstoffen (Kohle, Kunstdünger usw.) und Industrieprodukten aus Deutschland angewiesen war und im Austausch dafür praktisch seine ganze Produktion an kriegswichtigem Erz, Nutzholz usw. zur Verfügung stellte, konnte in wirtschaftlicher Hinsicht als in den deutschen Großraum integriert gelten ${ }^{\mathbf{2 7 9}}$. Nach der Besetzung Norwegens willigte es bis August 1943 auch in den Transport deutscher Truppen und Kriegsmaterials von und nach Norwegen durch sein Staatsgebiet ein. Äußerungen Hitlers ${ }^{280}$ und Himmlers ${ }^{281}$ sowie Goebbels' Tagebücher ${ }^{\mathbf{2 8 2}}$ verdeutlichen, wie problematisch die Selbständigkeit Schwedens und der Schweiz nach einem Sieg des Dritten Reiches gewesen wäre.

Auf die Unabhängigkeit Spaniens, das im August 1940 vom Zustand der Neutralität zum Zustand der Nichtkriegführung zugunsten der Achsenmächte übergegangen war, aber seit Herbst 1940 dem deutschen Drängen zum Kriegseintritt gegen England und zur Teilnahme an der im Januar 1941 vorgesehenen Eroberung Gibraltars (Operation Felix) geschickt widerstanden hatte ${ }^{283}$, hätte Hitler bei einer Aktion im westlichen Mittelmeer gewiß keine Rücksicht genommen, wenn er nicht durch die Entwicklung auf dem Balkan und den ihm vordringlich erscheinenden Feldzug gegen die Sowjetunion abgelenkt worden wäre. Aber im Falle eines Sieges im Osten und eines weiteren Widerstandes Englands wäre die Einnahme Gibraltars wieder akut geworden und die Iberische Halbinsel in den Bannkreis Hitlers geraten ${ }^{284}$. Seit der spanischen Ablehnung eines Kriegseintrittes nahmen Hitlers Äußerungen über seine Unzufriedenheit mit dem Franco-Regime an Schärfe zu: Franco habe nicht das Format gehabt, den Einfluß der katholischen Kirche auszuschalten und „eine wirklich umfassende nationale Revolution “ durchzuführen. Für eine eventuelle "Zweite Revolution" der alten Falange müsse man daher die an der Ostfront kämpfende Blaue Division unter General Muñoz Grande

279 Vgl. dazu Joachim Joesten, „Scandinavia in the 'New Order'" (Foreign Affairs, Vol. 19, 1940/41, S. 825). Über das Verhältnis Hitlers zur Schweiz vgl. Kordt, a. a. O., S. $254 \mathrm{f}$.

280 Picker, a. a. O., S. 45 (Schweden als Germanen), S. 57 f. (Schwedischer König als Störungsfaktor des Germanenzusammenschlusses); Trevor-Roper, a. a. O., S. 260 (Vertreibung der Juden auch aus Schweden und der Schweiz), S. 660 (Der Schweizer Staat als „Pickel im Gesicht Europas", der beseitigt werde).

281 vgl. oben Anm. 155. In einem Schreiben Bergers an Himmler v. 8. 9. 41 ist bereits von einem „Reichskommissar" für die Schweiz die Rede (NO-1394).

282 z. B. Eintragung vom 15. 4. 1942: „Es wäre schon gut gewesen, wenn wir bei der NordAktion Schweden gleich mit vereinnahmt hätten. Der Staat hat ja überhaupt keine nationale Existenzberechtigung mehr..." (Goebbels, Tagebücher, S. 161; ferner: S. 309, 314). Aus der Goebbelsschen Wiedergabe einer Äußerung Hitlers (a. a. O., Eintragung 8.5. 43, S. 325) schließt der Herausgeber der Goebbels-Tagebücher, Louis Lochner, „daß Hitler im Falle seines Sieges die Schweiz dem Reich einzuverleiben trachtete..." (Anm. S. 326). In einem Presseinterview vom April 1941 äußerte Goebbels, die Besetzung Schwedens und der Schweiz würde lediglich „eine Bagatelle" sein (Joesten, a. a. O., S. 826).

283 s. Kordt, a. a. O., S. $265 \mathrm{ff}$; Schmidt, a. a. O., S. $500 \mathrm{ff}$.

284 Über die beabsichtigte Wiederaufnahme des Projekts "Operation Felix" nach Beendigung des Rußlandfeldzuges s. Dok. 057-C (IMT 34, S. 260 ff.), vgl. ferner die Forderung Dönitz in der Besprechung mit Hitler vom 14. Mai 1943, zitiert aus dem Tagebuch ABmanns (IMT 13, S. 386). 
und die in deutschen Lagern arbeitenden rotspanischen Revolutionäre, die nicht als "Rote" im deutschen Sinne anzusehen seien, bereithalten ${ }^{285}$.

\section{g) Ideologische Ausrichtung in Hitlers Großraum (Judenpolitik)}

Was die ideologische Ausrichtung des europäischen Großraumes angeht, so behauptete die nationalsozialistische Theorie, daß der Nationalsozialismus als „die dem deutschen Volke gemäße Gestalt der politischen Verfassung“ keine „Exportware" darstelle. Andererseits betonte sie, daß „Völker, die in eine chaotische Vielzahl von Weltanschauungen, Parteien, Gruppen und Klassen aufgespalten sind und in diesem Pluralismus ihre Einheit und Gemeinschaft verloren haben, ... nicht die Grundlage für eine europäische Ordnung abzugeben "vermögen"286. Selbst die in den "südosteuropäischen Staaten praktisch bestehenden Militärdiktaturen oder autoritäts-staatsähnlichen Systeme mit königlicher Spitze " wurden noch lange nicht „als Ausdruck des staatlich gestaltenden Volkswillens ..., als ein Sich-hin-Finden zu eigenständigen Formen " angesehen ${ }^{287}$. Hitler selbst wandte sich „im deutschen Interesse“ gegen eine Übertragung des Nationalsozialismus auf die Satellitenstaaten, so z. B. auf Ungarn ${ }^{288}$. Wie aus seiner Äußerung zu v. Hanneken bezüglich Dänemarks hervorgeht, sollte auf der anderen Seite zumindest im engeren Bereich der "Neuen Ordnung“ unter deutscher Führung eine demokratische Staatsordnung keinen Platz finden ${ }^{289}$. Umgekehrt war Hitler jedoch bereit, die Demokratie, die er als Mittel außenpolitischer Schwächung ansah, z. B. Frankreich für später zuzubilligen ${ }^{290}$. In der Praxis erfolgte die Ausrichtung in den besetzten "germanischen " Gebieten durch die Förderung der dortigen Nazi-Parteien, während sie sich in den Satellitenstaaten und in Vichy-Frankreich auf die Nachahmung wenigstens der autoritären Staatsform (mit Gesetzgebungsgewalt der Regierung und Beschneidung der persönlichen Freiheitsrechte) beschränkte, die jedoch weniger auf Volksbewegungen mit weltanschaulichen Grundsätzen als auf autoritär-militärischer Regierungsgewalt und dem nationalen Gedanken aufbaute. Ihre Grundlage war weniger ein "revolutionäres“ als ein traditionelles Element. So beklagte sich Hitler z. B. bezüglich Rumäniens, daß der nur auf den Besitz der Exekutive sich stützenden Regierung Antonescus das politische Fundament einer Volkspartei fehle ${ }^{291}$.

Wenn auch nicht ersichtlich ist, wie weit die ideologische Gleichschaltung der Satelliten nach einem deutschen Endsieg vorangetrieben worden wäre, so sollte

285 Picker, a. a. O., S. 95; ferner: S. 93 u. 107; Trevor-Roper, a. a. O., S. 608 u. 568.

286 Georg Hahn, Grundfragen Europäischer Ordnung, Berlin-Wien 1939, S. 49, S. 56.

287 F. Ronneberger, „Die Wandlung des Südostens in der europäischen Politik“ (Geist der Zeit 17, 1939, S. 245).

288 Table Talk, S. 33 (17. 9. 41), S. 336 (26. 2. 42), S. 490 (20. 5. 42). Vgl. auch Anordnung $7 / 40$ g vom 2. 12. 40, Verfügungen, Anordnungen, Bekanntgaben, Bd. II, S. 484f.

289 s. o. Anm. 121.

290 Table Talk, S. 22 (2. 8. 41), Tischgespräche, S. 44.

291 Table Talk, a. a. O., S. 223 (18. 1. 42), Tischgespräche, a. a. O., S. 411 : „Den Horia Sima hätte ich erschießen lassen und die rumänische Legion zum Träger der Gewalt gemacht." 
sich doch der Wille zur Oktroyierung nationalsozialistischen Ideengutes auf die anderen europäischen Staaten an einem Punkte bereits mit aller Deutlichkeit offenbaren; an der Judenverfolgung in Europa. Sie stellt ein besonderes Kapitel der Ordnung des europäischen Großraumes nach dem Willen der Nationalsozialisten dar und ist zugleich Ausdruck dafür, daß diesem Großraum auch nach dem Kriege der Stempel des Nationalsozialismus aufgeprägt bleiben sollte. Hitler, der bereits in seiner Reichstagsrede vom 30. Januar 1939 angekündigt hatte, daß der nächste Krieg „die Vernichtung der jüdischen Rasse in Europa “ bringen werde ${ }^{292}$, blieb in diesem Punkte unerbittlich ${ }^{293}$. Die Diskriminierungs-, Verschleppungs- und Ausrottungsmaßnahmen, die in den von Deutschland besetzten oder beeinflußten Gebieten gegen die europäischen Juden ergriffen wurden, können in diesem Zusammenhang nicht im einzelnen behandelt werden ${ }^{294}$. Uns interessiert die Judenverfolgung vor allem als Symptom für die „Ausrichtung“ und die Einmischung in innere Angelegenheiten, die die anderen Staaten im nationalsozialistischen Großraum erfahren mußten.

Georg Hahn bezeichnete bereits 1939 in seinen „Grundfragen europäischer Ordnung" die „Absonderung" des Judentums neben der Revision des Versailler Diktats und dem Kampf gegen den Bolschewismus (-Fragen, um die es Hitler, wie wir sahen, im Grunde gar nicht ging -) als "gemeinsame Gegenwartsaufgabe", die „eine verbindende Schicksalsgemeinschaft aller europäischen Völker schaffe ${ }^{295}$. Die Beteiligung an der „Lösung der Judenfrage" wurde schließlich sogar als "Grundvoraussetzung" der Eingliederung der europäischen Staaten in den europäischen Großraum angesehen. Anläßlich der Einführung der Judengesetze in der Slowakei, die weitgehend den Nürnberger Gesetzen entsprachen, schrieb Julius von Medeazza, einer der eifrigsten „theoretischen “ Verfechter der diskriminierenden Gesetzgebung gegen die Juden in Europa:

„Es besteht kein Zweifel, daß sich die Slowakei dadurch, daß sie schon jetzt das Judenproblem löste, die Hände frei machte für weitere Aufgaben und Zielsetzungen $z u$ einer späteren entscheidenden Zeit, wenn die anderen europäischen Partner der Neuordnung noch mit der Erreichung der Grundvoraussetzung für ein neues Europa alle Hände voll zu tun haben werden. " 298

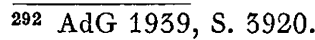

293 Vgl. Goebbels Tagebucheintragungen über seine Unterredungen mit Hitler vom 14. 2. 42 (S. 87), 13. 3. 42 (S. 134), 27. 4. 42 (S. 179); ferner über die Ausrottung der Juden in Europa: S. 113, 114, $142 \mathrm{f}, 225$.

294 S. darüber Gerald Reitlinger, Die Endlösung, Hitlers Versuch der Ausrottung der Juden Europas 1939-1945, Berlin 1956; ferner: Gutachten des Instituts für Zeitgeschichte, München 1958, Abschnitt III.

295 Georg Hahn, Grundfragen Europäischer Ordnung, S. 47 f., S. 30; H. Krüger, „Der Raum als Gestalter der Innen- und Außenpolitik " (Reich-Volksordnung-Lebensraum, Jg. 1, 1941, S. 164) meint, völkische Verschiedenheiten seien nur dann nicht unter einem Reich zusammenzufassen, wenn sie auf absolut verschiedenen Rassen beruhten. „Die Juden kommen demnach als Mitglieder und Mitträger des äußeren Reiches ebensowenig in Betracht wie für das innere Reich... Es verlangt also auch das äußere Reich ... eine Gesetzgebung, die das Judentum aus dem völkischen Leben... ausschaltet und von ihm dauernd fernhält."

296 Julius v. Medeazza, „Slowakischer Juden-Kodex" (DR 41, II, 1941, S. 2277) (Hervorhebung 
E. H. Bockhoff schrieb 1942, daß die Judenfrage bereits nicht mehr zur souveränen Zuständigkeit des einzelnen Staates gehöre, sondern ein „Pflichtproblem, also keine Frage der Souveränitätsbindung " innerhalb des europäischen Kontinents mehr sei ${ }^{297}$.

Die Übernahme des nationalsozialistischen Programmpunktes der Judenverfolgung wurde seitens der Nationalsozialisten als Prüfstein für die Ausrichtung eines europäischen Staates auf die ,ideologische Neuordnung “298 im europäischen Großraum angesehen, dabei vielfach die in den verbündeten Satellitenstaaten, insbesondere auch in Italien, erlassenen Gesetze gegen die Juden als zu "großherzig" bezeichnet $^{299}$. In der außenpolitischen Praxis wurde neben dem Drängen auf eine entsprechende Gesetzgebung in den anderen Staaten des Großraumes seit 1941/4.2 besonders auf eine Teilnahme dieser Staaten an der sogenannten „Endlösung “ der Judenfrage, d. h. an der Deportation der Juden in die Vernichtungslager hingearbeitet ${ }^{300}$. Der Gedanke, die antijüdischen Maßnahmen mit den Satelliten durch einen Kollektivvertrag der Partner des Antikominternpaktes zu koordinieren, mußte allerdings wegen des zu erwartenden Widerstandes Italiens, Spaniens und Ungarns aufgegeben werden. Man beschloß daher, auf bilaterale Abkommen mit dem Satelliten zu dringen ${ }^{301}$.

Nachdem Göring am 31. Juli 1941 den Chef der Sicherheitspolizei und des SD Heydrich zum Beauftragten für die Vorbereitung der "Gesamtlösung der Judenfrage im deutschen Einflußgebiet in Europa " bestellt hatte ${ }^{\mathbf{3 0 2}}$, war dieser "praktisch gesehen ,Judenkommissar für Europa“"303 geworden. In einer Besprechung über die „Endlösung“ am 20. Januar 1942 führte Heydrich aus, daß „im Zuge der praktischen Durchführung der Endlösung ... Europa von Westen nach Osten durchgekämmt" werden solle. Im besetzten und unbesetzten Frankreich, in der Slowakei und Kroatien werde die Aktion „ohne große Schwierigkeit" vor sich $\overline{\text { vom Verfasser) }}$; vgl. auch Paul Herre, Deutschland und die europäische Ordnung, Berlin 1941, S. 188 .

297 E. H. Bockhoff, „Die kontinentale Wohlstandssphäre als Rechtsbegriff. Vom horizontalen Weltrecht zum vertikalen Völkerrecht“ (NS-Monatshefte, Jg. 13, 1942, S. 785).

298 Julius v. Medeazza, „Judenfrage und Judengesetzgebung in Europa “ (DR 11., II, 1941, S. 682). Die ideologische Vorarbeit für eine europäische Gesamtlösung der Judenfrage wurde auf einem Kongreß in Frankfurt im März 1941 geleistet, auf dem auch Vertreter der Satellitenstaaten anwesend waren. Vgl. Max Weinreich, Hitler's Professors, The Part of Scholarship in Germany's Crimes against the Jewish People, New York 1946, S. $106 \mathrm{ff}$., $113 \mathrm{ff}$.

299 So besonders die italienischen und die ungarischen, s. Medeazza, „Das neue ungarische Ehegesetz als erster Schritt zur Lösung der Judenfrage" (DR 41, II, 1941, S. 2397 f.).

$300 \mathrm{Vgl}$. Memorandum des Unterstaatssekretärs Martin Luther vom 4. Dezember 1941 (Das Urteil im Wilhelmstraßenprozeß, Robert Kempner und Carl Haensel, Schwäbisch Gmünd 1950, S. 84), ferner die Aufzeichnung „Wünsche und Ideen des Auswärtigen Amtes zur vorgesehenen Gesamtlösung der Judenfrage in Europa " vom 8. Dezember 1941, a. a. O., S. 85. 301 Memorandum Emil Albrechts von der Rechtsabteilung des Auswärtigen Amtes vom 23. Dezember 1941, a. a. O., S. $84 \mathrm{f}$.

302 Auftrag Görings an Heydrich vom Juli 1941, s. Dok. 710-PS, IMT 26, S. 266 f.

${ }^{303}$ Diese Bezeichnung im Vermerk des Judenreferenten beim Befehlshaber der Sicherheitspolizei und des SD in Frankreich vom 22. Februar 1942, Dok. 1210-RF, IMT 38, S. 741. 
gehen. In Rumänien habe die Regierung bereits einen Judenbeauftragten eingesetzt, in Ungarn sei es „erforderlich, in Zeitkürze einen Berater für Judenfragen der ungarischen Regierung aufzuoktroyieren". Mit den italienischen Stellen sollte entsprechende Verbindung aufgenommen werden. Auf Verlangen des Auswärtigen Amtes sollte die Aktion in den nordischen Staaten mit ihrer geringen jüdischen Bevölkerung zurückgestellt werden, um unnötige Schwierigkeiten zu vermeiden ${ }^{304}$.

In den unmittelbar von Deutschland beherrschten Gebieten, in Frankreich, Belgien, Holland, Dänemark (erst nach der Ausschaltung der dänischen Regierung und der Erklärung des Ausnahmezustandes 1943), Norwegen, den Ostgebieten, Serbien, Griechenland und den „unabhängigen " Staaten Slowakei und Kroatien wurden Verschleppungen zur Vernichtung der Juden in unterschiedlichen Ausmaßen durchgeführt. Schwieriger gestaltete sich die Durchführung jedoch in den anderen unter deutschem Einfluß stehenden Staaten. Die Vichy-Regierung konnte auf dem ihr verbleibenden Territorium wenigstens die Deportation von Juden französischer Staatsangehörigkeit bis zur Besetzung Restfrankreichs im November 1942 verhindern. Italien schloß sich trotz wiederholter Bemühungen deutscherseits den Deportationen nicht an; sie erfolgten in Norditalien erst nach der deutschen Besetzung 1943. Auch in ihren Besatzungszonen in Südfrankreich, in Kroatien und Griechenland ließen die Italiener selbst nach persönlicher Einwirkung Ribbentrops auf Mussolini ${ }^{\mathbf{3 0 5}}$ keine Verschleppungen zu. Finnland vermochte durch seine Politik der Wahrung seiner Unabhängigkeit auch seine kleine jüdische Minderheit vor allen Unhelligkeiten zu bewahren. Auch Bulgarien verweigerte die Deportation seiner Juden, mußte jedoch im März 1943 unter deutschem Druck die Verschleppung der Juden aus seinen ehemals griechischen und jugoslawischen Gebieten zulassen. Rumänien führte in den rückeroberten Gebieten Bessarabien und Bukowina eigene Pogrome und Deportationen nach den besetzten russischen Gebieten durch, wobei allerdings teilweise Juden auf deutsch besetztes Territorium der Ukraine abgeschoben wurden. Als sich jedoch durch den Zusammenbruch der deutsch-rumänischen Front die Niederlage bei Stalingrad abzeichnete, stoppte Antonescu im Dezember 1942 die Deportationen zugunsten der Auswanderung der Juden nach Palästina und war zu einer Zusammenarbeit zwecks Deportation in die polnischen Vernichtungslager nicht $\mathrm{zu}$ bewegen ${ }^{306}$. Ungarn bot auch in dieser Frage das Beispiel dramatischen, aber schließlich vergeblichen Widerstandes gegen die „Ordnungsmacht" im europäischen Großraum. Zwar schoben die Ungarn die Juden aus dem von der Slowakei gewonnenen Territorium der Karpatho-Ukraine auf deutsch besetztes Gebiet ab. Sie verweigerten aber im Herbst 1942 eine generelle Koordination ihrer Judenpolitik mit Deutschland, insbesondere die Deportation der ungarischen

304 Wannsee-Protokoll, Leon Poliakov und Josef Wulf, Das Dritte Reich und die Juden, Dokumente und Aufsätze, Berlin 1955, S. $123 \mathrm{f}$.

305 Unterredung am 25. 2. 1943 (Poliakov und Wulf, a. a. O., S. 408). Über die Einwirkung auf Rom im Februar 1943, italienischen Juden die Staatsangehörigkeit abzuerkennen, s. Wilhelmstraßen-Prozeß, a. a. O., S. 98.

306 Über die Verhinderung der Palästina-Aktion, s. Wilhelmstraßen-Prozeß, a. a. O., S. 102 f. 
Juden. Im Januar 1943 z. B. bedrängte der Unterstaatssekretär Luther den ungarischen Gesandten Sztójay: „Es erfülle uns mit sehr großer Sorge, daß ein uns befreundetes Land mitten in Europa allein etwa eine Million Juden beherberge. Wir könnten dieser Gefahr auf die Dauer nicht untätig zusehen "307. Am 17. April 1943 wurde Horthy in einer Unterredung mit Hitler und Ribbentrop in Schloß Kleßheim in dieser Frage unter persönlichen Druck gesetzt. Im Protokoll der Unterredung findet sich folgender Satz:

„Auf die Gegenfrage Horthys, was er denn mit den Juden machen solle, nachdem er ihnen so ziemlich alle Lebensmöglichkeiten entzogen habe - erschlagen könne er sie doch nicht - erklärte der RAM, daß die Juden entweder vernichtet oder in Konzentrationslager gebracht werden müßten. Eine andere Möglichkeit gebe es nicht." "308

Trotz dieser persönlichen Einwirkungen war die ungarische Regierung in der Frage antijüdischer Maßnahmen in der Folge lediglich zu „taktischen Konzessionen " bereit, um eine Mitwirkung an der „Endlösung" der Judenfrage auch weiterhin um so entschiedener zu verweigern ${ }^{309}$. Die Deportation ungarischer Juden begann erst nach der deutschen Besetzung Ungarms im März 1944.

Es ist nicht uninteressant, daß dieser Druck auf Horthy im April 1943 in dem Moment ausgeübt wurde, in dem Hitler und Ribbentrop auf Grund eines abgefangenen und dechiffrierten Telegrammwechsels zwischen der ungarischen Regierung Kállay und der Türkei befürchteten, daß Ungarn mit der Gegenseite Kontakt aufnähme, um durch „diplomatische Manöver" aus dem Verband der Dreierpaktmächte auszubrechen ${ }^{\mathbf{3 1 0}}$. Hier offenbart sich eine weitere Zielsetzung der nationalsozialistischen Judenpolitik in Europa: Die Regierungen der Satellitenstaaten sollten an dem Verbrechen gegen die Juden beteiligt und ebenfalls schuldig gemacht werden, um die Brücken hinter ihnen abzubrechen und sie auf Gedeih und Verderb an das nationalsozialistische Deutschland zu ketten. Denn daß die nationalsozialistischen Führer sich keine Illusionen darüber machten, was ihnen im Falle der Niederlage drohte, geht aus Goebbels Tagebucheintragung über eine Unterredung mit Göring im März 1943 hervor: „Vor allem in der Judenfrage sind wir ja so festgelegt, daß es für uns kein Entrinnen mehr gibt"311. Auch seine Eintragung vom September 1943, als bekannt wurde, daß Churchill die Auslieferung Mussolinis von der Badoglio-Regierung gefordert hatte, liegt auf derselben Linie: Hitler

307 Dok. NG-1798 vgl. dazu die Aufsätze von Broszat in: Gutachten des Instituts für Zeitgeschichte, S. 183 ff. Über Ribbentrops Einwirkung auf die Ungarn s. ferner seine Vernehmung in Nürnberg, IMT 10, S. $461 \mathrm{f}$. und Bericht Luthers an Ribbentrop vom 6. Oktober 1942 über die ausweichende Haltung des ungarischen Gesandten (Kempner u. Haensel, Das Urteil im Wilhelmstraßen-Prozeß, a. a. O., S. 94).

308 Dok. D-736, IMT 35, S. 428.

309 So Broszat a. a. O., S. 205. Goebbels Bedauerm über die ungarische Haltung s. Tagebücher, a. a. O., S. 324. (Eintragung vom 8. Mai 1943).

310 Dok. 736-D, IMT 35, S. 429f. Vgl. dazu Berger an Himmler 19. 4. 43 : „Die Grundhaltung der ungarischen Regierung ist, die Juden möglichst anständig zu behandeln, da man gegenüber den Anglo-Amerikanern die Grundeinstellung als feststehend nachweisen kann. " (NO-628) 311 Goebbels, Tagebücher, a. a. O., S. 242 (2. 3. 1943). 
sei darüber zufrieden, „weil er glaubt, daß der Duce jetzt unter keinen Umständen mehr mit der Gegenseite irgendeinen Kompromiß abschließen kann; denn schließlich spielte er dabei mit dem Leben “312. Hitlers bereits erwähnte Äußerungen über Mussert, Clausen und Quisling lassen die gleiche Tendenz erkennen. Ein weiteres bezeichnendes Beispiel in diesem Zusammenhang ist die Beurteilung der politischen Zuverlässigkeit des bulgarischen Ministerpräsidenten Filoff durch Staatssekretär Steengracht in seinem Telegramm an Ribbentrop vom 7. September 1943: „Ich glaube, daß wir Filoff, der ... durch die Durchführung der antijüdischen Maßnahmen festgelegt ist, vertrauen können "313. So sollte sich in einem ganz anderen Sinne jene "verbindende Schicksalsgemeinschaft" verwirklichen, die Hahn 1939 durch die gemeinsame Lösung der Judenfrage erstehen sehen wollte. Der Aufgabe, das Schicksal der europäischen Völker in dieser Frage an das des nationalsozialistischen Deutschland zu ketten, sollte auch jener „Internationale Antijüdische Kongreß" in Krakau dienen, den Rosenberg mit Hitlers Genehmigung und in Zusammenarbeit mit anderen Reichsministerien im Sommer 1944 vorbereitete. $\mathrm{Zu}$ diesem Kongreß waren antijüdisch eingestellte Vertreter des öffentlichen Lebens, der Wissenschaften, der Kunst usw. aus Italien, Frankreich, den Satellitenstaaten und den neutralen Staaten eingeladen worden und hatten ihr Erscheinen auch bereits zugesagt ${ }^{\mathbf{3 1 4}}$. Mit diesem Kongreß, bei dessen Vorbereitung bezeichnenderweise das Adjektiv „antijüdisch" durch „historisch-wissenschaftlich “ ersetzt wurde, sollte erreicht werden, „an die Bildungsschicht der europäischen Völker heranzukommen, die bisher mit der einfachen antijüdischen Propaganda nicht erfaßt werden konnte“315. Es sollten „internationale Arbeitsgemeinschaften zur Erforschung und Bekämpfung des Judentums " gebildet werden ${ }^{316}$, und am 4. Tage des Kongresses sollten die Teilnehmer auf der Burg zu Krakau ein feierliches Bekenntnis zur deutschen Judenpolitik und zur Entfernung der Juden aus Europa abgeben $^{\mathbf{3 1 7}}$. Dieser Plan eines Kongresses, der die nationalsozialistische Judenverfolgung als Ausdruck des Wollens der europäischen Geisteswelt erscheinen lassen sollte, wurde wegen der militärischen Ereignisse auf Hitlers Anweisung zunächst vertagt ${ }^{\mathbf{3 1 8}}$, dann Ende Juli 1944 endgültig fallengelassen ${ }^{\mathbf{3 1 9}}$.

312 Tagebücher, S. 435 (23. 9. 1943).

313 Nbg. Dok. NG-116.

314 Bericht Hagemeyers vom 15. Juni 1944, Dok. 1752-PS, IMT 28, S. 51 ff. Ribbentrop sollte den Ehrenvorsitz übernehmen (NG-2953).

315 s. Aufzeichnung Hagemeyers über eine vorbereitende Sitzung vom 23. Februar 1944, (Max Weinreich, a. a. O., S. 220). Einzelheiten über den Kongreß dort S. $219 \mathrm{ff}$.

316 Dok. 1752-PS a. a. O.

317 Weinreich, a. a. O., S. 223; Resolution „Europa frei von Juden" (NG-5013).

318 Schreiben Bormanns an Rosenberg vom 12. Juni 1944, zit. Reitlinger, a. a. O., S. 488.

319 Staatssekretär von Steengracht schrieb in Nürnberg die Verschleppung des Kongresses dem Auswärtigen Amt zu. Aussage vom 26. März 1946, IMT 10, S. 133 f. 


\section{h) Zusammenfassung}

Aus dem Voranstehenden wird evident, daß die Herrschaft der Nationalsozialisten über den europäischen Großraum das $\mathrm{Ma} \beta$ einer Hegemonie im Sinne eines Führungsverhältnisses einer Großmacht gegenüber schwachen oder militärisch entmachteten Schutzstaaten bei weitem überschritt. Es handelte sich vielfach um unmittelbare Beherrschung, ja sogar physische Dezimierung anderer europäischer Völker, ohne moralische oder völkerrechtliche Hemmungen und unter gröbster Verletzung des Willens der „Verbündeten “. Nicht Partnerschaft und Kooperation der europäischen Staatengemeinschaft auf der Basis der Gleichberechtigung und Freiwilligkeit bestimmten die Bildung dieses Großraums. Dies geschah vielmehr nach der von Hitler schon 1928 formulierten Devise, daß ein Zusammenschluß europäischer Völker nur auf dem Wege eines Hegemoniekampfes, nur durch die Unterwerfung unter die Gewalt des Stärksten erfolgen könne ${ }^{\mathbf{3 2 0}}$. Äußerungen Hitlers aus späterer Zeit belegen, daß er an dieser Maxime konstant festgehalten hat. Rauschning gegenüber erklärte er 1934, eine Organisation der Zusammenarbeit auf freiwilliger Basis, wie im Commonwealth, sei ein Zeichen des Verfalls und komme für die zukünftige Verfassung seines europäischen Reiches nicht in Frage ${ }^{\mathbf{3 2 1}}$. Im Jahre 1942 deklamierte Hitler: „Wenn ich ein freies Land unterwerfe, nur um ihm die Freiheit wiederzugeben, wozu das? Wer Blut vergossen hat, hat auch das Recht, die Herrschaft auszuüben "322; "über die ewige Rederei von Gemeinschaft könne er nur lächeln, da die großen Schwätzer meinten, Gemeinschaft lasse sich zusammenreden ... Gemeinschaft lasse sich eben nur durch Gewalt schaffen und erhalten "323. Noch im späten Stadium des Krieges hat Hitler nahezu alle Vorschläge, die auf die Milderung der Herrschaft in einem bestimmten Gebiet oder eine allgemeine Organisation Europas nach freiheitlichen Maßstäben hinausliefen und ihm teils von seinen engsten Gefolgsleuten unterbreitet wurden, abgelehnt. So auch Ribbentrops Vorschlag vom Winter 1942-43, den besetzten Gebieten „ein gewisses Maß Unabhängigkeit unter deutscher Führung" bei wirtschaftlicher Zusammenarbeit zu geben ${ }^{324}$. Das würde, so begründete Hitler seine Ablehnung, in Anbetracht der ungünstigen militärischen Lage nur „als Zeichen der Schwäche ausgelegt" ${ }^{\text {"325. }}$.

Von einer zwischenstaatlichen Hegemonie im europäischen Großraum hätte man im Falle eines deutschen Sieges höchstens gegenüber den romanischen Staaten

320 Hitlers Zweites Buch, S. $129 \mathrm{f}$.

321 Rauschning, a. a. O., S. 117.

322 Tischgespräche, a. a. O., S. 50 (3. 2. 42).

323 a. a. O., S. 71 (11. 4. 42).

324 Vgl. Aussagen des Staatssekretärs im Auswärtigen Amt, v. Steengracht, in Nürnberg am 26. 3. 1946, IMT 10, S. $130 \mathrm{f}$.

325 a. a. O. Auch Goebbels trug Hitler im März 1943 die Aufstellung eines Europa-Programms als "naheliegende politisch-propagandistische Parole" an, stieß aber ebenfalls auf Ablehnung. Ex erhielt lediglich die Erlaubnis, „das Thema einmal anzudeuten und auch etwas zu umreißen", ohne auf Einzelheiten einzugehen. Tagebücher, a. a. O., S. 259 (9. 3. 43) u. S. 295 (12. 4. 43). 
Italien, Frankreich, Spanien und Portugal sprechen können, von denen anzunehmen ist, daß sie ihre Eigenstaatlichkeit bei einer gewissen Abhängigkeit von Deutschland behalten hätten, allenfalls noch gegenüber Finnland, der Türkei und vielleicht einigen Balkanstaaten. In Mittel-, Nord- und Osteuropa jedoch, in dem Raum, in dem nach Hitlers Vorstellung die nordische "Herrenrasse" lebte oder zum Herrschen berufen war und den das "Germanische Reich Deutscher Nation" als Kern Europas umfassen sollte, hätte man nur von einer Beherrschung durch Deutschland sprechen können. Eine echte Eigenstaatlichkeit wäre hier kaum den privilegierten "germanischen "Völkern zugestanden worden, die dem Reich durch ideologische Gleichschaltung und Unterstellung unter deutschen militärischen Schutz angegliedert werden sollten, geschweige denn den slawischen "Untermenschen ", die der Ausbeutung und Verdrängung verfallen und deren Territorium als germanischer - sprich deutscher - Lebens- und Siedlungsraum dienen sollte.

Das Ziel der Beherrschung Europas unter Beseitigung der kleineren europäischen Staaten hat Hitler selbst in einer Rede auf der Reichs- und Gauleiterbesprechung nach dem Staatsakt für Viktor Lutze im Mai 1943 ausgesprochen. Goebbels gibt den Inhalt dieser Rede in seinem Tagebuch (fast in den gleichen Worten, die Hitler im Frühjahr 1934, gegenüber Rauschning gebrauchte) wieder:

„Aus alledem hat der Führer die Konsequenz gezogen, daß das Kleinstaatengerümpel, das heute noch in Europa vorhanden ist, so schnell wie möglich liquidiert werden muß. Es muß das Ziel unseres Kampfes bleiben, ein einheitliches Europa zu schaffen. Europa kann aber eine klare Organisation nur durch die Deutschen erfahren ...."326

„Der Führer gibt seiner unumstößlichen Gewißheit Ausdruck, daß das Reich einmal ganz Europa beherrschen wird ... Von da ab ist praktisch der Weg zu einer Weltherrschaft vorgezeichnet. Wer Europa besitzt, der wird damit die Führung der Welt an sich reißen.

In diesem Zusammenhang können wir natürlich Fragen von Recht und Unrecht überhaupt nicht zur Diskussion akzeptieren ... der Sieg gibt uns das größte Recht. “327

Solche Mißachtung des Rechtsgedankens durch eine Philosophie der Gewaltsamkeit war nur die Kehrseite der Tatsache, daß die Art und Weise, wie das Dritte Reich seine Großraumziele verfolgte, ohne rücksichtslose Verletzung der Grund-

326 Goebbels, Tagebücher, a. a. O., S. 325 (8. 5. 43); vgl. Hitlers Worte zu Rauschning : „Nur wir können den kontinentalen Großraum schaffen, und nur durch unsere Herrschaft, durch unsere einzig und allein... Wir werden diesen Kampf auf uns nehmen. Er wird uns die Pforte zur dauernden Herrschaft über die Welt aufstoßen." (Rauschning, a. a. O., S. 126). Hitler glaubte, daß die Deutschen einmal „,aus rein biologischen Gründen ... mit 150 bis 200 Millionen deutschen Menschen die unumschränkten Herren Kontinental-Europas würden ". (Tischgespräche, a. a. O., S. 179, 5. 7. 42.) Hitler über die Beseitigung der Kleinstaaten aus militärischen Notwendigkeiten s. Fuehrer Conferences on Naval Affairs 1939-1945 in: Brassey's Naval Annual 1948, London-New York, S. 359.

${ }^{327}$ Goebbels a. a. O., S. 326. Hitlers Anspielungen auf eine „Weltpolitik“ nach der Erreichung der Kontrolle über den europäischen Kontinent s. Table Talk S. 93 (26.-27. Oktober 1941) u. 328 (22.2. 42). Über den Willen zur Herrschaftsstellung in der Welt hinter Hitlers Konzeption vom kontinentalen Imperium vgl. H. Rauschning, Die Revolution des Nihilismus, S. 410. 
prinzipien des bestehenden Völkerrechts nicht möglich war. Diese Rechtsbrüche angefangen von der Entfesselung von Angriffskriegen bis zur Judenverfolgung aufzuzählen, ist hier nicht der Ort. Sie machten es jedenfalls zwingend, daß man im Dritten Reich überall dort, wo man nach einer Legitimierung der eigenen Großraumpolitik suchte, das überlieferte und von Europa über die Welt verbreitete universalistische Völkerrecht, das vom Nebeneinander souveräner Staaten ausgeht, nicht gebrauchen konnte und ihm eine Ordnung angeblich eigenen und anderen Rechts entgegenstellen mußte: das Großraum-Prinzip, von dem man fälschlich vorgab, es stünde in Analogie zur Monroe Doctrine. Die Abwegigkeit dieser Bezugnahme kann jetzt, auch was die Staatenbeziehungen innerhalb des Großraumes betrifft, nicht mehr zweifelhaft sein : Im Gegensatz zur Monroe Doctrine begründete die nationalsozialistische Doktrin eine Hegemonialherrschaft über die anderen raumzugehörigen Staaten. Sie zielte auf die Beseitigung der Souveränität und Unabhängigkeit dieser Staaten ab, teilweise sogar auf die Beseitigung ihrer Eigenstaatlichkeit, oktroyierte einer Anzahl von ihnen eine bestimmte politische Idee und Regierungsform und beabsichtigte die Zerstreuung und physische Vernichtung von Teilen ihrer Bevölkerung. Im Gegensatz zur Monroe Doctrine verneinte die nationalsozialistische Doktrin damit eine völkerrechtliche Ordnung, die auf einer Vielheit von Staaten mit politischer Unabhängigkeit und territorialer Unverletzlichkeit und dem Grundsatz der rechtlichen Gleichheit dieser Staaten beruht und suchte sie durch ein ihr adäquates „neues Völkerrecht", eine sogenannte "völkerrechtliche Großraumordnung “, zu ersetzen.

\section{Das neue Großraum- "Völkerrecht" (C. Schmitt)}

Carl Schmitts "völkerrechtliche Großraumordnung“ sagt über die Rechtsbeziehungen innerhalb des Großraumes nichts Konkretes aus. Weder aus dem Begriff des Reiches noch aus dem Begriff des Großraumes läßt sich in dieser Hinsicht etwas Genaues entnehmen. Aus dem wenigen darüber Ausgeführten erhellt jedoch folgendes.

Einerseits soll der Großraum nicht einfach eine Erweiterung der staatlichen Grenzen des Reiches darstellen. „Das Reich ist nicht einfach ein vergrößerter Staat"328, es ist nicht "der von ihm vor Interventionen bewahrte Großraum selber" 329. Die Staaten (Nicht-Reiche) müssen als eigene Größen und Völkerrechtssubjekte zweiten Ranges bestehen bleiben, wenn die Rechtsbeziehungen ReichStaaten nicht innerstaatlicher Art und der Großraum kein Groß-oder Überstaat sein sollen.

Andererseits sind die Staaten im Großraum ihrer echten „erstrangigen“ Völkerrechtspersönlichkeit und - wie wir sehen werden - auch ihrer Souveränität und „Impermeabilität“ zugunsten des Reiches beraubt. Der Großraum soll kein auf 328 Großraumordnung, a. a. O., S. 52.

329 a. a. O., S. 35. 
gleichberechtigten Staaten aufbauendes Vertragsgebilde, kein zwischenstaatliches Gebilde sein. Nach außen tritt der Großraum als eigene Größe auf; Schmitt spricht von Beziehungen „zwischen den Großräumen im ganzen“330. Da dem Großraum als solchem jedoch keine Völkerrechtspersönlichkeit zugesprochen wird, Recht aber keine Beziehung zwischen Räumen als Sachen sein kann ${ }^{331}$, kann nur das Reich den Gesamtwillen des Großraumes gegenüber anderen Großräumen wahrnehmen und Träger der Beziehungen zwischen den Großräumen sein, wenn der Großraum kein Bund gleichberechtigter Staaten sein soll ${ }^{\mathbf{3 2 2}}$.

Infolgedessen besteht im Großraum die Gesamtexistenz des Großraumes neben den Einzelexistenzen der Staaten, ein Dualismus bzw. Pluralismus von Existenzen. Der Schwierigkeit der rechtlichen Erfassung dieses Zustandes geht Schmitt mit der These aus dem Wege, daß ,jede bündische Zusammenfassung politischer Einheiten ... weder rein zwischenstaatlich noch rein innerstaatlich sein “ könne, „sondern eben etwas Drittes, Anderes sein " müsse, "das sich derartigen Alternativen entzieht". Gebilde solcher Art - zu denen übrigens auch das britische Commonwealth (wenn auch nicht als Großraum) gehöre - seien folglich durch das bisherige Völkerrecht, das vom Staatsbegriff mit seinem „scharfen, ausschließlichen EntwederOder dieser Alternative" von zwischenstaatlich und innerstaatlich ausgeht, nicht zu begreifen. „Kein Reich und kein Bund läßt sich in diese Disjunktion hineinpressen, die ... daher entfällt, wenn solche Gebilde nicht mehr normativistisch,

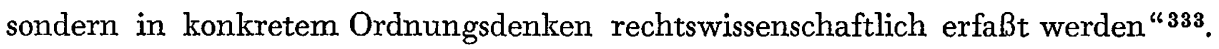
So kommt z. B. Jahrreiß in seiner Besprechung von Schmitts Schrift zu der Feststellung, daß „eine Kritik an Carl Schmitts Thesen im Namen der früheren ,wahren" Völkerrechtsordnung . . . ohne Grundlage " sei ${ }^{334}$. Wir sind im Gegenteil der Ansicht, daß die bisherige Völkerrechtsordnung die einzige Grundlage ist, von der aus der konkrete rechtliche Gehalt der Schmittschen Theorie erkannt werden kann. Das "werdende" Völkerrecht Schmitts kann nur vom bestehenden Völkerrecht aus beurteilt werden, wenn man nicht eine rechtspolitische Forderung zum Recht erheben will. Das ist im letzten Grunde eine Frage des politisch-ideologischen Standortes: Solange man davon ausgeht, daß jedes Volk - das durch eine funktionierende staatliche Organisation seine Qualifikation dafür nachgewiesen hat - seine Geschicke selbst entscheiden und diese Entscheidungen sich weder von anderen auf-

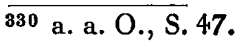

${ }^{331}$ "Vgl. Küchenhoff, „Großraumgedanke und völkische Idee im Recht" (ZaöRVR, Bd. 12, 1944, S. 47), dex daher im Großraum überhaupt nur ein Objekt sieht: „Der Großraum ist... keine selbständige Ordnungsgröße, sondern Gegenstand oder Bereich menschlicher Ordnungen", a. a. O., S. 48. Damit wird Schmitts These von Beziehungen zwischen GroBräumen als Ganzen verneint.

332 Gerade letzteres abex wird durch die Einführung des Reichsbegriffes verneint und war mit den nationalsozialistischen Absichten unvereinbar. Vgl. auch Max Clauß, "Tatsache Europa", Das Reich, Nr. 22 vom 20. 10. 1940, S. 5, Sp. 2 : eine „Majorisierung des Reiches" käme nie in Frage, da es allein für die Sicherheit des Großraumes verantwortlich sei.

333 Schmitt, „Führung und Hegemonie" (Schmollers Jahrbuch für Gesetzgebung, Verwaltung und Volkswirtschaft im Deutschen Reich, Jg. 63, 1939, S. 516f.).

334 Jahrreiß, „Völkerrechtliche Großraumordnung“, a. a. O., S. 609. 
erlegen lassen noch selbst anderen oktroyieren sollte, muß man die organisierten Völker, die Staaten, als unabhängig und daher unter sich gleich ansehen. Billigt man den Staaten Unabhängigkeit zu, so beruhen die Beziehungen auf gegenseitiger Achtung der Unabhängigkeit. Sollen diese Beziehungen in der Form eines allen gemeinsamen Völker-Rechts geregelt sein, dann muß es die Gleichheit aller vor dem Recht anerkennen. Nur wenn dieses Recht allen Staaten ein gleiches Maß an Sicherheit gewährt, werden alle ein Interesse an der Aufrechterhaltung und Einhaltung dieses Rechtes haben. Folglich muß die Völkerrechtsordnung eine genossenschaftliche Struktur der Staatengemeinschaft, ein Nebeneinander unabhängiger Staaten aufweisen, von denen keiner dem anderen gegenüber befugt ist, von sich aus und ohne Zustimmung des anderen Herrschaft auszuüben, d. h. Befehle zu erteilen und sie durch Anwendung von Gewalt zu erzwingen. Das Prinzip der Staatengleichheit bedeutet, daß die Staaten als Normadressaten selbst - „autonom “ Recht setzen und bei Rechtsschöpfung durch Vertrag das Einstimmigkeitsprinzip gilt. Natürlich ist sich eine solche Auffassung von Völkerrecht bewußt, daß Rechtsgleichheit nicht faktische Gleichheit, formale "Gleichheit nicht materielle Gleichheit bedeutet, daß es in der politischen Wirklichkeit große und kleine, starke und schwache Staaten und infolgedessen zahlreiche Abhängigkeitsverhältnisse gibt und daß ein Kleinstaat sich dem Willen einer Großmacht oft genug beugen muß und seine Zugeständnisse auch noch vertraglich anerkennen muß. Diese Auffassung übersieht nicht, daß hier ein echtes Dilemma besteht, ein Auseinanderklaffen von Sein und Sollen, das seine Ursache letztlich in der unvollkommenen Organisation der Völkerrechtsgemeinschaft, in der ungenügenden Möglichkeit der Durchsetzung des Rechts in der internationalen Gemeinschaft hat. Sie kann aber die These von der Gleichberechtigung der Völkerrechtssubjekte nicht aufgeben, ohne ihre weltanschauliche Prämisse aufzugeben: daß jedem Volk das Recht zusteht, seine Geschicke selbst zu bestimmen, bzw. daß diese Selbstbestimmung nur mit seiner Zustimmung einer anderen oder übergeordneten Instanz übertragen werden kann. Denn das Festhalten an der Vorstellung vom Nebeneinander unabhängiger Staaten gibt erst den Maßstab, nach dem die verschiedenen Abhängigkeitsverhältnisse unterschieden und nach dem vor allem Handlungen und Tatbestände als völkerrechtswidrig oder völkerrechtsgemäß beurteilt werden können ${ }^{\mathbf{3 3 5}}$. Besteht man allerdings wie Schmitt nicht auf den genannten Prämissen, geht man wie die Nationalsozialisten von der Überzeugung aus, daß einige Völker aus rassischen oder anderen Gründen dazu berufen sind, die Geschicke rassisch oder anderweitig „minderwertiger" Völker zu bestimmen (- was wohlgemerkt mit dem ganz anderen Problem der noch „unentwickelten "Völker nichts zu tun hat -), dann kann man das bisherige Völkerrecht der Auseinanderreißung von Recht und Wirklichkeit zeihen ${ }^{\mathbf{3} 6}$ und es als „abstrakt-normativistisch “, „lebensfern “ und den konkreten Gegebenheiten nicht gerecht werdend getrost über Bord werfen. Dann kann man auch durch „konkretes Ordnungsdenken" die politische Wirklichkeit

335 Vgl. dazu Bilfinger, „Englische Völkerrechtspolitik, ein Rückblick“, a. a. O., S. 225.

336 Schmitt, „Nationalsozialistisches Rechtsdenken" (DR Jg. 4, 1934, S. 225). 
einfach zum „Recht", das Sein zum Sollen und den politischen Tatbestand der Hegemonie oder Herrschaft eines starken Staates (Reiches) über benachbarte schwächere Staaten zum Rechtsprinzip erheben. Die „völkerrechtliche Großraumordnung" besteht, wie wir sehen werden, dann im Grunde nur darin, die politische Realität Imperialismus dann als Rechtsinstitution anzuerkennen und zu sichern, wenn sie sich für einen geographisch zusammenhängenden Raum als gegeben erweist. Wir werden die Großraumordnung daraufhin zu untersuchen haben, worin der Gerechtigkeitsgehalt dieses „Rechts“ liegen soll.

Die Behauptung, daß die Großraumordnung das bisherige Völkerrecht derart umwälze und seine Staatsrecht und Völkerrecht, „innerstaatlich“ und „zwischenstaatlich " unterscheidende Systematik so grundsätzlich zerstöre, daß sie von diesem Recht aus nicht mehr verstanden und erfaßt werden könne, ist für uns daher nicht stichhaltig. Für uns ist der Großraumbegriff ein „situationsgemäßer", ein politischer Begriff, an den wir mit den bisherigen Begriffen der Völkerrechtswissenschaft herangehen wollen, um über die Rechtsbeziehungen im Großraum Klarheit zu gewinnen, soweit das aus Schmitts skizzenhaften und elastischen Angaben möglich ist.

Rekapitulieren wir: Ein "politisch erwachtes" Volk „strahlt" in die Gebiete benachbarter Völker eine politisch-weltanschauliche Idee aus, die zum beherrschenden Ordnungsprinzip dieses Raumes wird, und schützt diesen Raum gegen raumfremde Interventionen. Ein solches staatlich organisiertes Volk, das sich dieser Ordnungsaufgabe gewachsen zeigt, Garant und Hüter eines derartigen Raumes zu sein, ist als führende Macht ein "Reich". Rechtsbegrifflich, d. h. der Rechtsform nach, ist solch ein Reich ein Staat, denn für die rechtliche Wirklichkeit auch in der Zeit 1939-1945 hatten die führenden Mächte wie z. B. das Deutsche Reich, Japan und die USA eben die rechtliche Gestalt von Staaten und unterschieden sich darin nicht von anderen Staaten. Auch Triepel hat es z. B. nicht für notwendig erachtet, bei der Erfassung und Darstellung der Hegemonie, die für ihn ein „Führungsverhältnis zwischen einem Staat und einem oder mehreren anderen Staaten "337 darstellt, vom Staatsbegriff abzugehen: sein Buch trägt den Titel „Die Hegemonie. Ein Buch von führenden Staaten".

Das Gebiet außerhalb des Staatsgebietes des Reiches - das Gebiet der anderen Völker also - ist der "Großraum". (Rechnet man das „Reichsgebiet" selbst mit zum Großraum, dann muß es heißen: Das Staatsgebiet des Reiches und das Gebiet der anderen Völker sind der "Großraum“, was für unsere Erörterung belanglos ist.) Diese anderen Völker können staatlich organisiert sein oder nicht. Sind sie nicht in eigenen Staaten organisiert, weil sie nicht die Fähigkeit und Kraft dazu besitzen oder ihnen diese Möglichkeit durch eine Großmacht genommen ist, dann kann zwischen dem führenden Staat und einem solchen Volk keine völkerrechtliche Beziehung vorliegen, sie ist staatsrechtlich geregelt. Beispiele dafür sind im nationalsozialistischen Großraum, wie schon gezeigt, das Protektorat Böhmen und Mähren und das Generalgouvernement, um nur zwei Gebilde endgültigen Charak387 Triepel, Die Hegemonie, S. 125. 
ters zu nennen. Sind diese Völker jedoch in eigenen Staaten organisiert, dann liegt zwischen dem Reich und diesen Staaten ein völkerrechtliches Verhältnis vor. Die Stellung dieser Staaten im Großraum, am Maßstab des Völkerrechts gemessen, soll im folgenden untersucht werden.

Die Ausdehnung des Großraumes wird nicht allein durch geographische Gegebenheiten, durch Meere oder andere natürliche Grenzen bestimmt, sondern durch die "Reichweite“, innerhalb deren die beherrschende politische Idee durchgesetzt werden kann, d. h. sie wird praktisch vom Reich bestimmt. Da eine Idee die Qualität des Politischen überhaupt erst durch ihre Position gegen einen bestimmten Gegner erhält ${ }^{338}$, kennt das "politisch erwachte “, die Idee tragende Volk seinen Feind und den Feind der anderen Völker seines Großraumes. Mit anderen Worten: wie das Reich den völlig unbestimmt bleibenden Begriff der verbotenen raumfremden Intervention "definiert, interpretiert und anwendet" (s. o. S. 65), bestimmt es auch den Feind für die anderen Staaten und beraubt sie der freien Entscheidung zwischen Freund und Feind und im gegebenen Falle des jus belli (im Sinne von jus ad bellum). Diese Übertragung des jus belli auf das Reich ist auch noch aus einem anderen Grund notwendig: Wenn der Großraum eine befriedete und von einem Ordnungsprinzip beherrschte Einheit darstellen soll - und gerade auf der Überwindung der pluralistischen Zersplitterung und Unordnung des labilen zwischenstaatlichen Gleichgewichtssystems soll ja die Überlegenheit der stabilen Großraumordnung beruhen -, müssen innerhalb des Großraumes Kriege ausgeschaltet werden. Das Wesen einer politisch existenten Einheit, schreibt Schmitt, bestehe darin, daß innerhalb dieser Einheit die äußerste Gegensätzlichkeit der Freund-Feind-Gruppierung, der bewaffnete Kampf, ausgeschlossen werde ${ }^{\mathbf{3 3 9}} \mathrm{Ob}$ es sich um eine förmliche Übertragung des jus belli handelt, oder sich das Reich die letzte Entscheidung über die Zulässigkeit eines Krieges vorbehält, geht aus Schmitts Darlegungen nicht hervor und ist auch belanglos: im entscheidenden Konfliktsfalle dürfte das Reich jedenfalls darüber entscheiden. Diese „Übertragung“ des jus belli müßte aber im Großraum nicht nur auf den tatsächlich-machtmäßigen Gegebenheiten - der faktischen Überlegenheit des Reiches - beruhen, sondern rechtlich geregelt sein, wenn sich ein Unterschied zum bisherigen zwischenstaatlichen Völkerrecht ergeben soll. Denn das soll ja gerade das Wirklichkeitsnahe und Konkrete des „neuen Völkerrechts" sein, daß in ihm die Abhängigkeitsverhältnisse, die in der bisherigen Völkerrechtsordnung durch die formale Gleichberechtigung "verschleiert" waren (,indirekte Herrschaft"), rechtlich und offen-verantwortlich zutageliegen.

Schmitt hatte sich in seinen früheren Schriften über den Völkerbund gegen den Anspruch von Staaten oder Staatengruppen gewandt, im Namen einer überstaatlichen Ordnung die letzte Entscheidung über die rechtliche Zulässigkeit oder Unzulässigkeit des Krieges an sich zu ziehen, weil durch den diskriminierenden Kriegsbegriff der klassische Kriegsbegriff zerstört werde und der Kampf sich als

338 Schmitt, Großraumordnung, a. a. O., S. $18 \mathrm{ff}$.

339 Schmitt, Der Begriff des Politischen, Hamburg 1936, S. 11. 
Strafsanktion auf der einen und als Verbrechen auf der anderen Seite unter Einbeziehung des Wirtschafts- und Propagandakrieges zu grausamer Totalität ohne Unterscheidung von Kombattanten und Nichtkombattanten steigere. „Der Krieg hat nach überliefertem. Völkerrecht sein Recht, seine Ehre und seine Würde darin, daß der Feind kein Pirat und kein Gangster, sondern ein ,Staat' und ein ,Völkerrechtssubjekt" ist.“340 Jetzt im Großraum wird den Staaten die echte „Völkerrechtspersönlichkeit ersten Ranges" und das jus belli durch das neue Völkerrecht genommen. Der einzige Träger eines selbständigen jus belli im Großraum ist - anscheinend eben nicht nur faktisch, sondern rechtlich - das Reich: die Staaten müssen sich der Entscheidung des Reiches über Krieg und Frieden unterwerfen, oder sie wenden sich - sofern sie die faktische Möglichkeit zur Kriegführung überhaupt behalten - gegen die "völkerrechtliche Großraumordnung" und werden selbst Objekt des jus belli. Stellen sie sich aber auf die Seite eines raumfremden (und damit ideologischen!) Gegners des Reiches, der vom Reich der Verletzung des Interventionsverbotes der Großraumordnung bezichtigt wird, dann führen sie keinen nichtdiskriminierten Staatenkrieg mehr, sie begehen Rechtsbruch, Rebellion, Verrat, Bürgerkrieg und erleben eine Reichsexekution. Damit tritt im Großraum genau das ein, was Schmitt auf universaler Ebene bekämpfen wollte: der totale Krieg.

Ebenso steht es mit dem Recht zur Neutralität, das mit dem jus belli naturgemäß gekoppelt ist. Es ist nicht anzunehmen, daß einem Staat im Großraum das Recht zustände, den Status echter Neutralität einzunehmen, wenn die Intervention einer raumfremden Macht gegen das Reich vorliegt oder das Reich im Namen des Großraums einen Krieg gegen eine raumfremde Großmacht führt ${ }^{341}$. Es bestünde bestenfalls die Pflicht zur Neutralität, wenn das Reich sie fordert. Schmitt hat vor Kriegsausbruch - als es der nationalsozialistischen Außenpolitik darum ging, die nächsten Opfer der Aggression zu isolieren - einen zähen "wissenschaftlichen" Kampf um die Erhaltung echter Neutralität gegenüber dem Anspruch kollektiver Verantwortung und Verteidigung geführt. Er trat für eine Neutralität ein, die nicht nur auf militärische Hilfeleistung, sondern auch auf moralische und wirtschaftliche Diskriminierung eines der Kriegführenden verzichtet. Durch die völkerbundsrechtliche Unterscheidung von gerechten und ungerechten Kriegen sah er den klassischen Neutralitätsbegriff zerstört, die Hegung des Krieges und

340 Schmitt, Die Wendung zum diskriminierenden Kriegsbegriff, S. $40 \mathrm{f}$.

341 Vgl. Freytagh-Loringhoven, „Nichtkriegführung und wohlwollende Neutralität" (ZAkDR 7, 1940), S. 332 : Vollkommene Neutralität sei nur möglich, wenn der betr. Staat nicht einem Großraum angehöre, der in einen Krieg verwickelt sei. G. v. Schmoller („Der völkerrechtliche Status der Vereinigten Staaten nach Inkrafttreten des England-Hilfegesetzes" ZAkDR 8, 1941 , S. 155) sieht zumindest im Status der Nichtkriegführung die der „raumordnungsmäßigen Bindung an einen Kriegführenden" entsprechende Rechtsstellung auf Grund der Erkenntnis, „daß die neue, sich jetzt herausbildende völkerrechtliche Ordnung, der auch der Begriff der Nichtkriegführung angehört, durch das Großraumprinzip bestimmt wird".

Über Neutralität und jus belli im Großraum auch E. R. Huber, „Positionen und Begriffe", a. a. O., S. 37. 
schließlich das Völkerrecht selbst in Gefahr, da es in einem Kriege nur so viel wirkliches Völkerrecht gebe, wie wirklich Neutrale existierten ${ }^{\mathbf{3 4 2}}$. Letztere These sollte sich gerade in ihrer Umkehrung als richtig erweisen: gegenüber dem totalitären nationalsozialistischen Deutschland, das das Völkerrecht und die Neutralität in vielen Fällen mißachtete, gab es eben nur so viel Völkerrecht, wie sich Staaten zu seiner aktiven Verteidigung bereitfanden. Noch 1938 hat sich Schmitt in einer eigenen Arbeit gegen die Behauptung gewandt, „das die Totalität eines staatlich organisierten Volkes die völkerrechtliche Neutralität überhaupt gefährdet oder sogar unmöglich macht, ... indem sie die anderen zu einer unbedingten und totalen Anerkennung der eigenen Ansprüche zwinge". Er argumentierte damals, daß die Totalität eines Staates „eine auf ihn selbst bezogene Angelegenheit ist. Je mehr sich ein Volk ganz auf sich selbst besinnt, erkennt es mit seiner Eigenart auch seine Grenzen, erwacht sein Respekt vor der Eigenart und den Grenzen anderer Völker und entsteht erst die sichere Grundlage für das Verständnis der völkerrechtlichen Neutralität eines Volkes in den Konflikten dritter Völker“"343. In der Großraumtheorie wird nunmehr offenbar, daß die Totalität über Volk und Staat hinausgreift und beansprucht, benachbarten Staaten nicht nur die faktische Möglichkeit, sondern sogar das Recht zur Neutralität zu nehmen.

Die Staaten im Großraum verlieren aber nicht nur Rechte außenpolitischen, sondern auch solche innenpolitischen Handelns: Sowohl die Abweisung raumfremder Interventionen als auch die „Aufstellung und Durchführung" der „für einen solchen Großraum geltenden Grundsätze "344 und die Herstellung und Wahrung einer gewissen Homogenität, deren der Großraum für seine Existenz als politische Einheit bedarf, bedingen Interventionen des Reiches in die Staaten. Das Reich bestimmt als Träger der politischen Idee nicht nur den äußeren, sondern auch den inneren Feind des Großraumes. Kräfte, die der beherrschenden politischen Idee des Großraumes entgegenstehen, Herde raumfremder Ideologien müssen mit Hilfe der Reichs-Intervention ausgemerzt werden, wenn sich der Einzelstaat als dazu nicht willig oder nicht fähig erweist. Die „Ausstrahlung“ der politischen Idee des Reiches muß, zumindest in der Zeit des Aufbaus des Großraumes, bei Widerstand mit handgreiflichen, machtmäßigen Mitteln unterstützt werden. Wie der Begriff der raumfremden Intervention unbestimmt bleibt, bleibt auch das Maß der exlaubten Reichs-Intervention in die raumzugehörigen Staaten unbestimmt. Wenn aber kein verschleiertes Interventionsrecht vorliegen soll, wie es laut Schmitt dem Imperialismus der demokratischen Westmächte mit seinen "indirekten Methoden“ eigen ist, muß die Reichsintervention innerhalb des Großraumes offen und rechtlich festgelegt werden. Das bedeutet, daß der Staat (Nicht-Reich) im Großraum die "Geschlossenheit und Undurchdringlichkeit nach außen, seine ,Impermeabi-

342 Schmitt, Großraumordnung, a. a. O., S. $42 \mathrm{f}$.

${ }^{343}$ Schmitt, „Völkerrechtliche Neutralität und völkische Totalität (1938)" (Positionen und Begriffe, Hamburg 1940, S. 256 f.).

344 Schmitt, Großraumordnung, a. a. O., S. 33. 
lität “"345, und die letzte Entscheidung über seine inneren Geschicke, das Recht der Selbstbestimmung, verliert. Da den Staaten des Großraumes die Entscheidungsrechte über die Selbsterhaltung und Selbstbestimmung dadurch genommen werden, daß die völkerrechtliche Großraumordnung über sie das Reich als Völkerrechtssubjekt ersten Ranges rechtlich institutionalisiert, verlieren sie diese Rechte nicht nur faktisch, sondern de jure. Die Übertragung dieser Entscheidungsrechte an das Reich aber bedeutet, daß unter der Großraumdoktrin die Staaten im Großraum ihre Souveränität, ihre Unabhängigkeit und territoriale Unversehrtheit verlieren ${ }^{346}$, während sie sie unter der Monroe Doctrine behielten.

In seinen Schriften über den Völkerbund hatte Schmitt argumentiert, daß ein Staat diesem Bund das jus belli unter anderem deshalb nicht abtreten könne, ohne damit das Recht zur Wahrung der eigenen Existenz aufzugeben, weil diesem aus heterogenen politischen Einheiten zusammengesetzten Gebilde die nötige "Gemeinschaftssubstanz" fehle. Ebenso stehe es mit dem Verzicht auf das Selbstbestimmungsrecht zugunsten eines solchen heterogenen Gebildes ${ }^{347}$. „Die besten bündischen Einrichtungen und Verfahrensweisen sind nicht nur wertlos, sie sind schädlich und ein Hindernis der dringend notwendigen Neuordnung, wenn sie auf einer nur fiktiven Gemeinschaft aufgebaut sind"348. Unter Gemeinschaftssubstanz eines Bundes ist dabei eine gewisse Gleichartigkeit der Mitglieder ${ }^{\mathbf{3 4 9}} \mathrm{zu}$ verstehen, eine Homogenität, die "meistens in einer nationalen Gleichartigkeit der Bevölkerung“, ihrer „seinsmäßigen Verwandtschaft", bestehe, jedoch „verschiedenen Gebieten des menschlichen Lebens angehören, ... eine religiöse, eine zivilisatorische, eine soziale oder klassenmäßige" sein könne, vor allem aber eine "Gleichartigkeit des politischen Prinzips (Monarchie, Aristokratie oder Demokratie)" aufweisen müsse. Nur das Vorhandensein einer derartigen substantiellen Homogenität mache es „vernünftigerweise möglich, eine Feindschaft auch der Eventualität nach als dauernd ausgeschlossen zu betrachten " ${ }^{350}$, und löse die Kern-

345 Schmitt, Verfassungslehre, München und Leipzig 1928, S. 371; vgl. auch Begriff des Politischen, a. a. O., S. 29.

346 Vgl. Schmitt, „Neutralität und Neutralisierungen (1939) “ (Positionen und Begriffe, a.a.O., S. 271 ff.), S. 285 : „Staatliche Selbständigkeit und Unabhängigkeit bewähren sich darin, daß der Staat aus eigener Entscheidung und auf eigene Gefahr Krieg führt oder nicht führt, d. h. im Kriege Dritter neutral bleibt. “ Verfassungslehre, a. a. O., S. 364: „Das eben heißt, souverän“, daß nicht ein Fremder über die politische Existenz entscheidet."

Zur Beseitigung der Souveränität vgl. Waldemar Ernst, „Das Reich, der Südosten und ein neues Völkerrecht“ (Reichsverwaltungsblatt 61, 1940, S. 200); Hans Frank, „Das Recht und die europäische Neuordnung" (DR 12, 1942, S. 994); Ulrich Scheuner, „Der Bau des Reiches und seine politischen Lebenskräfte" (a.a. O., S. 1171); ferner die völkischen Theorien von Daitz und Höhn; Ferner P. Herre, Deutschland und die europäische Ordnung, S. 189.

347 Schmitt, diskriminierender Kriegsbegriff, a. a. O., S. 53; vgl. auch Schmitts Lehre vom Bunde in: Verfassungslehre, a. a. O., S. $370 \mathrm{f}$. und $377 \mathrm{f}$.

348 Schmitt, diskriminierender Kriegsbegriff, a. a. O., S. 53.

349 Schmitt, Die Kernfrage des Völkerbundes, Berlin 1926, S. 63.

350 Schmitt, Verfassungslehre, a. a. O., S. $376 \mathrm{f}$. 
frage jedes Bundes, die Garantie der Existenz seiner Mitglieder ${ }^{351}$ : In einem Kreise von homogenen Partnern gebe ein Staat mit dem Verzicht auf sein jus belli nicht zugleich seine politische Existenz auf, da er auf dieses Recht nur zugunsten einer Gemeinschaft von solchen Staaten verzichte, denen gegenüber die Möglichkeit der Feindschaft ausgeschlossen sei. Ebenso sei die Zulassung einer Intervention unter Durchbrechung des Prinzips der Selbstbestimmung keine seinsmäßig fremde Einmischung und gefährde folglich die eigene Existenz nicht. Der Ausschluß von Konflikten hängt aber nach Schmitt eben „nicht einfach vom guten Willen der Menschen $a b$ ". Eine geistig-willensmäßige Homogenität genügt Schmitt anscheinend nicht: „Der beste Wille ist ohnmächtig gegenüber der konkreten Wirklichkeit verschieden gearteter Völker und kollidierender Interessen und Überzeugungen, deren seinsmäßige Besonderheiten im Staat ihre politische Form findet“"352. Deshalb könne der mögliche Konflikt „nicht durch irgendwelche Abmachungen, Wünsche und Beschwörungen " ausgeschlossen werden, dieser Weg "wäre leer und trügerisch, wenn nicht betrügerisch, so lange die seinsmäßige Gleichartigkeit und Verwandtschaft fehlt" ${ }^{353}$.

Trotz der Unbestimmtheit von Schmitts Homogenitätsbegriff läßt sich behaupten, daß im nationalsozialistischen „europäischen Großraum“, wie aus der vorangegangenen Darstellung der politischen Realitäten hervorgeht, die substantielle Homogenität, die "Gemeinschaftssubstanz", nie mehr als eine Fiktion hätte sein können. Nicht allein wegen des Fehlens der nationalen Homogenität: für Schmitt erfüllte die „nationale und völkische Verwandtschaft" der europäischen Völker also das, was die orthodox-völkische Richtung die gemeinsame „biologische Substanz" des europäischen Großraumes nannte - durchaus die Voraussetzung der für einen „echten " europäischen Bund erforderlichen Homogenität ${ }^{354}$. Wir meinen vielmehr die bei weitem wichtigere politisch-willensmäßige Homogenität, die im nationalsozialistischen Großraum nach Lage der Dinge eben nicht in einer interessenausgleichenden Einigung, sondern nur in der unmöglich zu realisierenden, bedingungslosen Annahme der nationalsozialistischen Forderungen hätte bestehen können. Diese „Homogenität" hätte nur durch die Unterwerfung unter einen Willen verwirklicht werden können und die Aufrechterhaltung dieser gewaltsam erzwungenen "Homogenität" laufende Interventionen des Reiches als eines für die anderen Staaten „heterogenen“ Partners bedeutet. Es fehlte die ideenmäßige Einheit, die nur durch die Rezeption der nationalsozialistischen Ideen seitens der anderen Völker hätte hergestellt werden können, wobei sich diese Völker aber wie z. B. die nach diesen Ideen „rassisch-minderwertigen“ Slawen - nicht einmal 351 Schmitt, „Die siebente Wandlung des Genfer Völkerbundes (1936)“ (Positionen, a. a.O., S. $210 \mathrm{ff})$., S. 210 .

352 Schmitt, Verfassungslehre, a. a. O., S. 377.

353 a. a. O., S. 379 ; vgl. Schmitts Ausführungen über „arteigenes Rechtsdenken“ am unten, Anm. 379, angegebenen Ort. Im internationalen Bereich unterläßt es Schmitt dagegen, rassische und völkische Gemeinsamkeiten zu den alleinigen Homogenitätskriterien für eine gemeinsame Rechtsordnung zu machen.

354 Schmitt, „Die siebente Wandlung des Genfer Völkerbundes“ (a. a. O., S. 213). 
dadurch die Sicherung ihrer Existenz hätten erkaufen können. Es fehlte eben die Garantie der Existenz der anderen Völker, die nur in der Anerkennung der gleichen Stellung vor dem Recht, in einer "Homogenität" der gleicherweise Berechtigten und Verpflichteten (die nach Schmitt augenscheinlich eine „unkonkrete “, nicht substantielle, sondern abstrakte Homogenität darstellt) bestehen kann. Diese Garantie fehlte, weil gerade das mächtigste Glied des Großraumes die Gleichberechtigung verwarf, auf Unterwerfung und Verdrängung "minderwertiger" Völker ausging und sich durch diesen seinen Imperialismus zum existentiellen Feind dieser Völker machte. Gerade die „formelle" Homogenität der gegenseitigen Anerkennung der Gleichberechtigung aller selbständigen Staaten war - bei aller Heterogenität der Nationalitäten, Staatsformen und Regierungssysteme - im „amerikanischen Großraum" der Monroe Doctrine von 1823 vorhanden und machte die gemeinsame Anti-Position gegen den „heterogenen " äußeren Feind aus: gegen die Heilige Allianz, die die Unabhängigkeit der amerikanischen Staaten und damit die „formelle" Homogenität des amerikanischen Raumes bedrohte.

Was aber bedeutet der Verlust der Souveränitätsrechte, des jus belli und des Rechts der Selbstbestimmung zugunsten des Reiches für die Staaten im heterogenen Großraum? Schmitt selbst hat diese Frage in seinen Schriften beantwortet:

„Solange ein Volk in der Sphäre des Politischen existiert, muß es, wenn auch nur für den extremsten Fall - über dessen Vorliegen es aber selbst entscheidet die Unterscheidung von Freund und Feind selber durch eigene Entscheidung und auf eigene Gefahr bestimmen. Darin liegt das Wesen seiner politischen Existenz ${ }^{355}$." Für ein staatlich organisiertes Volk aber ist „die reale Möglichkeit, im gegebenen Fall kraft eigener Entscheidung den Feind zu bestimmen und ihn zu bekämpfen" das jus belli ${ }^{356}$. "Ein Staat, der auf sein Recht zur Selbstverteidigung endgültig verzichtet oder dieses Recht einem anderen Staat oder einer anderen Instanz überläßt, hat keine eigene politische Existenz. Es kommt hier nicht darauf an, wie man die verschiedenen ,halbsouveränen Zwischengebilde bezeichnet und ob es aus verschiedenartigen Rücksichten üblich ist, hier immer noch von Staat zu sprechen. Jedenfalls gehört es zur politischen Existenz eines Staates, daß er die Möglichkeit der eigenen Entscheidung über die Verteidigung seiner eigenen Existenz behält. “357

Da im heterogenen Großraum die Auffassung von Freund und Feind verschieden sein kann, bedeutet die Aufgabe des jus belli der Staaten zugunsten des Reichs nicht nur den Verlust ihrer Souveränität, Unabhängigkeit und territorialen Unversehrtheit, sondern nach Schmitts Thesen zugleich ihrer politischen Existenz schlechthin: Im Großraum gibt es nur noch einen souveränen Staat, das Reich, in dessen Händen allein die letzte Entscheidung über die politische Existenz der anderen Völker des Großraumes liegt. Nur das Reich existiert in der "Sphäre des Politischen", die "Staaten" mögen als Verwaltungseinheiten mit gewissen autonomen Rechten im Großraum bestehen bleiben.

355 Schmitt, Der Begriff des Politischen, a. a. O., S. 32.

356 a. a. O., S. 28.

357 Schmitt, Verfassungslehre, a. a. O., S. 365. 
Da allein die Reiche Träger und „Kreatoren“ des „neuen Völkerrechts" sein sollen, können nur die Beziehungen zwischen den Großräumen, d. h. zwischen den Reichen als deren Willensträger, nach bestehender Auffassung völkerrechtlich sein. Den ihrer rechtlichen Unabhängigkeit und Souveränität beraubten „Völkerrechtssubjekten zweiten Ranges" muß die Qualität echter Völkerrechtspersönlichkeit im Sinne einer Stellung als formal gleichberechtigte, einander nicht über- und untergeordnete "Rechtsgenossen " abgesprochen werden. Sie werden sogar - z. B. bei einer Abgrenzung der Großräume zwischen den Reichen - Objekte der Abmachungen zwischen den Völkerrechtssubjekten ersten Ranges. Die Rechtsbeziehungen innerhalb des Großraumes können daher nicht zwischen gleichberechtigten Völkerrechtssubjekten vertraglich geregelt, nicht völkerrechtlich sein, mögen die „Staaten “ als Verwaltungseinheiten vorbehaltlich der Zustimmung des Reiches auch untereinander noch technische Vereinbarungen über die Zusammenarbeit treffen können. Wie sehr auch die Terminologie der rechtlichen Ordnung der Beziehungen zwischen dem Souveränitätsträger Reich und den nichtsouveränen „Staaten“ der Begriffswelt des Völkerrechts entnommen sein mag, sie ist (bundes-) staatsrechtlicher Natur. Wenn innerhalb des Großraumes nicht die gleiche, verschleierte, unsichtbare, „indirekte Herrschaft" 358 bestehen soll, wie sie Schmitt dem Imperialismus der Demokratien vorwirft - also keine zwischenstaatliche, auf politischfaktischen, nicht-juristischen Voraussetzungen beruhende, Hegemonie -, sondern die Stellung des Reiches in einer sichtbaren, rechtlich-meßbaren, "direkten" Überordnung besteht, liegt die Errichtung eines „Überstaates" vor, und die Raumhoheit des Reiches ist nichts anderes als die erweiterte staatliche Gebietshoheit einer Großmacht über die Gebiete ihrer Nachbarvölker.

Betrachten wir das Ganze nochmals von der Territorialordnung her. Während bisher die Großmächte durch Interventionsansprüche, Abgrenzung von Interessensphären usw. über ihr Staatsgebiet hinaus wirkten, ohne daß das staatsbezogene Völkerrecht, dessen "Raumbild ... an dem Begriff ,Staatsgebiet' ausgerichtet war", diese Wirkung territorialrechtlich erfaßte und zum Ausdruck brachte, nimmt das Reich nunmehr eine „Raumhoheit“ über das durch eigene Interventionen vor fremden Interventionen bewahrte Territorium der Großraum-Interessensphäre in Anspruch, eine Hoheit, die laut Schmitt bisher schon zur "Wirklichkeit des Völkerrechts" gehörte wie die Reiche selbst ${ }^{359}$. Sie wird durch das Reich über das Staatsgebiet der anderen, benachbarten Staaten des Großraumes ausgeübt. Worin liegt aber das Wesen der Raumhoheit und der Unterschied zwischen ihr und der staatlichen Gebietshoheit, in welchem Verhältnis stehen sie zueinander, welche Hoheit geht der anderen rechtlich vor? Schmitt schweigt darüber, und andere Staats- und Völkerrechtler im Dritten Reich, wie z. B. Klein, umgehen diese Fragestellung, indem sie sie als "falsch" bezeichnen, weil es sich um zwei nicht vergleichbare Größen handele:

358 Über das Wesen der ,,indirekten Gewalt" s. Schmitt in: „Der Leviathan in der Staatslehre des Thomas Hobbes", Hamburg 1938, S. 117.

359 Schmitt, Großraumordnung, a. a. O., S. $51 \mathrm{f}$. 
„Raumhoheit als Ausdruck großräumigen Denkens ist gegenüber der überkommenen Gebietshoheit als einem rechtstechnischen Begriff spezifisch staatlich-kleinräumigen Denkens nicht ein Mehr oder ein Weniger, sondern ein aliud. Das folgt allein schon daraus, daß ein Staat sowohl Gebietshoheit (nämlich innerhalb seines engeren, Staatsgebietes') als auch Raumhoheit (nämlich innerhalb seines weiteren, das ,Staatsgebiet' mit umfassenden Lebens- und Wirtschaftsraumes) haben kann, daß also anders ausgedrückt Gebiets- und Raumhoheit gleichzeitig in der Hand ein und desselben Subjekts (Trägers) und sogar hinsichtlich desselben Objektes (Territoriums) vereint sein können. " ${ }^{\mathbf{3 6 0}}$.

Wenn aber die Raumhoheit des Reiches $u$. a. das Recht auf Intervention in die Gebiete der anderen Großraum-Staaten einschließt und die Gebietshoheit dieser Staaten im Konfliktsfall nicht genügt, sie rechtlich abzuweisen, muß die Raumhoheit der Gebietshoheit übergeordnet sein. Im umgekehrten Falle wäre jegliche „Ausstrahlung“ und Einwirkung des Reiches auf die Staaten und die Bekämpfung raumfremder Interventionen in ihnen ausgeschlossen. Steht aber die Raumhoheit rechtlich über der Gebietshoheit, dann liegt das vor, was Klein selbst beschreibt: „Wäre aber die Raumhoheit . . . nur' eine stärkere Gebietshoheit, dann gäbe es keine echten völkerrechtlichen Großraumordnungen, da alsdann . . . nur Mammutstaatsgebilde mit einem mehr oder weniger großen Kranz von versklavten Tributärstaaten vorhanden wären und da alsdann jeder Großraum nur ein vergrößerter Kleinraum wäre" $\mathbf{3 6 1}$.

Sobald man daher den Maßstab des Völkerrechts an Schmitts Großraumordnung legt, kommt man - sowohl was die hoheitlich-organisatorische als auch was die territorial-ordnungsmäßige Seite angeht - zu dem Ergebnis, daß sie die politische Unabhängigkeit und territoriale Unversehrtheit der Staaten im Großraum aufhebt und die Herrschaft ${ }^{\mathbf{3 6 2}}$ des Reiches über die Staaten und ihr Gebiet etabliert. Um

360 Friedrich Klein, „Zur Stellung des Generalgouvernements in der Verfassung des Großdeutschen Reiches", a. a. O., S. 259, Anm. 126 (Hervorhebungen im Original).

361 a. a. O.

362 Der Begriff Herrschaft wird hier bewußt in Triepels Sinn als „Fähigkeit eines Willens, andere Willen durch die Aussicht auf äußeren Zwang zu motivieren " benutzt (Triepel, a.a.O., S. 141), da die Hegemonie (als zwischen bloßem Einfluß und Herrschaft stehend S. 141) „sich immer auf eine Anerkennung des geführten Staates" stützend (s. 140), eine soziale Beziehung von grundsätzlich sekundärer Natur (S. 129), "die Ausgestaltung oder Modifikation" eines bereits vorhandenen rechtlichen Grundverhältnisses, wie z. B. Bündnis, Bundesstaat, ist. Soweit sie "juridifiziert" wird wie in der Großraumordnung, bleibt sie nach Triepel „überwiegend im Völkerrechtlichen verfangen" (S. 143). Tritt sie dagegen bei einem föderalis tis ch organisierten Staatswesen - denn ohne „einen gewissen Grad von Föderalismus ... ohne das Bündische im Gesamtorganismus entbehrt sie jeden Sinnes" (S. 135) - in die Sphäre des Staatsrechts, kann sie nux in der Form der „indirekten Hegemonie“ bestehen (S. 143). Eben diese soll ja aber in der Großraumordnung durch Juridifizierung beseitigt werden, so da $B$ nur noch die offene Herrschaft bleibt. Das Festhalten Triepels am Staatsbegriff und dem Dualismus von Völkerrecht und Staatsrecht bei der Darstellung der Hegemonie trägt ihm seitens Schmitt eine scharfe Kritik ein. (Vgl. Schmitt, „Führung und Hegemonie“, a. a. O.).

$\mathrm{Da}$ das Reich im Großraum nicht nur Führung im Sinne Triepel'scher „indirekter Gewalt", sondern auch Herrschaft ausüben werde, s. E. R. Huber, „Herrschaft und Führung“ (DR 41, II, 1941, S. 2023f.) 
diese politisch-psychologisch bedeutsame Tatsache rechtlich nicht offenbar werden zu lassen, mußte Schmitt die Konsequenz ziehen und mit der Systematik des auf gleichberechtigten Staaten aufbauenden Völkerrechts mit seiner Unterscheidung von Staatsrecht und Völkerrecht brechen. Man muß sich aber darüber im klaren sein, daß damit nicht nur eine „Systematik“ zerstört wird, sondern das Völkerrecht schlechthin: „Der Grundsatz der Staatengleichheit ...", schrieb Bilfinger 1934, „bedeutet mehr als lediglich ein Rechtsprinzip der völkerrechtlichen Ordnung: Er ist der vollkommenste Ausdruck des Sinnes und Inhaltes dieser Ordnung, er ist maßgebend für das Verhältnis von Recht und Macht der Staaten untereinander. Wer den Gleichheitssatz in der Lehre und Wissenschaft des Völkerrechts angreift, gleichviel mit welcher Begründung, muß sich darüber klar sein, daß er damit wider das Völkerrecht streitet“. Die Hegemonie kann „wegen ihrer Unvereinbarkeit mit der völkerrechtlichen Grundanschauung nicht im eigentlichen Sinne eine völkerrechtliche Institution sein “363. Sie dennoch zu einer „völkerrechtlichen " Institution zu erklären, um damit die dem nationalsozialistischen Imperialismus in Europa adäquate „Rechts"-theorie zu schaffen, ist das Ziel von Schmitts "völkerrechtlicher Großraumordnung“364.

Abgesehen davon, daß diese Großraumordnung inhaltlich selbst kein Völkerrecht darstellt, läßt sie sich auch durch kein völkerrechtliches Prinzip rechtfertigen : Der Versuch, die „Raumhoheit" des Reiches über das Gebiet der anderen Staaten etwa durch das Prinzip der Kontiguität, das die Ausübung von Sonderrechten (exclusive rights) über ein an das Staatsgebiet angrenzendes Gebiet rechtfertigen will, zu erklären und völkerrechtlich zu begründen, scheidet schon deshalb aus, weil dieses Prinzip nur einen Anspruch bezüglich staatenlosen Gebietes (wie z. B. des Kontinentalsockels) im Auge hat; obwohl es mit der Großraumdoktrin gemeinsame Elemente aufweist: die Konzeption der räumlichen Einheit, die Ersetzung der "leeren ", neutralen Raumvorstellung durch die eines recht-schaffenden Leistungsraumes, die Frontstellung gegen den Rechtspositivismus und die Verwischung der Grenzen zwischen Recht und Politik ${ }^{365}$.

Mit der Leugnung des bestehenden Völkerrechts und der Aufstellung rechtspolitischer Forderungen und Wunschbilder und einseitiger Anmaßung von Sonderrechten wird noch kein neues Völkerrecht geschaffen, das nun einmal erst durch die Willensübereinstimmung der Mitglieder der Völkerrechtsgemeinschaft, durch die Zustimmung der anderen betroffenen Staten zu wirklichem, als geltend und bindend angesehenen objektivem Recht wird. Wir wollen aber beim Nachweis, daß die NS-Großraumordnung kein Völker-Recht sein kann, nicht im Rechtspositivismus stecken bleiben.

363 Carl Bilfinger, "Gleichheit und Gleichberechtigung der Staaten" (NS-Handbuch für Recht und Gesetzgebung, herausgegeben von Hans Frank, 2. Aufl., München 1935, S. 117, S. 127). 364 Die Aufstellung dieses Zieles war unumgänglich, wenn das Reich als „politische bzw. soziale Wirklichkeit" juristisch erfaßt werden sollte.

365 Vgl. Hans Kelsen, „Contiguity as a title to territorial sovereignty“ (Rechtsfragen der Internationalen Ordnung. Festschrift für Hans Wehberg, Frankfurt a. M. 1956, S. 204f.) 
Die Erhaltung eines auf gleichberechtigten und unabhängigen souveränen Staaten aufbauenden Völkerrechts ist nicht Selbstzweck, es soll dem Leben und der Entwicklung der in Staaten organisierten Völker, letztlich dem Einzelmenschen dienen. Die Durchbrechung des Prinzips der rechtlichen Gleichheit und die rechtliche Überordnung eines „Reiches“ über andere Völker in einem Großraum wäre daher - wenn wir einmal von der gewaltsamen Erreichung dieser Überordnung absehen - an sich noch nicht zu verwerfen und gegenüber der ,alten "Völkerrechtsordnung abzulehnen, nämlich dann nicht, wenn sie allen beteiligten Völkern größere Sicherheit und Förderung ihrer Wohlfahrt bringen könnte. Das läuft auf eine Untersuchung der Frage hinaus, ob die Großraumordnung gegenüber der zwischenstaatlichen Völkerrechtsordnung eine überlegene sittliche und rechtsbegründende Kraft aufweisen kann und worin diese besteht. Vom Standpunkt des nationalsozialistischen „konkreten" Rechts- und Ordnungsdenkens aus wies „das bisherige zwischenstaatliche Völkerrecht“ den Mangel auf, „seine wirkliche Garantie nicht in einem inhaltlichen Gerechtigkeitsgedanken oder einem sachlichen Verteilungsprinzip“ zu finden, sondern lediglich ,in einem Gleichgewicht der Staaten " 366 . Eine gerechte Ordnung im internationalen Leben müßte nach dieser Auffassung nicht unbedingt in einer formalen Gleichberechtigung unabhängiger staatlich-souveräner Völker (die in der Welt der Tatsachen jedoch materielle Ungerechtigkeit bedeute) bestehen, sondern könnte „lebensnaher" im Sinne materieller, sachlicher Gleichberechtigung verstanden werden. Angesichts der tatsächlichen Verschiedenheit der Staaten oder Völker kann materielle Gleichheit dann aber nicht als eine absolute, sondern muß als eine relative Gleichheit aufgefaßt werden mit dem Ziel, nicht jedem das Gleiche, sondern „jedem das Seine“ zu geben. „Relative Gleichheit . . . ist verhältnismäßig gestuftes Einflußrecht und verhältnismäßige Pflicht zu Leistungen nach der Leistungsfähigkeit"367. In einer auf unabhängigen Staaten beruhenden Völkerrechtsordnung fehlt aber sowohl der gemeinsame Maßstab für die „Verhältnismäßigkeit“ als auch die übergeordnete und mit Zwangsgewalt ausgestattete Machtinstanz, die ihn festlegen, anwenden und durchsetzen könnte. Bilfinger z. B. erklärt es aber „im Rahmen konkreter partikulärer Staatenverbindungen" für "möglich, zu Maßstäben und Methoden jenes Ausgleichs zu gelangen“, und zwar um so eher, je mehr sie "das Element der Hegemonie in sich" tragen ${ }^{368}$ :

„Der Gedanke der Führung durch eine Vormacht . . . gehört in die Sphäre der relativen Gleichheit. Die bündische Hegemonie ist eine Übergangsform . . . zwischen Völkerrecht und Staatsrecht. Sie zeigt, wie beim Vorhandensein einer zentralen Kraftquelle, die vergleichbar ist der Macht des Staates, die gerechte Gleichbehandlung realisiert werden kann. Denn hier ist das gegeben, was sonst im zwischenstaatlichen Kreis fehlt, nämlich eine Stelle, die über den Maßstab der Gleichheit entscheidet ${ }^{369 . " ~}$

366 Schmitt, Großraumordnung, a. a. O., S. 42.

367 Bilfinger, „Zum Problem der Staatengleichheit im Völkerrecht", a. a. O., S. 494.

368 a. a. O., S. 482 (Hervorhebung im Original).

369 a. a. O., S. 496 (Hervorhebung im Original). 
Im Großraum ist nunmehr diese „zentrale Kraftquelle“ im Reich gegeben, das mit den Völkern seines Großraumes sogar in engeren als zwischenstaatlichen Beziehungen steht und sich und diesen Völkern im Interesse der Wohlfahrt des Ganzen „jedem das Seine“ zuteilen kann. „Der rechtliche Gehalt der Großraumordnung beruht nach innen . . . darin, daß hier nicht bloß äußere Zwangsgewalt gegenüber Unterworfenen wirksam ist, sondern daß ein führendes Volk anderen ihm zugeordneten Völkern Entwicklungsmöglichkeiten, Förderung, Beistand und Schutz gewährt"370. Denn die Grundlage zumindest des den europäischen Großraum beherrschenden Ordnungsprinzips soll ja „die Achtung jedes Volkstums“, die "Achtung jedes Volkes als einer durch Art und Ursprung, Blut und Boden bestimmten Lebenswirklichkeit" sein ${ }^{371}$. Diese distributive Gerechtigkeit soll aber konkret geordnet sein, d. h. an Stelle des Ausgleichs von Interessengegensätzen durch formale Rechtsregeln soll eine konkrete Ordnung der Sachgemäßheit treten, denn der Großraum ist ja auch wiederum nicht Selbstzweck, sondern gemeinsamer Lebensraum, „Bereich menschlicher Planung, Organisation und Aktivität "372, insbesondere gemeinsamer Wirtschafts- und Leistungsraum, der dem gemeinsamen Wohl der in ihm zusammengefaßten Völker dient. Jedem Volk soll im Großraum die Stellung zugewiesen werden, an der es auf Grund seiner Fähigkeit und Leistung dem Ganzen am besten dient. „Der Grundsatz ,Jedem das Seine' führt . . . zu einer sinnvollen und gerechten Einordnung. " Das bedeutet, daß die Völker im Großraum dem Reich nicht in gleicher Weise zu- und untergeordnet sind, sondern eine Skala von „konkreten " individuellen Zuordnungsverhältnissen existiert ${ }^{\mathbf{3 7 3}}$.

Es fragt sich, inwieweit eine derartige individualisierte und sachgemäße Regelung einmaliger konkreter Situationen, bei der die Sachgemäßheit allein dem Urteil des Reiches überlassen bleibt, d. h. bei der das Reich den anderen Völkern auf Grund „konkreten Ordnungsdenkens" das ihnen Zustehende zuweist, überhaupt noch „Recht" ist und nicht in das entgegengesetzte Extrem der Willkür umschlägt. Der Bereich der Regelung durch Recht liegt zwischen „Willkür", d. h. der verschiedenen Behandlung :leichartiger Zustände ohne eine allgemeine Norm, einerseits und der Regelung durch absolute Sachgemäßheit, d. h. der ebenfalls ohne allgemeine Norm erfolgenden Entscheidung des einzelnen Falles gemäß dem Erfordernis des individuellen Sachverhalts, andererseits. Beides sucht Recht durch eine gewisse Gleichheit vor dem Gesetz zu vermeiden.

„Das Recht setzt ... ein gewisses Minimum formaler Gleichheit voraus. Geschaffen wird diese in einer Welt widerstreitender Interessen durch Kom-

370 E. R. Huber, „Positionen und Begriffe“, a. a. O., S. 41.

371 Schmitt, Großraumordnung, a. a. O., S. 37, S. 49. Über die „anti-imperialistische Grundhaltung des nationalsozialistischen Völkerrechtsdenkens", s. ferner Walz, "Das Verhältnis von Völkerrecht und staatlichem Recht nach nationalsozialistischer Auffassung ", ZfVR, Jg. 18, 1934, S. 147 f., derselbe, „Nationalsozialismus und Völkerrecht“ (Völkerbund und Völkerrecht), Jg. 1, 1934/35, S. 475.

372 Schmitt, „Raum und Großraum im Völkerrecht“, a. a. O., S. 149.

373 H. H. Dietze, „Vom deutschen Verfassungsrecht zum europäischen Verfassungsrecht" (DR 11, I, 1941, S. 809 f.). 
promiß: Im Wege gegenseitigen Nachgebens wird ein Durchschnittszustand des ,Gleichgewichts' hergestellt, der den Ausgleich dieser Interessen darstellt, sei es, daß dieser Ausgleich vorgenommen wird durch die Rechtsgenossen selbst (,Autonomie' der Rechtssetzung), sei es, daß sie gleicherweise einer ihn vornehmenden Gewalt unterworfen sind: Recht darf nicht im Sinne des Aufklärungs-Naturrechts als auf liberal-demokratische Organisationsformen beschränkt angesehen werden, sondern ist durchaus auch mit , autokratischer ${ }^{6}$ Rechtssetzung vereinbar, sofern nur eine die formale Gleichheit der Rechtsunterworfenen garantierende Organisation vorhanden ist. Im Völkerrecht allerdings ist, so lange diese letztere Alternative einer den ,Rechtsgenossen' übergeordneten Macht nicht gegeben ist, ein gewisses Minimum von Autonomie der Rechtssetzung Voraussetzung seiner Existenz als ,echten Rechts' ${ }^{\text {874. }}$."

Im Großraum ist diese „übergeordnete Macht“ zwar gegeben, aber die Völker sind ihr nicht gleichermaßen untergeordnet und daher, wie bereits ausgeführt, keine echten "Rechtsgenossen " mehr. Deshalb kann hier kein "echtes Recht" im Sinne einer sittlich begründeten, ausgleichenden Ordnung vorliegen, sondern nur im Sinne einer äußeren Ordnung, eines technisch reibungslosen Funktionierens ${ }^{375}$. Wenn das, was das Reich anderen Völkern als sachgemäß oktroyiert, „Recht“ ist, kann schon deshalb kein „echtes Recht" vorliegen, weil nicht mehr die Möglichkeit besteht, die Handlungen des Reiches im gegebenen Fall als Rechtsbruch zu kennzeichnen und diesbezüglich Unrechtstatbestände festzustellen. Durchbricht das Reich das von ihm gesetzte Ordnungsprinzip der „Achtung anderer Völker" und setzt Maßnahmen durch, die die Existenz eines anderen Volkes im Großraum bedrohen, welche rechtliche Handhabe hat dieses Volk nunmehr überhaupt dagegen, da ein von allen gleichermaßen anzuerkennendes übergeordnetes Recht fehlt? Handlungen, die nach dem „alten" zwischenstaatlichen Völkerrecht vor aller Welt als Unrecht kenntlich waren, sind nunmehr positivrechtlich nicht mehr erfaßbar. Gab es vorher wenigstens noch Schranken des Rechtes gegen die Verletzung von Interessen oder die Unterdrückung eines Staates durch einen anderen, über die sich ein faktisch starker Staat zwar hinwegsetzen konnte - doch nur, indem er vor den anderen Mitgliedern der Völkerrechtsgemeinschaft das Odium des Rechtsbrechers auf sich nahm -, so sind diese Schranken innerhalb des Großraumes für das Reich durch die „völkerrechtliche Großraumordnung" beseitigt und der Willkür seitens des Reiches Tür und Tor geöffnet.

Konnte innerhalb der zwischenstaatlichen Völkerrechtsordnung einem Staat der unter Brechung des Völkerrechts seine Nachbarstaaten zu unterdrücken suchte, durch

$\overline{374}$ Eduard Bristler (Pseudonym für John H. Herz), Die Völkerrechtslehre des Nationalsozialismus, Zürich 1938, S. 197, bei der Erörterung des Erkenntnisgehalts der nationalsozialistischen Völkerrechtslehre (Hervorheb. v. Verf.). Über die Forderung der nationalsozialistischen Völkerrechtslehre nach materieller Gleichheit s. auch a. a. O., S. $77 \mathrm{ff}$.

375 Kein anderer als Roland Freisler hat darüber selbst das Urteil gesprochen, wenn es auch gegen England gerichtet war: „Das aber kann kein Recht sein! Ein Zustand, in dem der Nutznießer zugleich der Gendarm seiner Ordnung und der Richter über die Zwistigkeiten innerhalb des von ihm beherrschten Großraumes ist; das kann kein Recht sein..." (R. Freisler, "Zwischenstaatliche Zusammenarbeit der Rechtswahrer. Rede auf der Internationalen Juriienbesprechung in Berlin, April 1941" (DR 11, I, 1941, S. 901). 
Ausbalanzierung der Macht Einhalt geboten werden, indem sich eine genügende Zahl anderer Staaten in Willensübereinstimmung mit dem direkt betroffenen dem Rechtsbrecher entgegenstellten oder - soweit völkerrechtlich vereinbart - kollektive Maßnahmen gegen ihn eingeleitet wurden, kann ein Machtausgleich innerhalb des Großraumes nicht mehr erfolgen. Einmal wäre die Auflehnung der Großraumvölker gegen das Reich rechtlich ein Bruch der „völkerrechtlichen Großraumordnung ", zum anderen ist sie faktisch durch die Überlegenheit des Reiches über die Gesamtheit der anderen Großraumvölker, die eine Voraussetzung der Großraumbildung überhaupt ist, unmöglich. Denn diese Überlegenheit kann nicht mehr durch das Gegengewicht „raumfremder" Macht aufgewogen werden, ohne das „neue Völkerrecht“ zu brechen, weil die Völker des Großraumes als „Völkerrechtssubjekte 2. Ranges" nicht mehr die Möglichkeit haben, mit „raumfremden “ Staaten oder Großmächten Allianzen gegen einen „raumeigenen " Partner, geschweige denn gegen das Reich, einzugehen und fremde Großmächte durch das Nichtinterventionsprinzip rechtlich am Eingreifen gehindert sind oder sich als „Reiche" anderer Großräume im eigenen Interesse an das gegenseitige Interventionsverbot halten. Die einzige reale Garantie des „bisherigen "Völkerrechts, die eben „nur“ im Gleichgewichtssystem der Mächte lag - dessen immanente Fehler das System der kollektiven Sicherheit durch die Organisation eines „automatischen " Übergewichts gegen den Angreifer zu beheben suchte -, wird durch die Großraumordnung beseitigt. Die Großraumtheorie läuft auf die Aufteilung der Welt unter einige Großmächte hinaus, bei der die Mittel- und Kleinstaaten völlig entmündigt werden. Das Interventionsverbot dient dabei nur dem Zweck - und hierin liegt abermals ein eklatanter Gegensatz zur Monroe Doctrine -, die Vorherrschaft seines Proklamators über den von ihm „beschützten" Raum zu sichern. Schmitts „völkerrechtlicher Großraumordnung" als der dem deutschen Imperialismus in Europa adäquaten „Rechts“-theorie muß daher eine dem zwischenstaatlichen Völkerrecht überlegene sittliche rechtsbegründende Kraft abgesprochen werden.

Gerade in der Übereinstimmung mit den Zielen und theoretischen Grundanschauungen des Nationalsozialismus liegt der Hauptgrund für die Verneinung der Rechtsqualität der Großraumdoktrin. Man muß sich darüber im klaren sein, daß - wie die außenpolitischen Zielsetzungen des Nationalsozialismus nur gegen das Völkerrecht $\mathrm{zu}$ verwirklichen waren - auch seine theoretischen Grundlagen bei logischer Folgerung von vornherein zur Verneinung eines allgemeinen Völkerrechts führen müssen.

Schmitts Großraumtheorie erweist sich hierin - wenn man einmal von den rein völkischen Theorien absieht, die nicht mehr zur Völkerrechtswissenschaft gerechnet werden können - als die Krönung der nationalsozialistischen Völkerrechtstheorie überhaupt, die nunmehr mit dem machtpolitischen Aufschwung des Deutschen Reiches in Europa die aus opportunistischen Gründen beibehaltene Bejahung eines allgemeinen universalen Völkerrechts glaubte über Bord werfen zu können. Daß die auf die nationalsozialistische Weltanschauung ausgerichteten 
Theorien kein geltendes Völkerrecht darstellen, wurde auch von der deutschen Völkerrechtswissenschaft festgestellt. So schreibt z. B. Berber 1939:

„Ist heute in erster Linie die Zeit der außenpolitischen Tat und nicht der völkerrechtlichen Systematisierung, die vielmehr, wie nach einem bekannten Worte Hegels alle Wissenschaft, der Eule der Minerva gleich erst mit der einbrechenden Dunkelheit ihren Flug beginnt, so kann erst recht nicht erwartet werden, daß diese in den Anfängen stehende deutsche Doktrin, die dem Positivismus entschlossen den Krieg angesagt hat, schon wesentlichen Einflu $\beta$ auf die faktische Gestaltung des zwischenstaatlichen Rechts hätte gewinnen können. Aber das Ziel ist bereits in seinen Grundlinien klar . . ."376

John Herz hat bereits 1938 in einer eindrucksvollen Arbeit den Flug dieser „Eule der Minerva" der nationalsozialistischen Völkerrechtslehre, die nicht erst ihre Flügel hob, als zum zweiten Male „über Europa die Lichter ausgingen“, sondern schon zu einer Zeit, in der die ersten Schatten des Nationalsozialismus über Europa fielen, mit scharfem und kritischem Auge verfolgt ${ }^{377}$. Ohne auf die von Herz analysierten mannigfaltigen Theorien und Systeme der nationalsozialistischen Völkerrechtler in der Zeit vor 1939, die jeweils der Ausdruck konkreter außenpolitischer Forderungen waren, näher einzugehen, wollen wir doch einige Grundzüge aufzeigen, die darlegen, daß Schmitts Großraumdoktrin, die der Verneinung des Völkerrechts endgültig zum Durchbruch verhalf, den Schlußstein im Gebäude dieser Theorien darstellt und wie sehr sie mit den Grundthesen der nationalsozialistischen Weltanschauung harmoniert.

Die nationalsozialistische Rechtstheorie, etwa die sogenannte "Rassengesetzliche Rechtslehre" Nicolai's"37, die alles Recht auf eine bestimmte rassisch-substantiell bedingte Rechtsüberzeugung zurückführte und mit der sich der Staatsrechtler Schmitt in bezug auf das innerstaatliche Recht identifizierte ${ }^{379}$, mußte bei konsequenter Folgerung ein allgemeines Völkerrecht im Sinne von Recht zwischen verschiedenen Rassen verneinen. Nicolai selbst hat 1932/33 aus verständlichen außenpolitischen Rücksichten die Konsequenz nicht gezogen, sondern nur betont, daß ein universales Völkerrecht „notwendig unentwickelt" bleiben müsse, nur "ganz wenige und äußerliche Rechtssätze aufweisen " könne und sich nur unter rassisch-

376 Fritz Berber, „Die deutsche Völkerrechtswissenschaft" (Geist der Zeit 17, 1939, S. 731 ff.) S. 733. (Hervorhebung vom Verfasser.)

377 Unter dem Pseudonym Eduard Bristler, a. a. O. Ferner John H. Herz, "The National Socialist Doctrine of International Law and the Problems of International Organisation " (Political Science Quarterly 54, 1939, S. 536 ff.). Beide Schriften behandeln die GroBraumdoktrin noch nicht.

378 Helmut Nicolai, Die rassengesetzliche Rechtslehre. Grundzüge einer nationalsozialistischen Rechtsphilosophie, München 1932; über diese Lehre vgl. Bristler, a. a. O., S. $63 \mathrm{ff}$. u. $68 \mathrm{ff}$.

379 Vgl. Schmitt über „arteigenes Rechtsdenken “ in: Staat, Bewegung, Volk. Die Dreigliederung der politischen Einheit (Der deutsche Staat der Gegenwart), 2. Aufl., Hamburg 1933, S. 44 ff. Dagegen zögert Schmitt, wie oben dargelegt, im Bereich des Internationalen, rassische und völkische Gemeinsamkeiten zu den alleinigen Kriterien des Homogenitätsbegriffs zu machen und damit seinen Theorien die Rassenlehre zugrunde zu legen (Vgl. Bristler, a. a. O., S. 118). 
artverwandten Völkern (Nicolai erwähnt nur das Beispiel der "germanischen“ Völker) kraft gemeinsamen Rechtsbewußtseins ein wirklich bindendes Völkerrecht bilden könne ${ }^{380}$. Hier offenbart sich bereits die Tendenz zur „Minimisierung “ und „Regionalisierung" des Völkerrechts im Sinne der Abgrenzung partikulärer Völkerrechtskreise artverwandter Gruppen - wie sie später von Schmitt unter räumlichgeographischen Gesichtspunkten vertreten werden sollte-, doch noch keine Leugnung des bestehenden Völkerrechts. Im Gegenteil wurde die staatsrechtsmonistische Lehre Schechers vom Völkerrecht als bloßem "deutschen Außenstaatsrecht", die Völkerrecht nur durch den einseitigen Willen des deutschen Staates für gültig erklären wollte ${ }^{381}$, von der deutschen Völkerrechtswissenschaft - und zwar aus teilweise offen zugegebenen "Nützlichkeitserwägungen“ heraus ${ }^{382}$ - in der damaligen außenpolitischen Situation Deutschlands abgelehnt ${ }^{383}$. In der Zeit von 1933 bis zu Schmitts Theorie von 1939 blieb daher auch die nationalsozialistische Völkerrechtslehre bei der dualistischen Lehre vom Recht, die neben dem staatsrechtlichen einen eigenen völkerrechtlichen Rechtskreis mit eigenen Geltungsgründen und Normadressaten anerkennt ${ }^{384}$. Die zwei von Herz unterschiedenen Systemgruppen der damaligen Völkerrechtslehre im Dritten Reich entsprachen den ersten beiden Etappen der nationalsozialistischen Außenpolitik, in denen die weitgesteckten Expansionsziele zunächst zurückgestellt werden mußten: Die überwiegend auf der Grundlage von Naturrecht und Staatengrundrechten aufbauenden Lehren ${ }^{385}$ entsprachen der Politik der Durchsetzung von Deutschlands Gleichberechtigung durch Wiederherstellung der „Wehrhoheit", insbesondere der Wiederaufrüstung und der Remilitarisierung des Rheinlandes (1933-1936). Die überwiegend auf der Grundlage von Rasse und Volkstum aufbauenden Lehren ${ }^{386}$ entsprachen der Politik einer Vereinigung aller deutschstämmigen Menschen im Großdeutschen Reich (1936-1939). Wie später bei der Großraumtheorie erwies sich schon hier der Ausweg der Völkerrechtslehre im Dritten Reich aus dem Dilemma, sich einerseits den Forderungen der nationalsozialistischen Führung unterzuordnen, andererseits den Rahmen der internationalen Völkerrechtswissenschaft nicht zu verlassen, im Aufbau eines als „echtes" Völkerrecht deklarierten Systems rechtspolitischer Forderungen, das einen direkten Gegensatz zur überkommenen und im Ausland betriebenen Wissenschaft am gleichen Material $\overline{380}$ Nicolai, a. a. O., S. 44ff.

${ }^{381}$ Ludwig Schecher, Deutsches Außenstaatsrecht, Berlin 1933, S. 136. Über Schechers Lehre vgl. Bristler, a. a. O., S. 65 f.

382 Ernst Wolgast, "Nationalsozialismus und internationales Recht" (DR, Jg. 4, 1934, S. 198). ${ }^{383}$ Bristler, a. a. O., S. 66 f. Dort S. 68 prophetisch: „,... also Anerkennung des Völkerrechts aus rein politischen, opportunistischen Gründen heraus, die nicht erkennen lassen, ob nicht etwa nach ihrem Wegfall, z. B. bei Wiedererstarkung Deutschlands, damit auch der Grund für die Anerkennung eines echten Völkerrechts entfallen soll."

384 Vgl. den Angriff Schmitts auf die dualistische Lehre in: „Über das Verhältnis von Völkerrecht und staatlichem Recht" (ZAlsDR 7, 1940, S. 4ff.).

385 Bristler, a. a. O., S. $71 \mathrm{ff}$. Dort besonders die Lehren von Bruns (S. $79 \mathrm{ff}$.$) und Bilfinger$ (S. $81 \mathrm{ff}$.$) .$

${ }^{386}$ Bristler, a. a. O., S. $108 \mathrm{ff}$. 
des positiven Rechts vermied ${ }^{387}$. Einerseits endeten beide genannten Richtungen in der Darstellung einer idealen, konfliktlosen, ausgeglichenen Gemeinschaft von wahrhaft gleichberechtigten und unabhängigen, bzw. rassisch-völkisch gesättigten, unimperialistischen und sich gegenseitig achtenden Nationalstaaten, wie sie sich nach Erfüllung der nationalsozialistischen Forderungen als Träger eines wahren Völkerrechts verwirklichen sollte. Dabei standen beide Richtungen sowohl mit den innenpolitisch verwirklichten als auch mit den allgemein-rassentheoretischen Grundanschauungen des Nationalsozialismus nicht im Einklang: das System gleichberechtigter Staaten mit "Grundrechten" widersprach der innerstaatlichen Beseitigung des „liberalistischen Individualismus" und der Entrechtung des einzelnen in der "Volksgemeinschaft"; das System der Gleichheit von gegenseitig ihre Selbstbestimmung achtenden Rassen und Völkern widersprach der innerstaatlich verfolgten Rassenpolitik, und beide widersprachen der Lehre von der Ungleichwertigkeit der Rassen. Andererseits stellten beide Richtungen den utopischen Endbildern höchst reale, aus der "Theorie" entwickelte Forderungen nach Unabhängigkeit und Souveränität, d. h. Freiheit von rechtlichen Bindungen in Form von „Freiheitsrechten ", Beseitigung von Kollektivverträgen etc. entgegen, um möglichst große Handlungsfreiheit entsprechend den Notwendigkeiten des „völkischen Lebenswillens “ und „nationalen Interesses “ zu erhalten ${ }^{388}$. Beruht schon der Gedanke der ausgeglichenen Ruhelage gleichberechtigter und völkischer Staaten auf der bloßen Annahme, daß solche Staaten keine expansiven Bestrebungen zeigen und damit ernste Konflikte ausgeschaltet würden, so wird die Unsicherheit in einer solchen Völkerrechtsgemeinschaft dadurch erhöht, daß die den Einzelstaaten Freiheit gebenden Grundrechte durch keinerlei entsprechende Grundpflichten kompensiert werden, ja, daß sogar das einzige die Freiheit beschränkende Prinzip, die Gleichheit, von gewissen, schon in der nationalsozialistischen Völkerrechtslehre jener Jahre auftretenden Hegemonietendenzen erschüttert wird : bei der Forderung nach materieller, relativer Gleichheit wurde für den Maßstab der „Verhältnismäßigkeit “ neben anderen Kriterien auf die rassische Hoch- oder Unterwertigkeit ${ }^{\mathbf{3 8 9}}$, auf die „naturgesetzliche Höher- und Geringerwertigkeit" der Staaten ${ }^{\mathbf{3 9 0}}$ verwiesen, ohne daß man damals konkret darauf einging, wer ihn anwenden sollte. Nur gelegentlich wurde die "Ahnung" eines „deutschen Sendungsgedankens" geäußert ${ }^{\mathbf{3 9 1}}$.

387 Bristler, a. a. O., S. $182 \mathrm{f}$.

388 Zum Voranstehenden vgl. Bristler, a. a. O., S. $168 \mathrm{ff}$.

${ }^{389}$ So Tatarin-Tarnheyden, "Völkerrecht und organische Staatsauffassung" (Archiv für Rechts- und Sozialphilosophie, Bd. 29, 1936, S. 306), ähnlich derselbe, „Organisches Völkerrecht" (Völkerbund und Völkerrecht, Jg. 3, 1936/37, S. 26).

390 Max Schweizer, Eine ideengeschichtliche Grundlage der Staatengleichheit. Zugleich ein Beitrag zur Geschichte des Natur-, Staats- und Völkerrechts, Breslau 1936, S. 50 f.

391 So z. B. Friedrich Lange, "Volksrecht-Völkerrecht" (Deutsche Juristenzeitung 1933, S. $806 \mathrm{f}$.), der die "Neuordnung der gesamten Rechtsverhältnisse" in dem "ganzen Raum zwischen deutschem und russischem Kerngebiet, zwischen finnischem, schwarzem und adriatischem Meer", „in dem unsere Vorväter gearbeitet haben und in dem - so Gott will - auch unsere Kinder und Kindeskinder wieder einmal arbeiten sollen, "als Deutschlands Aufgabe ansieht. 
Von beiden Richtungen wurden hierbei „im Namen des Völkerrechts " für Deutschland Rechte gefordert, die den anderen Staaten später in der Großraumordnung gerade abgesprochen werden sollten. Schmitt hat diesen Opportunismus 1940 bestätigt, indem er schrieb, daß „es damals . . zunächst darauf ankam, alle Positionen der staatlichen Souveränität und Geschlossenheit zu verteidigen und entehrenden Mißdeutungen nicht nachzugeben ... Heute aber wird der Staatsbegriff des 19. Jahrhunderts von uns selbst durch den Reichsbegriff überwunden. Daher sind wir jetzt in der Lage, die überkommene dualistische Lehre unter neuen Gesichtspunkten zu überprüfen “392. E. R. Huber lobte „die besondere wissenschaftliche Gabe Schmitts, neue Tendenzen und Strukturen unter der Oberfläche alter Systeme und hinter den Masken und Schleiern herkömmlicher Formeln zu spüren und durch begriffliche Fassung an das Licht und in das Bewußtsein zu heben " 393 . Man braucht sich nur das Datum (1. April 1939) ins Gedächtnis zu rufen, an dem Schmitt in seinem Vortrag "Völkerrechtliche Großraumprinzipien" auf der Kieler Arbeitstagung des Instituts für Politik und Internationales Recht zum ersten Mal seine Großraumtheorie im Zusammenhang mit dem Reichsbegriff darlegte, um zu begreifen, daß abermals eine Weiterentwicklung der nationalsozialistischen Völkerrechtstheorie fällig war. Zwei Wochen vorher hatte Hitler unter Bruch des Münchener Abkommens die Tschechoslowakei besetzt und durch die Errichtung des „Protektorats Böhmen und Mähren“ (neben der Schutzherrschaft über den „unabhängigen " slowakischen Staat) ein fremdes Volk unter seine Herrschaft gebracht und damit die dritte Etappe der nationalsozialistischen Außenpolitik eingeleitet: die Etappe des expansiven Imperialismus. Es gab Autoren, die offen davon sprachen, daß „das völkische Prinzip seine geschichtliche Rolle in der Wiedervereinigung des deutschen Reichsgebietes erfüllt" habe und nunmehr das Prinzip der Großräume an seine Stelle getreten sei ${ }^{394}$. Andere Autoren der orthodox-völkischen Richtung hingegen, wie z. B. Georg Hahn, leugneten, daß die Besetzung der Tschechoslowakei einen Bruch des völkischen Prinzips darstelle, sondern wollten im Gegenteil durch die Übernahme der „übervölkischen " Ordnungsaufgabe in Deutschland den "Vollstrecker des völkischen Gedankens" erblicken, der die Interessen der gemeinsam in einem Lebensraum existierenden Völker am besten wahrnehmen könne ${ }^{395}$. Wie sehr Schmitts neue Völkerrechtstheorie, die er für die im März 1939 beginnende „europäische Epoche des nationalsozialistischen Großdeutschen Reiches" 396 entwarf, auf den machtpolitischen Gegebenheiten aufbaut, geht aus seinen eigenen Worten hervor:

„Als ich im Herbst 1937 meinen Bericht über ,Die Wendung zum diskriminierenden Kriegsbegriff" ... vorlegte, war die politische Gesamtlage von der

392 Schmitt, „Über das Verhältnis von Völkerrecht und staatlichem Recht“, a. a. O., S. 5. (Hervorhebung vom Verfasser.)

${ }^{393}$ Huber, „Positionen und Begriffe“, a. a. O., S. 25.

394 Hans Offe, „Im Zeichen der werdenden Großräume" (Monatsschrift für das deutsche Geistesleben, Jg. 43, 1941, S. 179 f.).

395 Georg Hahn, Grundfragen Europäischer Ordnung, a. a. O., S. $189 \mathrm{f}$.

396 Dieser Ausdruck für die imperialistische Epoche bei Hahn, a. a. O., S. 190. 
heutigen noch wesentlich verschieden. Damals hätte der Reichsbegriff nicht, wie das jetzt geschieht, zum Angelpunkt des neuen Völkerrechts erhoben werden können. Im Anschluß an jenen Bericht wurde die Frage gestellt, was ich denn eigentlich Neues an die Stelle der alten Staatenordnung zu setzen hätte, da ich weder einfach beim alten bleiben, noch mich den Begriffen der westlichen Demokratien unterwerfen wollte. Heute kann ich die Antwort geben. Der neue Ordnungsbegriff eines neuen Völkerrechts ist unser Begriff des Reiches ... Der Gedanke eines zu den Trägern und Gestaltern eines neuen Völkerrechts gehörenden Deutschen Reiches wäre früher ein utopischer Traum und das auf ihm aufgebaute Völkerrecht nur ein leeres Wunschrecht gewesen. Heute aber ist ein machtvolles Deutsches Reich entstanden ... Die Tat des Führers hat dem Gedanken unseres Reiches politische Wirklichkeit, geschichtliche Wahrheit und eine große völkerrechtliche Zukunft verliehen ${ }^{397}$."

Doch auch die neue Lehre zerstört aus opportunistischen Gründen das Völkerrecht nicht völlig: Schmitt will durch die Hinüberrettung der staatlichen Ordnungselemente ins "neue Völkerrecht" vor allem das Kriegsrecht der bisherigen Völkerrechtsordnung erhalten. Denn auch das nationalsozialistische Deutschland hatte schließlich für die Dauer des weltumstürzenden Kampfes ein Interesse daran, daß sich wenigstens die Gegner soweit wie möglich an die Regeln des Kriegsrechts hielten ${ }^{398}$. Daher schreibt Schmitt bei der Begründung der Erhaltung der staatlichen Ordnungselemente $u$. a.: „Insbesondere hat der Krieg, als eine anerkannte Einrichtung dieser zwischenstaatlichen Ordnung, sein Recht und seine Ordnung wesentlich darin, daß er ein Staatenkrieg ist, d. h. daß Staaten als konkrete Ordnungen ihn gegen Staaten als konkrete Ordnungen gleicher Ebene führen ... Der Krieg ist in diesem völkerrechtlichen System eine Beziehung von Ordnung zu Ordnung und nicht etwa von Ordnung zu Unordnung “399. Nur soll nunmehr das Reich als die mit dem jus belli ausgestattete "konkrete Ordnung" an die Stelle des Staates treten, quasi in dessen Rüstung eines satisfaktionsfähigen Duellanten schlüpfen. Vom „alten" Völkerrecht wird also gerade soviel übernommen, wie in der gegebenen Situation nützlich ist. Sonst aber hat die neue Theorie keine Rücksichten zu nehmen und gibt in der Tat den "rechtlichen " Rahmen ab, innerhalb dessen die innenpolitisch verwirklichten Grundanschauungen nunmehr auch auf das außenpolitische Feld projiziert und in Europa praktiziert werden können und auch die Rassentheorie in der Gestaltung des internationalen Lebens ihren Platz findet:

Wie innerstaatlich der Pluralismus autonomer Gruppen und sein Rechtssystem in der "Volksgemeinschaft" „überwunden" waren, in der der einzelne seiner Grundrechte beraubt dem totalitären Staat entrechtet gegenüberstand, sollte nun

397 Schmitt, Großraumordnung, S. $48 \mathrm{f}$.

398 Folgender interessanter Vergleich bei Dietze, „Deutschland - der Feind des Völkerrechts?", (DR 1940, II) S. 1909: Wie sich die nationalsozialistische Revolution der legalen Mittel der Verfassung im Kampf gegen Weimar bedient habe, so bediene sie sich nun der Rechtseinrichtung des Krieges, um die Neuordnung durchzusetzen, „vorausgesetzt, daß die Kriegsführung in den Formen des allgemein anerkannten Völkerrechts und also im Rahmen der Rechtsordnung überhaupt erfolgt".

399 Schmitt, a. a. O., S. 42. 
die Großraumordnung das „pluralistische System" der unabhängigen und gleichberechtigten Staaten durch die Schaffung einer europäischen "Völkergemeinschaft" beseitigen ${ }^{400}$. Wie innenpolitisch „Führung“, d. h. eine plebiszitäre Diktatur ohne Verantwortlichkeit vor dem Volk und ohne rechtsstaatliche Machteindämmung bestand, sollte die Beseitigung der Schranken des zwischenstaatlichen Völkerrechts die „Führung" des Reiches, d. h. dessen Herrschaft im europäischen Großraum ermöglichen: eine zwischenstaatliche Hegemonie sollte es deshalb nicht sein, da „jeder Pluralismus ein System indirekter Gewalten und daher der Führung entgegengesetzt" sei ${ }^{401}$. Wie im Innern an die Stelle „abstrakt-formalistischer Gleichmacherei" eine „organische Rangordnung“ getreten war, über die die Führung bestimmte, sollte jetzt das Reich eine rangordnungsmäßige Gestaltung der europäischen „V̈̈lkergemeinschaft" nach einem „durch die Gemeinschaftssubstanz vorbestimmten "Wertprinzip vornehmen ${ }^{402}$, indem es über die Stellung der einzelnen Völker im Großraum als dienender Heloten oder Nutznießer verschiedenen Grades entschied.

Hier ist auch zugleich der Punkt, an dem sich Schmitts Großraumtheorie durch ihre Elastizität mit den rassentheoretischen Grundanschauungen von der Ungleichwertigkeit der Rassen, ihrem "ewigen Kampf" und dem "Recht des Stärkeren“ in Einklang bringen läßt: Die Überordnung des Reiches und der hierarchische Aufbau des Großraumes brauchen nur noch rassentheoretisch begründet zu werden. So überwindet Schmitts Theorie erstmals das Dilemma und die Widersprüche, die sich bei den oben genannten Theorien der Völkerrechtslehre im Dritten Reich einstellten, und macht eine durchgängige Kontinuität nationalsozialistischer Ideen und Prinzipien in den Bereichen des Nationalen, Innerstaatlichen und des Internationalen, Zwischen- oder Überstaatlichen möglich, in Übereinstimmung mit der Forderung der völkischen Richtung, daß die „Bewährung der gleichen Lebensgrundsätze“ und die "Anwendung der gleichen rechtsschöpferischen Geisteshaltung" wie im Innern des Reiches auch im europäischen Lebensraum erfolgen sollten ${ }^{403}$. Schmitts Theorie ermöglicht das durch die „Überwindung “ des Dualismus von Staatsrecht und Völkerrecht ${ }^{404}$ und die „rechtswissenschaftliche“ Er-

400 Diese Parallele der Überwindung des Pluralismus im innerdeutschen und europäischen Recht s. Dietze "Vom deutschen Verfassungsrecht zum europäischen Verfassungsrecht", a. a. O., S. 802, 804ff.; ders. „Deutschland - der Feind des Völkerrechts?" a. a. O., S. $1907 \mathrm{f}$. Über die Parallele der Idee von Volksgemeinschaft und Völkergemeinschaft, ferner Hasse, „Von der Volksgemeinschaft zur Völkergemeinschaft" (Die SA, Zeitschrift der Sturmabteilungen der NSDAP, 2. Jg., Folge 3, S. 1); Hahn, Grundfragen Europäischer Ordnung, a. a. O., S. $31 \mathrm{ff}$.

401 E. R. Huber, „Herrschaft und Führung“, a. a. O., S. 2023. Dort S. 2023 f. das Eingeständnis, daß das Reich im Großraum neben Führung auch Herrschaft ausüben werde. Vgl. ferner derselbe, "Bau und Gefüge des Reiches" (Deutsche Rechtswissenschaft 6, 1941, S. 22 ff.).

402 Dietze, "Vom deutschen Verfassungsrecht zum europäischen Verfassungsrecht", a. a. O., S. 808; vgl. dazu auch: G. A. Walz, "Gleichheit und Rangordnung im Recht" (DR 11, 1941, S. $2209 \mathrm{ff}$.).

403 So Höhn, RVL I, S. 286; RVL II, S. 124 (vgl. oben Anm. I/45). Ferner Dietze a. a. O., S. 805. 404 Dietze, a. a. O., S. 812: „Wenn das neue europäische Völkerrecht nicht nur mehr ohne das 
fassung des neuen Zustandes durch „konkretes Ordnungsdenken “. Nach bisherigem „normativistischem" Rechtsdenken tendiert die neue Theorie im Grunde zu einem Staatsrechtsmonismus auf einer höheren Ebene, sozusagen einem „Reichsrechtsmonismus".

Vom Reich als dem Zentralbegriff des „neuen Völkerrechts“, seinem Träger und „Kreator" her gesehen, stellt nunmehr nur das „Völkerrecht" dar, was es selbst geschöpft hat: Innerhalb des Großraumes gilt als Recht nur das, was durch den einseitigen Willen des Reiches für bindend und gültig erklärt wird. Es erhält seine Qualität als „Recht" dadurch, daß das Reich als Souverän des Großraumes mit raum-hoheitlichem Zwang für seine Durchsetzung sorgt. Der Großraum wird „Überstaat", sein Recht Staatsrecht. Aber auch zwischen den Großräumen würde bei Leugnung der Existenz eines universalen Völkerrechts nur noch das „Völkerrecht" darstellen, was das Reich für die Beziehungen zwischen dem eigenen und den anderen Großräumen als solches anerkennt, wie es z. B. auch über den Interventionsbegriff von sich aus entscheidet. Das Prinzip des Großraumes als eines geschlossenen, von einer politischen Idee beherrschten Körpers ist ohne Primat des Großraum-Staatsrechts kaum denkbar. Alles Völkerrecht im Sinne von ZwischenGroßraum-Recht steht unter dem Vorbehalt dieses Primats, denn das Reich als Schöpfer dieses Rechts und zugleich als Träger der politischen Idee seines Großraumes wird nach außen keine rechtlichen Verpflichtungen eingehen oder anerkennen und keine Interventionen im Namen des Zwischen-Großraum-Rechts zulassen, die der politischen Idee des eigenen Großraumes widerstreben und die Beherrschung des eigenen Großraumes stören. Doch, einmal angenommen, daß alle Reiche sich formalrechtlich über die Abgrenzung ihrer entsprechenden Großräume, das Nichtinterventionsprinzip usw. einigen würden, wo läge die reale machtmäßige Garantie für die Einhaltung und gegen die einseitige Aufsagung dieses Rechts zwischen derartigen Großraum-Machtblöcken? Die Bildung einer über ihnen stehenden Organisation in der Form eines „Reiche-Bundes" wäre nach Schmitts Auffassung allein wegen der mangelnden Homogenität der nach unterschiedlichen politischen Grundprinzipien geordneten Großräume unmöglich. Außerdem würde ein solches universales Zwischen-Großraum-Recht abermals ein nicht raumgebundenes, „entortetes" Recht darstellen, von einer Übereinstimmung mit der rassengesetzlichen Rechtslehre ganz zu schweigen. Für das einzelne Reich als Träger und Schöpfer des neuen Völkerrechts ist eben innerhalb seines Großraumes und zwischen diesem und einem anderen Großraum nur das Recht, was es selbst als solches anerkannt.

In dieser Tendenz zur monistischen Theorie vom Recht der einzig wirklich souveränen Staaten, der Reiche, kommen „die Konsequenzen der nationalsozialistischen Weltanschauung für die rechtliche Ordnung der auswärtigen Beziehun-

deutsche Verfassungsrecht vorstellbar ist, sondern auch nach dessen Vorbild praktisch ausgestaltet wird, dann ist ein Gegensatz, ein Dualismus, zwischen beiden Rechtskreisen entfallen." 
gen " 405 zum Durchbruch, wie sie sich aus der rassengesetzlichen Rechtslehre ergeben und z. B. in Schechers Lehre vom „Deutschen Außenstaatsrecht" und auch gelegentlich von anderen Autoren im Dritten Reich ${ }^{406}$ schon gezogen, aber aus realpolitischen Gründen unterdrückt worden waren: die Übereinstimmung der nationalsozialistischen Völkerrechtstheorie mit dem Grundsatz „Recht ist, was dem deutschen Volke nutzt". Schmitts Großraumordnung repräsentiert diese Übereinstimmung in idealer Weise und stellt insofern die im nationalsozialistischen Sinne fortgeschrittenste, in das Gewand der Völkerrechtswissenschaft gekleidete Legitimierung der nationalsozialistischen Großraumpolitik dar, wenn man von den rein "völkischen "Großraumtheorien absieht, die nicht mehr zur Rechtswissenschaft gerechnet werden können. Mit der Unbestimmtheit und Veränderlichkeit ihres Inhaltes ist Schmitts "völkerrechtliche Großraumordnung" nicht Völkerrecht, sondern politische Doktrin. Dies, aber nur dies, hat sie mit der Monroe Doctrine gemeinsam. Im übrigen steht sie zu dieser in eklatantem Gegensatz: Während die Monroe Doctrine die politische Unabhängigkeit und territoriale Unversehrtheit der selbständigen Staaten des amerikanischen Kontinents grundsätzlich nicht berührt, gegenüber nichtamerikanischen Staaten garantiert und dadurch mit einer völkerrechtlichen Ordnung im Einklang steht, die auf einem Pluralismus souveräner Staaten und auf dem Grundsatz der rechtlichen Gleichheit dieser Staaten beruht, verneint Schmitts "völkerrechtliche Großraumordnung" - deren "Präzedenzfall" die Monroe Doctrine angeblich darstellen soll - eine solche Ordnung und legitimiert die nationalsozialistische Vorherrschaft über Europa.

405 Diese Beurteilung der monistischen Theorie Schechers bei Hans K. E. L. Keller, Das Recht der Völker, Berlin, 1938, S. 125, Anm. 125.

406 s. z. B. auch Otto Forsthoff, „Nationale Friedenspolitik“ (Europäische Revue, Jg. 11, 1935, S. 102). 